\title{
Desigualdades em Saúde do Adulto: Análise do Estilo de Vida no Estado de São Paulo
}

\section{Vanessa Martins Valente Guimarães}

Tese apresentada ao Programa de PósGraduação em Saúde Pública da Faculdade de Saúde Pública da Universidade de São Paulo para obtenção do título de Doutor em Saúde Pública.

Área de Concentração: Epidemiologia Orientador: Prof. Tit. Chester L. G. César

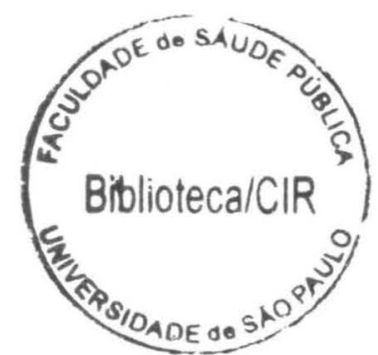

São Paulo

2006 


\title{
En 0911112006
}

\author{
Aprovada pela CPG em sua 9a / Sessia. \\ realizada em 091 1) 2006 \\ ấviabansilea \\ 1) Maria Aparecida Mendes \\ Secretária
}

É expressamente proibida a comercialização deste documento tanto na sua forma impressa como eletrônica. Sua reprodução total ou parcial é permitida exclusivamente para fins acadêmicos e científicos, desde que na reprodução figure a identificação do autor, título, instituição e ano da tese.

$$
5195412010 \text { doe }
$$


Para Elcio,

Lucas,

Paulo Vinícius e

Ludmilla 


\section{AGRADECIMENTOS}

Meus especiais agradecimentos ao Prof. Tit. CHESTER LUIZ GALVÃO CÉSAR pela orientação prestada, compreensão e incentivo permanente para realização deste trabalho.

À FAPESP e Secretaria de Saúde do Estado de São Paulo pelo financiamento deste projeto.

A todos os pesquisadores e integrantes da equipe do ISA-SP.

Aos entrevistados, pela paciência e colaboração.

A todos que, direta ou indiretamente, colaboraram para a execução deste trabalho. 
"Talvez mais que teoricamente justos, esteticamente sensíveis ou politicamente inteligentes, o que nós precisamos ser é ativamente bons." 


\section{RESUMO}

Guimarães VMV. Desigualdades em Saúde do Adulto: Análise do Estilo de Vida no Estado de São Paulo. São Paulo; 2006. [Tese de Doutorado - Faculdade de Saúde Pública da USP].

INTRODUÇÃO. Reduzir a morbidade que acompanha o envelhecimento das populações tem sido prioridade em diversos países, incluindo o Brasil. Neste contexto, o incentivo a um estilo de vida saudável é de fundamental importância para promoção da saúde, prevenção e controle das doenças crônicas e das incapacidades a elas relacionadas. OBJETIVO. Analisar as desigualdades no estilo de vida da população adulta, de 20 a 59 anos de idade, segundo características demográficas e sócio-econômicas, em quatro áreas do Estado de São Paulo. METODOLOGIA. Inquérito domiciliar do tipo transversal (ISA-SP), em quatro áreas: Região Sudoeste da Grande São Paulo, constituída pelos Municípios de Taboão da Serra, Itapecerica da Serra e Embu; Distrito do Butantã, no Município de São Paulo; Município de Campinas; e Município de Botucatu. Para avaliação do nível de atividade física foi utilizado o Questionário Internacional de Atividade Física (QIAF), versão 8, forma curta, com aplicação da entrevista referente a uma semana usual. A prática regular de esporte ou exercício físico, tabagismo e etilismo também foram interrogados a partir de questionários aplicados por entrevistador. Para investigação da dieta, foi utilizado inquérito recordatório de 24 horas. Análises bivariadas e multivariadas dos dados foram realizadas a partir de Modelos de Regressão de Poisson. Realizou-se análise de agrupamentos (cluster) para identificação de subgrupos de maior vulnerabilidade. Todas as análises foram estratificadas por sexo. RESULTADOS. Em 826 homens entrevistados, observa-se a formação de quatro agrupamentos. O cluster 1 agrupou homens de baixa renda e escolaridade, de 40-59 anos, tabagistas, etilistas e sedentários, com baixa ingestão de frutas e baixo Índice de Qualidade da Dieta. O cluster 2 propôs um grupo de homens de baixa renda, 4-7 anos de escolaridade, porém que nunca fumaram e têm alta ingestão de gorduras na dieta. O cluster 3 agrupou indivíduos de alta renda e escolaridade, e elevada ingestão de frutas e verduras. E o cluster 4 agrupou os indivíduos mais jovens, praticantes de exercício físico e com 8-11 anos de escolaridade. Em 820 mulheres, houve a formação de dois agrupamentos. No cluster 1 se concentraram as mulheres de mais alta renda, elevada ingestão de frutas, praticantes de exercício físico, que nunca fumaram e que ingerem bebida alcoólica em freqüência de até uma vez/semana. O cluster 2 agrupou mulheres de baixa renda, baixa ingestão de frutas, sedentárias e tabagistas. CONCLUSÕES. Observa-se o agrupamento desigual das variáveis do estilo de vida segundo nível sócio-econômico em ambos os sexos. Para reduzir as desigualdades em saúde é essencial conhecer os segmentos de maior vulnerabilidade e a análise de cluster, neste estudo, mostrou-se um instrumento útil para identificação dos grupos de maior risco.

Palavras-chave: Estilo de Vida; Saúde do Adulto; Análise de Cluster; Inquéritos de Saúde. 


\section{SUMMARY}

Guimarães VMV. Social Inequalities in Young Adults: Cluster Analysis of Lifestyle Factors in São Paulo, Brazil. São Paulo; 2006. [Doctorate Thesis Faculdade de Saúde Pública da USP]

INTRODUCTION. Reducing the burden of chronic diseases related to aging is a priority in developing countries, including Brazil. Thereby, encouraging a healthy lifestyle is fundamental to health promotion, prevention and treatment of chronic diseases, and rehabilitation. OBJECTIVE. To analyse lifestyle inequalities in adults aged 20-59 y, according to demographic and socio-economic characteristics. METHODS. Household cross-sectional survey carried out in four areas of São Paulo State, Brazil. To investigate level of physical activity, the International Physical Activity Questionnaire - IPAQ, version 8, short form, was used. We also asked about the regular practice of sports or physical exercise, smoking and alcohol drinking. A one-day dietary recall was carried out to collect data from diet habits. Bivariate and multivariate Poisson regression analyses, and TwoStep Cluster analyses were performed to detect associations and high-risk groups. All analyses were stratified by gender. RESULTS. The cluster analysis in male gender $(n=826)$ produced four groups. The Cluster 1 grouped low-income and low-education men, who usually drank, smoked and had a poor fruit ingestion and low Healthy Eating Index. The Cluster 2 grouped low-income men, 4-7 years of education, who had never smoked and had a high fat consumption. Cluster 3 grouped high-income and high-education men, with a high consumption of fruits and vegetables. And Cluster 4 grouped younger men who practiced physical exercise, 8-11 years of education. In female gender $(n=820)$ the cluster analysis produced two subgroups. The Cluster 1 concentrated high-income women, who practiced physical exercise, never smoked and drank 1 time/week. Cluster 2 grouped sedentary, low-income women who consumed tobacco and had low fruit consumption. CONCLUSION. An unequal clustering of lifestyle factors according to socio-economic level was seen in both genders. In order to reduce health inequalities, it is essential to know the vulnerable sets, and the cluster analysis, in this study, was an useful instrument in identifying the high-risk groups.

Key-words: Lifestyle; Adult Health; Cluster Analysis; Cross-Sectional Survey. 


\section{ÍNDICE}

1 INTRODUCÃO

2 OBJETIVOS 23

3 METODOLOGIA 24

3.1 DELINEAMENTO GERAL 24

3.2 ÁREAS DE ESTUDO 24

3.3 PLANO DE AMOSTRAGEM 25

3.4 COLETA DE DADOS 28

3.5 VARIÁVEIS DE ESTUDO 30

3.5.1 Demográficas e Sócio-Econômicas 30

3.5.2 Atividade Física e Exercício Físico 31

3.5.3 Tabagismo 34

3.5.4 Etilismo $\quad 35$

3.5.5 Hábito Alimentar 35

3.6 ANÁLISE DOS DADOS 38

4 RESULTADOS 42

4.1 CARACTERÍSTICAS DA POPULAÇÃO ADULTA 42

4.2 EXERCÍCIO FÍSICO E ATIVIDADE FÍSICA 46

4.3 TABAGISMO 52

4.4 ETILISMO

4.5 DIETA 57

4.6 ANÁLISE DE AGRUPAMENTOS (CLUSTER) 62

4.6.1 Sexo Masculino $\quad 62$

4.6.2 Sexo Feminino 65

5 DISCUSSÃO 68

5.1 ATIVIDADE FÍSICA E EXERCÍCIO FÍSICO 68

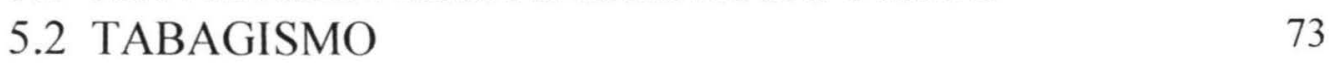

$\begin{array}{ll}5.3 \text { ETILISMO } & 79\end{array}$

$\begin{array}{ll}5.4 \text { DIETA } & 84\end{array}$

5.5 ANÁLISE DE CLUSTER $\quad 88$

6 CONSIDERAÇÕES FINAIS 92

7 REFERÊNCIAS BIBLIOGRÁFICAS 95

ANEXOS

Anexo 1-Questionário $\quad 119$

Anexo 2 - Aderência à Distribuição de Poisson 162

Anexo 3 - Análise de Resíduos dos Modelos de Regressão de Poisson 165

Anexo 4 - Histogramas - Sexo Masculino e Sexo Feminino 172

$\begin{array}{ll}\text { Anexo 5 - QQPlots das Variáveis Quantitativas } & 177\end{array}$

Anexo 6 - Análise de Cluster Sexo Masculino $\quad 180$

Anexo 7 - Análise de Cluster Sexo Feminino 190 


\section{LISTA DE TABELAS}

Tabela 1 - Características demográficas e sócio-econômicas segundo sexo em população adulta no Estado de São Paulo, 2002

Tabela 2 - Estilo de vida segundo sexo em população adulta no Estado de São Paulo, 2002

Tabela 3 - Prática de exercício físico segundo variáveis demográficas e sócio-econômicas em população adulta do sexo masculino, Estado de São Paulo, 2002

Tabela 4 - Prática de exercício físico segundo variáveis demográficas e sócio-econômicas em população adulta do sexo feminino, Estado de São Paulo, 2002

Tabela 5 - Prática de atividade física-QIAF segundo variáveis demográficas e sócio-econômicas em população adulta do sexo masculino, Estado de São Paulo, 2002

Tabela 6 - Prática de atividade física-QIAF segundo variáveis demográficas e sócio-econômicas em população adulta do sexo feminino, Estado de São Paulo, 2002

Tabela 7 - Prática de caminhada segundo variáveis demográficas e sócioeconômicas em população adulta do sexo masculino, Estado de São Paulo, 2002

Tabela 8 - Prática de caminhada segundo variáveis demográficas e sócioeconômicas em população adulta do sexo feminino, Estado de São Paulo, 2002

Tabela 9 - Tabagismo segundo variáveis demográficas e sócio-econômicas em população adulta do sexo masculino, Estado de São Paulo, 2002

Tabela 10 - Tabagismo segundo variáveis demográficas e sócio-econômicas em população adulta do sexo feminino, Estado de São Paulo, 2002

Tabela 11 - Hábito de fumar mais de 20 cigarros/dia segundo faixa etária em população adulta do sexo masculino, Estado de São Paulo, 2002

Tabela 12 - Hábito de fumar mais de 20 cigarros/dia segundo variáveis demográficas e sócio-econômicas em população adulta do sexo feminino, Estado de São Paulo, 2002 
Tabela 13 - Freqüência de consumo de bebida alcoólica - uma vez por semana ou mais - segundo faixa etária em população adulta do sexo masculino, Estado de São Paulo, 2002

Tabela 14 - Freqüência de consumo de bebida alcoólica - uma vez por semana ou mais - segundo religião em população adulta do sexo feminino, Estado de São Paulo, 2002

Tabela 15 - Índice CAGE positivo segundo variáveis demográficas e sócioeconômicas em população adulta do sexo masculino, Estado de São Paulo, 2002

Tabela 16 - Índice de Qualidade da Dieta-IQD segundo variáveis demográficas e sócio-econômicas em população adulta do sexo masculino, Estado de São Paulo, 2002

Tabela 17 - Índice de Qualidade da Dieta-IQD segundo escolaridade em população adulta do sexo feminino, Estado de São Paulo, 2002

Tabela 18 - Consumo de verduras segundo variáveis demográficas e sócioeconômicas em população adulta do sexo masculino, Estado de São Paulo, 2002

Tabela 19 - Consumo de verduras segundo variáveis demográficas e sócioeconômicas em população adulta do sexo feminino, Estado de São Paulo, 2002

Tabela 20 - Consumo de frutas segundo variáveis demográficas e sócioeconômicas em população adulta do sexo masculino, Estado de São Paulo, 2002

Tabela 21 - Consumo de frutas segundo variáveis demográficas e sócioeconômicas em população adulta do sexo feminino, Estado de São Paulo, 2002 


\section{LISTA DE FIGURAS}

p.

Figura 1 - Agrupamentos obtidos a partir de análise de cluster em população adulta do sexo masculino, Estado de São Paulo, 2002

Figura 2 - Mapa conceitual da análise de agrupamentos em população adulta do sexo masculino, Estado de São Paulo, 2002

Figura 3 - Agrupamentos obtidos a partir de análise de cluster em população adulta do sexo feminino, Estado de São Paulo, 2002

Figura 4 - Mapa conceitual da análise de agrupamentos em população adulta do sexo feminino, Estado de São Paulo, 2002 
O desafio de melhorar a saúde dos indivíduos a partir da construção de sociedades mais saudáveis requer uma compreensão mais ampla dos determinantes sociais do processo saúde-doença. A saúde é um sensível reflexo das circunstâncias sociais. A associação entre classe social e mortalidade já está bem estabelecida (MARMOT et al. 2001; PENSOLA \& MARTIKAINEN 2003; MARMOT 2005; VIRTANEN et al. 2005). Entretanto, enquanto reconhecemos que aqueles indivíduos que estão nos piores níveis sócio-econômicos também apresentam pior saúde, isto é apenas parte de um vasto gradiente social em saúde. Existem diversos indivíduos que, apesar de não serem considerados socialmente excluídos, estão em desvantagem relativa em termos de saúde. Assim, as desigualdades em saúde não estão confinadas às diferenças entre ricos e pobres: quanto maior a posição na hierarquia social, menor o risco de doenças e morte (WOODWARD \& KAWACHI 2000; KAWACHI et al. 2002; ZIGLIO et al. 2003; MARMOT 2004a).

Estas gradações na morbidade e mortalidade são um desafio para as políticas de saúde, pois significam mais que privações materiais. A pobreza também está relacionada à falta de oportunidades na vida, infra-estrutura precária, desemprego, pouca autonomia e baixos níveis de coesão social. E as desigualdades econômicas não são acidentais: elas resultam de conflitos da sociedade quanto a moradia, impostos, benefícios sociais, educação, regulamentação de negócios e empregos, e políticas de saúde, dentre outros (WOODWARD \& KAWACHI 2000; WHO 2006).

Com intuito de reorientar as ações em saúde pública e projetar políticas mais efetivas e sustentáveis, a Organização Mundial de Saúde desenvolveu uma comissão para investigar os determinantes sociais da saúde (WHO 2006). O grande desafio é equilibrar uma crítica baseada na justiça social, propondo mudanças estruturais de longo prazo, com intervenções focais que 
produziriam resultados rápidos evitando, entretanto, as estratégias apenas "própobreza", sem um enfoque sobre as verdadeiras causas das iniqüidades (VEGA \& IRWIN 2004; JONG-WOOK 2005). As políticas e intervenções essenciais desta comissão englobam (ZIGLIO et al. 2003; WILKINSON \& MARMOT 2003):

- Reduzir a estratificação social através da diminuição das desigualdades em poder, prestígio, renda e riqueza;

- Reduzir a exposição específica a fatores deletérios para saúde nas pessoas em posições de desvantagem;

- Diminuir a vulnerabilidade das populações em desvantagem para as condições deletérias à saúde que elas enfrentam;

- Intervir através de cuidado à saúde para reduzir as conseqüências desiguais das doenças, e prevenir maior degradação sócioeconômica entre os indivíduos enfermos em situação de desvantagem.

Os resultados desta investigação foram publicados em "The Solid Facts" (WILKINSON \& MARMOT 2003). Suas dez mensagens essenciais são (MARMOT 2004b):

- A saúde segue um gradiente social;

- O estresse danifica a saúde;

- O impacto sobre a saúde do desenvolvimento e educação dos primeiros anos dura a vida inteira;

- A pobreza e a exclusão social custam vidas;

- O estresse no local de trabalho aumenta o risco de doenças;

- A segurança no emprego melhora a saúde; o desemprego causa doenças e mortes prematuras;

- Redes de apoio social melhoram a saúde;

- Uso de álcool, drogas e tabaco são influenciados pelo cenário social;

- Alimentação saudável é uma questão política; 
- Transporte saudável significa caminhar e andar de bicicleta, e transporte público de qualidade.

Não existe nenhuma novidade em afirmar que a pobreza gera doenças. No entanto, reconhecer os efeitos da pobreza e delimitar ações para reduzir suas conseqüências propõe um entendimento produtivo para novas políticas econômicas e sociais. A urgência para a ação provém da magnitude dos sofrimentos, doenças e mortes prematuras causadas hoje em todo o mundo pela crescente desigualdade social.

Neste contexto, as ações voltadas para a mudança de comportamentos individuais são menos efetivas e, em muitas situações, mantêm ou até aumentam as desigualdades, devido aos diferenciais na aquisição de novas informações e tecnologias. Em exames de triagem, por exemplo, existe propensão a obter melhor resposta daqueles segmentos populacionais que estão menos expostos ao risco de contrair a enfermidade (ROSE 1988). As intervenções estruturais e ambientais e as estratégias populacionais afetam todos os indivíduos, promovendo melhor redução das desigualdades em saúde (WOODWARD \& KAWACHI 2000).

Sobre os modos de intervenção sobre os indivíduos e populações, ROSE (1988; 1992) enfatiza a necessidade de distinguir as causas dos casos das causas da incidência. Na primeira, o enfoque é centrado no indivíduo, buscando identificar os mais suscetíveis e oferecer a estes alguma proteção individual. Nas causas da incidência, uma influência maciça atua sobre toda a população e, portanto, precisa ser controlada com estratégias de largo alcance - estratégias populacionais.

A estratégia de alto risco busca obter algo similar ao truncamento da distribuição do risco. A primeira vantagem desta estratégia é promover a adoção de medidas apropriadas para as pessoas, obtendo-se, assim, motivação do indivíduo e da equipe de saúde envolvida, e uma relação custo-efetividade favorável 
principalmente quando os recursos são escassos. Entretanto, como não combate "as causas das causas", tem caráter paliativo e provisório, e resultados limitados, uma vez que a maior parte das pessoas que apresentam fatores de risco continuará com boa saúde, e muitos dos que não os apresentam, tornar-se-ão enfermos de forma inesperada (ROSE 1992).

Assim, segundo ROSE (1988):

"Um grande número de pessoas de baixo risco pode originar mais casos de uma enfermidade que o reduzido número de pessoas que tem risco elevado".

A estratégia populacional busca, então, ser radical - eliminar as causas subjacentes que fazem com que uma determinada enfermidade ou fator de risco seja comum. Assim, dizer que fumar cigarros causa câncer de pulmão ou infarto do miocárdio é uma afirmação incompleta e leva a uma mensagem geral de educação em saúde: "Não fume!" Mas por que as pessoas fumam? Quais são as causas desta causa? E as respostas mostram que, dentre outras, o tabagismo está inextricavelmente ligado a privações sócio-econômicas (ROSE 1992; WOODWARD \& KAWACHI 2000). O controle da hipertensão arterial é outro exemplo de fator de risco tratado primordialmente com enfoque de alto risco. Entretanto, alguns estudos demonstram a baixa eficiência em obter controle com estas medidas (TORMO et al. 1997; PURAS et al. 1998; CHALMERS et al. 1999; TILLY et al. 2002) e diversos estudos, como o MRFIT (Multiple Risk Factor Intervention Trial) (STAMLER et al. 1993) e o Framingham Heart Study (KANNEL \& BELLANGER 1991), evidenciaram riscos muito mais elevados de insuficiência coronariana, insuficiência cardíaca, doença renal e mortalidade geral para os indivíduos situados nos pontos mais altos da curva de pressão arterial, comparados aos indivíduos com pressão normal. Como mesmo modestas reduções na ingestão de sal na dieta têm sido associadas a redução da pressão arterial em hipertensos (HE et al. 2005), um exemplo de estratégia populacional seria a redução do sal na formulação de alimentos muito consumidos, como o pão francês. 
A maior parte das enfermidades crônicas provavelmente ainda vão requerer, por muito tempo, a aplicação das duas estratégias. Entretanto, os fatores relacionados ao estilo de vida, por sua ampla distribuição e elevada prevalência, necessitam de abordagens populacionais, pois "a abordagem de massa é inerentemente a única resposta definitiva para os problemas de uma doença de massa" (ROSE 1992).

Como exemplos bem-sucedidos de estratégias populacionais na redução das desigualdades em saúde, pode-se citar a fluoretação da água, que reduziu as cáries dentárias nas crianças de mais baixa renda (RILEY et al. 1999), e as mudanças nos impostos para aumentar o preço dos cigarros, diminuindo o tabagismo nos grupos de maior consumo (TOWNSEND et al). Alguns estudos têm apontado outras abordagens produtivas: melhora do acesso geográfico para as intervenções em saúde em comunidades pobres, subsídios para investimentos em saúde e cuidado em saúde, e marketing social (MACKENBACH \& BAKKER 2003; VICTORA et al. 2003).

A transição epidemiológica no Brasil também não ocorre de maneira uniforme. O envelhecimento progressivo da população é um dos fenômenos de maior impacto sobre as políticas de saúde no Brasil.

"O aumento considerável da expectativa de vida que foi observada nos países desenvolvidos nos últimos 30 anos, que resultou numa retangularização das curvas de sobrevivência, está sendo acompanhado também por uma compressão da morbidade, ou seja, está havendo também uma retangularização da curva de morbidade (BRITO \& LITVOC 2004)".

Portanto, reduzir a morbidade que acompanha o envelhecimento das populações tem sido prioridade nos países desenvolvidos. Entretanto, nos países 
em desenvolvimento, a teoria da compressão da morbidade de FRIES (1980) apresenta importantes diferenciais segundo estratos sócio-econômicos.

Estudos de mortalidade registram distribuições desiguais na mortalidade relacionada a doenças crônicas na população adulta em diversas regiões do Brasil. LESSA (1991) evidenciou que a mortalidade por doenças cerebrovasculares ocorre precocemente nas regiões mais pobres do país. No Município de São Paulo, STEPHENS et al. (1994) mostram excesso de mortes por doenças cerebrovasculares na faixa etária 45 - 64 anos nos moradores da área de pior condição socioambiental. Em 1996, no Município de Belo Horizonte, observou-se razão de odds de 3,0 para mortalidade por doenças cardiovasculares em indivíduos moradores de favelas quando comparados àqueles que residiam em bairros (ISHITAMI \& FRANÇA 2000). Em 1999, DRUMOND Jr \& BARROS, em análises socioespaciais de áreas homogêneas no Município de São Paulo, registraram, para o sexo masculino, risco relativo de 2,34 na mortalidade por doenças cerebrovasculares ao se comparar a área de pior com a de melhor condição socioambiental. Este estudo também revelou valores mais elevados nas piores áreas quanto a: probabilidade de morte, anos potenciais de vida perdidos, concentração de mortes de adultos em relação ao total de mortes e concentração de mortes mais precoces.

Além da mortalidade desigual em relação ao nível sócio-econômico, observamos que a ocorrência das doenças crônicas tem acontecido em faixas etárias cada vez mais precoces como, por exemplo, o diabetes, cuja incidência tem aumentado nas pessoas de 45 a 64 anos de idade. Segundo dados do IDB 2004 (RIPSA 2005), apesar do declínio da mortalidade por doenças do aparelho circulatório (Quadro 1), a taxa de mortalidade específica por diabetes pouco se alterou nas faixas etárias 30-39 e 40-49 anos, e apresentou elevação na faixa etária 50-59 anos, no período 1990-2002 (Quadro 2). O mesmo ocorreu com a taxa de mortalidade específica por neoplasias malignas, que não se alterou neste período de doze anos (Quadro 3). Cabe ressaltar as limitações dos dados de mortalidade por diabetes, pela sua inextricável ligação com as doenças cardiovasculares. 
Quadro 1. Distribuição das taxas de mortalidade específica (por 100.000 hab.) por doenças do aparelho circulatório segundo faixa etária, Brasil, 1990-2002.

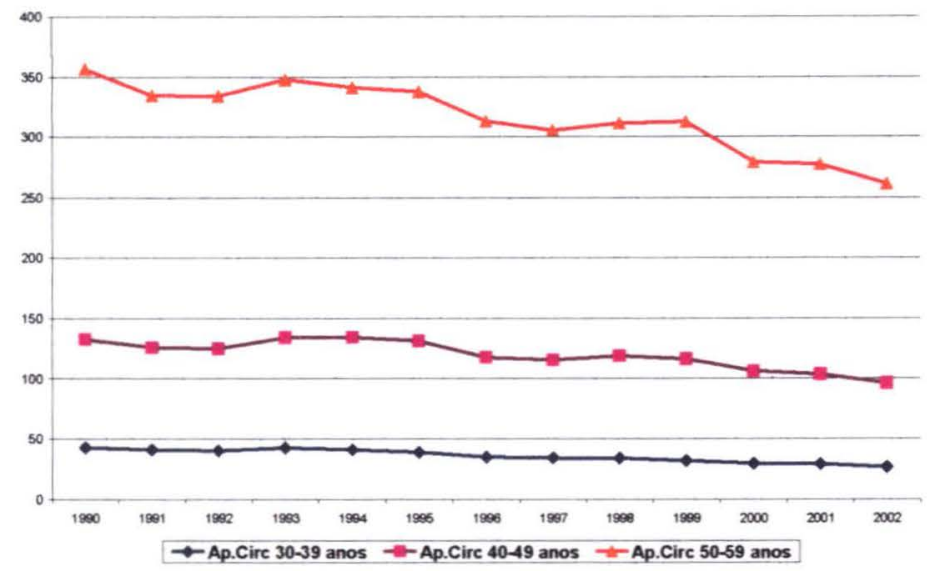

Fonte: IDB 2004

Quadro 2. Distribuição das taxas de mortalidade específica (por 100.000 hab.) por diabete melito segundo faixa etária, Brasil, 1990-2002.

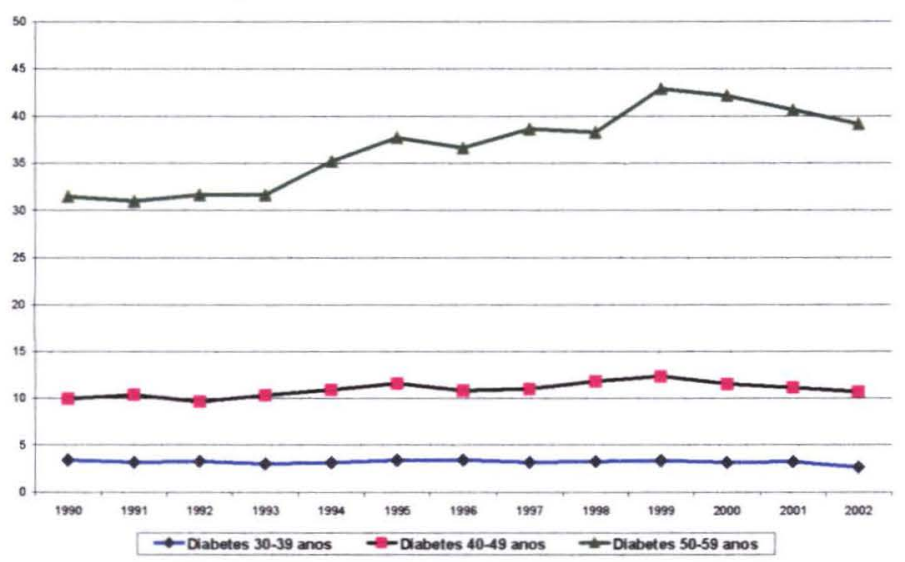

Fonte: IDB 2004

Quadro 3. Distribuição das taxas de mortalidade específica (por 100.000 hab.) por neoplasias malignas segundo faixa etária, Brasil, 1990-2002.

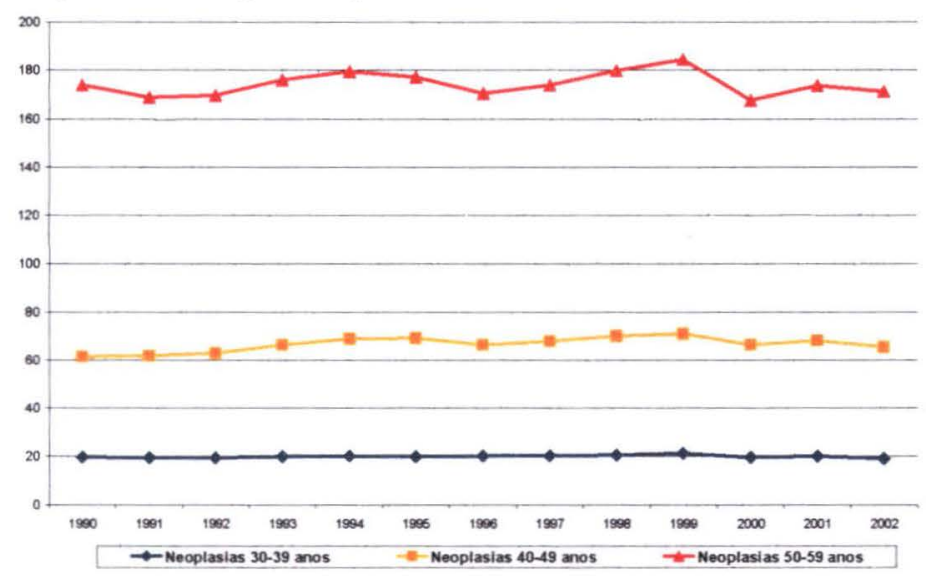

Fonte: IDB 2004 
Deste modo, algumas doenças típicas da população idosa estão cada vez mais freqüentes na população de adultos jovens. As doenças crônicas são responsáveis por cerca de $60,0 \%$ dos óbitos em todo o mundo e quase metade $(47,0 \%)$ da carga global de doenças, ambos concentrados principalmente nos países de baixa e média renda (WHO 2005a). As neoplasias malignas produzem 7,1 milhões de óbitos/ano (12,5\% do total de óbitos), e as doenças cardiovasculares 16,7 milhões de óbitos/ano (29,2\% do total de óbitos). Mais de 1 bilhão de adultos apresentam sobrepeso, com pelo menos 300 milhões clinicamente obesos (WHO 2005b).

Uma das graves conseqüências do aparecimento precoce das doenças crônicas é o incremento das incapacidades a elas relacionadas. As doenças crônicas são responsáveis pela grande maioria das incapacidades que ocorrem no decorrer do processo de envelhecimento, agravadas pelas co-morbidades e uso de múltiplos fármacos, muito freqüentes na população idosa (BRITO \& LITVOC 2004). A prevenção destas incapacidades depende, em grande parte, da incorporação de hábitos saudáveis relacionados ao estilo de vida. Acredita-se que mesmo pequenas mudanças no estilo de vida impliquem em grandes diferenças na prevenção de doenças crônicas (CDC 2001). Cerca de 80,0\% dos casos de doença arterial coronária, 90,0\% dos casos de diabetes tipo 2 e um terço dos cânceres poderiam ser evitados a partir de mudanças para uma dieta mais saudável, aumento da atividade física e interrupção do tabagismo e etilismo (WHO 2005c).

Poucos fatores de risco, em sua maioria preveníveis, respondem pela maior parte da carga global das doenças crônicas. Colesterol elevado, hipertensão arterial, obesidade, etilismo, tabagismo, inatividade fisica e vaixa ingestão de frutas e vegetais são os grandes responsáveis por mais de 75,0 \% das doenças cardiovasculares. Estas mudanças em hábitos da vida diária e padrões dietéticos são, também, reflexo da industrialização, urbanização, desenvolvimento econômico e propaganda de produtos alimentícios menos saudáveis (WHO 2005c). A redução 
dos gradientes sócio-econômicos responsáveis pela distribuição desigual destes fatores de risco também esbarra nos interesses das corporações que lucram diretamente com o comércio de produtos prejudiciais à saúde: produtores de cigarros, açúcar, fast food, álcool, automóveis e armas. Nos Estados Unidos da América, as indústrias de tabaco e álcool lucram, anualmente, quantias superiores a 100 bilhões de dólares (McGINNIS et al. 2002).

Dieta e atividade física são considerados, atualmente, pela Organização Mundial de Saúde, como prioridades em Saúde Pública (WHO 2005b). Em relação à inatividade física, provavelmente nenhum fator de risco conhecido tem uma prevalência tão elevada. Em 1987, no Município de São Paulo, o sedentarismo em atividades de lazer era de $69,3 \%$ na população entre 15 e 59 anos de idade (REGO et al. 1990). Inquérito também de 1987, no Município de Porto Alegre, evidenciou $69,0 \%$ de sedentarismo no lazer entre os homens e $82,0 \%$ entre as mulheres (DUNCAN et al. 1993). Estudo conduzido em 1992, na população urbana de Pelotas, RS, evidenciou 75,4 \% de sedentarismo no lazer (PICCINI \& VICTORA 1994). Inquérito de 1996, realizado no Município do Rio de Janeiro, evidenciou que 59,8\% dos homens e 77,8\% das mulheres nunca realizavam esporte ou exercício físico (GOMES et al. 2001). Dados da Pesquisa sobre Padrões de Vida, 1996-97, incluindo população das regiões Nordeste e Sudeste do Brasil, demonstraram que apenas 18,2\% dos homens e $8,2 \%$ das mulheres realizavam 30 minutos ou mais de atividade fisica, uma vez por semana. Avaliando o nível recomendado de 30 minutos de atividade física, cinco vezes por semana, o sedentarismo é de $96,5 \%$ para os homens e $96,8 \%$ para as mulheres! (MONTEIRO et al. 2003). As prevalências elevadas de inatividade física são observadas tanto na população geral, como em subgrupos específicos de portadores de fatores de risco para doenças crônicas. Em hipertensos referidos, o sedentarismo no lazer foi de 72,5 \% em quatro áreas do Estado de São Paulo, em 2002 (GUIMARÃES et al. 2003); em diabéticos, de 74,5\% (GUIMARÃES et al. 2004b). 
Quanto à dieta, as recomendações da Organização Mundial de Saúde (WHO 2005c) são: maior ingestão de frutas e vegetais, bem como nozes e grãos integrais; mudança no padrão de consumo de gorduras saturadas de origem animal para gorduras vegetais insaturadas; eliminação dos excessos de alimentos gordurosos, sal e doces na dieta e; manutenção do peso corporal normal (IMC entre 18,5 a 24,9). Existe uma tendência atual de dar maior valor aos alimentos que aos nutrientes. A Organização Mundial de Saúde, desde 1998, sugere que as orientações nutricionais para populações devem basear-se em alimentos ao invés de nutrientes. Em regiões metropolitanas foi observado, em estudo de tendência secular de componentes da dieta familiar, por MONTEIRO et al. (2000), um aumento no consumo das calorias lipídicas, valores elevados de consumo de colesterol dietético e ácidos graxos saturados, e valores excessivos de consumo de açúcar refinado e refrigerantes. Foi observada, ainda, redução no consumo de carboidratos complexos, leguminosas, verduras, legumes, frutas e sucos naturais, no período 1988-1996. Dados semelhantes foram observados em Bambuí, MG, utilizando-se Questionário Semiquantitativo de Freqüência Alimentar (BONOMO et al. 2003). SICHIERI et al (2003) observaram, a partir de dados da Pesquisa sobre Padrões de Vida, 1996-1997, que o local de residência, mesmo após controle para as variáveis individuais, foi um importante preditor para uma dieta mais saudável, com características mais próximas da alimentação tradicional do brasileiro, destacando-se principalmente arroz e feijão.

A interrupção do tabagismo também é uma das prioridades da Organização Mundial de Saúde. No Brasil, em 1986-1987, a prevalência de tabagismo na população entre 15-64 anos de idade, no Município de Porto Alegre foi de 40,0 \% (DUNCAN et al. 1993). No Município de São Paulo, no mesmo ano, de 37,9 \% (REGO et al. 1990). Em quatro regiões do estado de São Paulo, em 2002, a prevalência de tabagismo em pessoas com 18 anos ou mais foi de $24,0 \%$, sendo 25,5\% nos homens e 22,6 \% nas mulheres (BARROS et al. 2004a). Dados do BRFSS (Behavioral Risk Factor Surveillance System), de 2003, nos Estados Unidos, apontam uma prevalência de tabagismo de $22,1 \%$ na população adulta, 
maior entre os homens (24,8\%) que entre as mulheres (20,3\%) (CDC 2004a). Apesar da diminuição do consumo de tabaco, as prevalências ainda são elevadas em todo o mundo. O cigarro é a segunda maior causa de morte em todo o mundo. É o responsável por uma em cada 10 mortes, ou seja, cerca de 5 milhões de mortes/ano. Metade das pessoas que fuma hoje (cerca de 650 milhões), morrerá em função do uso do tabaco (WHO 2005d).

O consumo excessivo de álcool é a terceira causa prevenível de morte, e está associada a múltiplas conseqüências adversas para a saúde, como cirrose hepática, várias neoplasias, doenças cardíacas e cérebro-vasculares, transtornos psiquiátricos diversos, acidentes e violências (CDC 2004b). Estudo conduzido em 1999, no Estado de São Paulo, apontou 6,0 \% da população entre 12 e 65 anos de idade com dependência de álcool (GALDUROZ et al. 2003). Em 2002, em quatro áreas do Estado de São Paulo, foi observada dependência alcoólica (CAGE) de $5,9 \%$, com prevalência mais elevada nos homens $(9,6 \%)$ que nas mulheres $(2,4$ $\%$ ) (BARROS et al. 2004b). Nesse mesmo estudo, observou-se que 50,6\% dos homens e 19,8\% das mulheres ingerem álcool pelo menos uma vez por semana. Nos Estados Unidos, em 2001, estimou-se em 75.766 as mortes atribuíveis ao álcool e em 2,3 milhões os anos potenciais de vida perdidos, ou, em média, 30 anos de vida perdidos por cada óbito (CDC 2004b). Em 2002, nos Estados Unidos, $29,0 \%$ dos adultos embebedaram-se (binge drinking) pelo menos uma vez por mês (CDC 2004c). Em 2003, a dependência etílica foi de 6,9\% nos homens (CDC 2004d) e de 4,6 \% nas mulheres (CDC 2004e), nos Estados Unidos.

Nem todos os mecanismos pelos quais os determinantes sociais promovem saúde ou doença estão elucidados, embora sejam muitos os avanços neste campo teórico (ALMEIDA-FILHO 2000, 2004; KRIEGER 2005). Porém, inatividade física, dieta inadequada, tabagismo e etilismo são, certamente, aspectos do estilo de vida modificáveis e que se associam à pobreza, baixa escolaridade, exclusão social e menor nível sócio-econômico. Pelo fato dos segmentos 
populacionais de maior nível socioeconômico terem mais acesso à informação e a estímulos para adoção de comportamentos mais saudáveis, bem como às condições materiais de vida que permitem incorporá-los, estima-se que o percentual de problemas de saúde decorrentes do estilo de vida terá crescimento mais significativo nas regiões mais pobres, o que aumentará as desigualdades em saúde (WHO 2005a).

Estima-se que o Brasil, em 2025, tenha uma população de 34 milhões de pessoas de 60 anos de idade ou mais. Isto representa um incremento maior que o dobro da população idosa atual. Entretanto, a população adulta, de 20 a 59 anos de idade, será o grupo que mais crescerá no país em números absolutos nos próximos 20 anos: uma projeção de crescimento estimada em mais 26 milhões de adultos até 2025, e mais 34 milhões até 2050, comparando-se aos dias atuais. Isto totalizará uma população adulta total estimada de 124,5 milhões em 2025 e 132,9 milhões em 2050 (IBGE 2006). Compreendendo a melhora do estilo de vida da população adulta como um dos determinantes de sua qualidade de vida, espera-se um processo de envelhecimento bem-sucedido em que, mais que dicotomizar indivíduos em doentes ou saudáveis, seja possível a manutenção de sua autonomia e capacidade funcional pelo maior tempo possível.

Uma vez que, somente por meio de inquéritos de saúde é possível coletar dados que auxiliem na construção de indicadores relacionados à saúde, e não apenas às doenças, assim como sobre estilo de vida e determinantes sociais do processo saúde-doença (VIACAVA 2002), este trabalho se alinha às propostas para prevenção e controle das doenças crônicas, discutindo alguns aspectos do estilo de vida da população adulta no Estado de São Paulo, especialmente aqueles que estão sendo considerados como prioridades na agenda da Saúde Pública, enfocando as desigualdades em saúde. 


\subsection{OBJETIVO GERAL}

- Descrever as desigualdades em alguns aspectos do estilo de vida da população adulta, de 20 a 59 anos de idade, segundo características demográficas e sócio-econômicas, por meio de inquérito domiciliar de saúde, em áreas do Estado de São Paulo.

\subsection{OBJETIVOS ESPECÍFICOS}

- Descrever, em quatro áreas do Estado de São Paulo, quatro aspectos do estilo de vida da população adulta de 20 a 59 anos de idade

- Atividade física

- Hábito alimentar

- Tabagismo

- Etilismo

- Analisar nível de atividade fisica, dieta, tabagismo e etilismo na população adulta segundo sexo, idade, situação conjugal, cor ou raça, religião, índice de massa corpórea, escolaridade, atividade de trabalho e renda;

- Fornecer dados para programas de prevenção e controle de doenças crônicas, e de incentivo à prática de atividades físicas, dieta saudável e interrupção do tabagismo e etilismo. 


\section{METODOLOGIA}

O estilo de vida na população adulta foi avaliado juntamente com diversas variáveis demográficas e sócio-econômicas, bem como percepção de outras morbidades e utilização de serviços de saúde, como parte do projeto "INQUÉRITO DE Saúde no ESTado de São Paulo, ISA-SP”, com financiamento da Fundação de Amparo à Pesquisa do Estado de São Paulo-FAPESP (Processo n ${ }^{\circ}$ 98/14099-7) e Secretaria de Estado da Saúde, e participação das seguintes instituições:

- Faculdade de Saúde Pública da USP - Departamento de Epidemiologia;

- Faculdade de Ciências Médicas da UNICAMP - Departamento de Medicina Preventiva e Social;

- Faculdade de Medicina da UNESP de Botucatu - Departamento de Saúde Pública; e

- Faculdade de Medicina da USP - Departamento de Medicina Preventiva.

\subsection{DELINEAMENTO GERAL}

Estudo multicêntrico transversal para análise das condições de vida e saúde, realizado por meio de inquérito domiciliar de base populacional.

\section{2 ÁREAS DE ESTUDO}

Foram estudadas quatro áreas do Estado de São Paulo:

- Região sudoeste da Grande São Paulo, constituída pelos municípios de Taboão da Serra, Embu e Itapecerica da Serra;

- Distrito do Butantã, no Município de São Paulo;

- Município de Campinas; e

- Município de Botucatu. 


\subsection{PLANO DE AMOSTRAGEM}

A população de estudo refere-se à população não-institucionalizada residente em área urbana dos municípios de São Paulo, Itapecerica da Serra, Embu, Taboão da Serra, Campinas e Botucatu. Outras publicações já detalharam o plano de amostragem do projeto ISA-SP (ALVES 2002; ALVES 2005), sendo que a seguir apresentaremos apenas os aspectos relevantes relacionados a este estudo.

Para o cálculo do tamanho amostral foi utilizada a expressão matemática:

$$
\mathrm{n}_{0}=\frac{\mathrm{P}(1-\mathrm{P})}{\mathrm{d}^{2} / \mathrm{z}^{2}} \cdot \text { deff }
$$

Onde:

$\mathrm{P}=$ proporção de indivíduos a ser estimada;

$\mathrm{z}=$ valor na curva normal reduzida correspondente ao nível de confiança utilizado na determinação do intervalo de confiança de $\mathrm{p}$;

$\mathrm{d}=$ erro de amostragem;

deff $=$ efeito do delineamento.

Considerou-se que:

a) A proporção a ser estudada nas sub-populações é de $50 \%$ $(\mathrm{P}=0,50)$, por ser a de maior variabilidade, que leva à obtenção de tamanhos de amostras conservadores;

b) Deseja-se um coeficiente de confiança de $95 \%(z=1,96)$ na determinação dos intervalos de confiança das estimativas;

c) Admite-se um erro de amostragem de $10 \%(\mathrm{~d}=0,10)$, indicando que a distância entre a estimativa da amostra e o parâmetro populacional não deve exceder esse valor; 
d) Efeito do desenho (deff) considerado como 2 .

A expressão que define $\mathrm{n}_{0}$ em cada subgrupo amostral totaliza 192, arredondado para 200 .

Considerando-se que o percentual de indivíduos selecionados que não responderão ao questionário (casas fechadas e recusas) é de $20 \%$, o tamanho da amostra será corrigido, obtendo-se: $n^{\prime}=200 / 0,80=250$.

A fim de obter estimativas para subpopulações, foram considerados grupos de idade e sexo, denominados domínios amostrais. No projeto ISA-SP há os seguintes domínios amostrais:

- Menor de 1 ano masculino(M) e feminino(F);

- 1 a 11 anos $\mathrm{Me} \mathrm{F}$;

- 12 a 19 anos M;

- 12 a 19 anos F;

- 20 a 59 anos $\mathrm{M}$;

- 20 a 59 anos F;

- 60 anos e mais M;

- 60 anos e mais F.

Os domínios considerados neste estudo de estilo de vida em população adulta foram 20 a 59 anos-masculino e 20 a 59 anos-feminino.

A definição desses domínios deve-se principalmente ao fato de que alguns subgrupos populacionais, como os menores de um ano e os de idade muito avançada, representem uma proporção muito pequena do total da população e estes são os grupos que normalmente apresentam maiores prevalências de problemas de saúde e freqüentemente procuram mais os serviços de saúde. Assim, ao invés de entrevistar-se todos os moradores do domicílio, o que faria com que a amostra tivesse uma estrutura por sexo e idade semelhante à população, foram entrevistados números iguais de indivíduos (200) para cada domínio, garantindo-se assim, número 
suficiente de observações em cada grupo de idade e sexo, com um tamanho de amostra total menor (1600 em cada área estudada).

Além da estratificação geográfica, os setores censitários foram divididos segundo nível de escolaridade dos chefes de família. Esta última estratificação visou aumentar a probabilidade de que pessoas do estrato mais rico da população pertencessem à amostra, viabilizando a análise da situação de saúde e do uso de serviços de saúde segundo subgrupos sociais. Informações sobre escolaridade dos chefes estão disponíveis na contagem da população feita pelo IBGE em 1996, o que, acrescido da relação entre nível de escolaridade e nível sócio-econômico, justifica a escolha dessa variável para orientar a estratificação das áreas.

Foram formados três estratos, segundo percentual de chefes de família com nível universitário no setor: menos de $5 \%$; de 5 a $25 \%$; e com mais de $25 \%$.

Foi utilizada amostragem por conglomerados em dois estágios: setor censitário e domicílio.

As unidades primárias de amostragem foram, portanto, sorteadas com probabilidade proporcional ao tamanho, obtido pelo IBGE em contagem populacional de 1996. Foi utilizado sorteio sistemático, aplicado à relação de unidades primárias ordenadas segundo tipo de setor, dentro de cada estrato.

Os domicílios foram sorteados com probabilidade inversamente proporcional ao tamanho do setor, a partir de listagens feitas em visitas aos setores sorteados.

Foram sorteadas sub-amostras de domicílios, nos quais os indivíduos dos diversos grupos de sexo e idade deveriam ser entrevistados. Assim sendo, em alguns domicílios foram entrevistados todos os moradores. Em outros, apenas os que pertenciam a determinado domínio amostral. 


\subsection{COLETA DE DADOS}

Os dados foram coletados em seis cortes, ao longo de 12 meses, no período de abril de 2001 a setembro de 2002. As informações foram obtidas através de questionários aplicados por entrevistadores treinados, respondidos diretamente pelos moradores sorteados ou pela mãe ou responsável por crianças menores de 12 anos, garantindo-se assim maior confiabilidade das informações, principalmente aquelas referentes a problemas de saúde de menor gravidade.

O questionário, previamente testado em estudo piloto, foi organizado em blocos, segundo áreas temáticas, com a maioria das questões fechadas, com alternativas pré-definidas. Sempre que possível foram incluídas questões já testadas, previamente, em outros estudos. A codificação foi feita diretamente nos questionários a partir dos quais foi feita a digitação. O Anexo 1 apresenta o questionário utilizado na pesquisa.

O projeto ISA-SP estudou grupos temáticos, sendo que para cada um deles foram formuladas questões sobre aspectos específicos. Os conjuntos temáticos são descritos a seguir.

O BLOCO A refere-se a informações gerais sobre a composição familiar necessária para estabelecer os primeiros elementos das condições de vida;

O BLOCO B constitui-se em instrumento de controle para a realização das visitas, registrando-se as razões para eventual não-realização das entrevistas;

A morbidade referida é estudada no BLOCO $\mathrm{C}$, onde se procura identificar, nos indivíduos sorteados, as situações de saúde/doença experimentadas nos últimos 15 dias, com possibilidades de destaque para causas externas. Além desta identificação, procura-se trabalhar com a demanda gerada aos serviços de saúde e da satisfação da mesma; 
O BLOCO D levanta informações sobre a presença de diagnósticos de doenças crônicas, com ênfase naquelas de maior relevância e prevalência. Justificase esse bloco pela relevância crescente dessas doenças no nosso meio e pela sua complexidade manifestada nos programas de atenção à saúde. Há dois blocos específicos de doenças crônicas: o BLOCO D1 para hipertensão e o BLOCO D2 para diabetes. A presença de deficiência física é estudada no BLOCO E. Da mesma forma se justifica o BLOCO F, onde se investiga a ocorrência de acidentes ou violências nos doze meses anteriores à entrevista e suas conseqüências sobre os entrevistados.

O BLOCO $\mathrm{G}$ arrola questões relativas à utilização de serviços de saúde nos quinze dias anteriores à entrevista, na ausência de morbidade. O BLOCO $\mathrm{H}$ explora itens relativos à realização de exames preventivos, enquanto o BLOCO I ocupa-se de questões sobre imunização. No BLOCO J estuda-se o consumo de medicamentos pela população pesquisada. O BLOCO K compreende itens sobre hospitalizações ocorridas no último ano de vida do entrevistado.

No BLOCO L são exploradas questões referentes ao estilo de vida, aprofundados em quatro de seus tradicionais capítulos: atividade física, hábitos alimentares (através de inquérito recordatório de $\mathbf{2 4}$ horas), tabagismo e uso de álcool. $\mathrm{O}$ instrumento utilizado para avaliação da freqüência e nível de atividade física é o Questionário Internacional de Atividade Física - QIAF, versão 8, simplificada, já validada no Brasil (ARAÚJO et al. 2000; IPAQ 2005). Foram ainda, avaliados, a prática de esporte ou exercício físico, e o tempo gasto nas seguintes atividades da vida diária: assistir TV, no computador, trabalhando, estudando, no transporte, fazendo serviço em casa, em lazer e dormindo.

O BLOCO M levanta informações sobre distúrbios emocionais dos indivíduos entrevistados. Faz-se um uso direto da versão validada para o Brasil do inquérito sobre qualidade de saúde medida através do questionário de auto-avaliação de saúde (SF-36), no BLOCO N. O aproveitamento da versão original é feito de modo integral, mantendo-se todas as questões, respeitando-se seu conteúdo. 
Os BLOCOS O, P e Q estão voltados para a caracterização sócioeconômica da família, do domicílio e do entrevistado. Conjuntamente com as informações colhidas no BLOCO A, é possível descrever, com esses três blocos, as condições de vida dos indivíduos entrevistados, variável essencial para entender a distribuição das doenças, bem como o acesso às respostas sociais. No BLOCO R, procura-se apurar o gasto mensal familiar com a saúde nesse grupo estudado. E no BLOCO S, são levantados dados sobre pré-natal, parto e puericultura de todas as crianças menores de um ano.

\subsection{VARIÁVEIS DE ESTUDO}

\subsubsection{Demográficas e sócio-econômicas}

A caracterização de gênero foi obtida a partir da questão B06 e a idade foi obtida a partir da data de nascimento do entrevistado (questão B05) e analisada em quatro grupos de faixa etária: 20-29 anos, 30-39 anos, 40-49 anos e 5059 anos.

A questão B07 avaliou a cor ou raça do entrevistado. No ISA-SP, a cor ou raça foi auto-declarada pelo entrevistado e foi avaliada como qualitativa e, em alguns modelos multivariados, incluída como variável dicotômica (branca / nãobranca; ou negra/demais).

A religião (questão B08) foi avaliada em cinco categorias: sem religião, católica, evangélica, espírita e outras.

A situação conjugal (questões O05 ou Q18) foi avaliada como variável dicotômica (com e sem companheiro), bem como se o entrevistado exerce alguma atividade remunerada de trabalho (O08 ou Q10), que foi analisada como ‘sim / não'. 
O IMC - Índice de Massa Corporal foi calculado a partir de peso e altura referidos (L02 e L03) e os indivíduos foram analisados nas categorias: normal (menor que 25,0$)$, sobrepeso $(25,0$ a 29,9$)$ e obesidade $(\geq 30)$.

As questões O06 e Q08 abordam a escolaridade, que foi analisada em quatro categorias (até 3 anos; 4-7 anos; 8-11 anos; e 12 anos ou mais). Os dados de renda familiar mensal são resumidos na questão Q25. Esta variável foi analisada em salários-mínimos per capita, em quatro categorias: $<0,5 ; 0,5-1,49 ; 1,5-2,9 ; \mathrm{e} \geq 3$. $\mathrm{Na}$ análise de agrupamentos (cluster), esta variável foi analisada como contínua.

\subsubsection{Atividade física, exercício físico e caminhada}

A partir de conceitos publicados por CASPERSEN et al. (1985), atividade física é definida como qualquer movimento corporal produzido por musculatura esquelética que resulte em gasto energético, e exercício físico é um tipo de atividade física definida como movimento corporal planejado, estruturado e repetitivo com intuito de aumentar ou manter um ou mais componentes do condicionamento físico.

$\mathrm{O}$ instrumento utilizado para avaliação do nível de atividade física foi o Questionário Internacional de Atividade Física - QIAF, versão 8, forma curta, com interrogatório sobre uma semana habitual. Esta versão já foi validada no Brasil (ARAÚJO et al. 2000; MATSUDO et al. 2001).

Para classificação do nível de atividade física foi utilizada a segunda versão, de abril de 2004, das Diretrizes para Processamento e Análise de Dados do Questionário Internacional de Atividade Física (QIAF) - Versão Curta (IPAQ 2005). Esta nova versão não muda a classificação anterior quanto à inatividade física. Apenas propõe uma nova categoria para descrever os individuos mais ativos. 
O QIAF propõe uma medida geral de atividade física avaliando quatro domínios: atividades de lazer, atividades domésticas, atividades relacionadas ao trabalho e atividades relacionadas ao transporte.

Os dados obtidos a partir do QIAF foram processados de acordo com a segunda versão das diretrizes de abril de 2004. Assim:

- O tempo em todas as variáveis foi convertido para minutos;

- Os minutos foram convertidos para METs-min, considerando-se caminhada $=3,3$ METs, atividade física moderada $=4,0$ METs e atividade física vigorosa $=8,0$ METs. Os METs-min foram calculados multiplicando-se os valores acima pelos minutos realizados da respectiva atividade;

- Verificação do número de dias em que as atividades foram realizadas;

- Os indivíduos que relataram caminhada, atividade moderada ou vigorosa por tempo superior a 16 horas/dia foram excluídos da análise;

- Os indivíduos que relataram realizar atividade física por tempo superior a quatro horas ou 240 minutos/dia tiveram esta variável truncada, ou seja, recodificada para igual a 240 minutos/dia. Esta recodificação permite um máximo de 28 horas de atividade física semanal a ser relatada para cada categoria de atividade física e visa normalizar os níveis de atividade física em avaliações populacionais;

- Apenas valores de 10 minutos ou mais de atividade física foram considerados. Respostas menores que 10 minutos (e seus respectivos dias) foram recodificadas como zero;

- Avaliação do nível de atividade física em três categorias:

- INATIVOS

- Nível mais baixo de atividade física; inclui os indivíduos que não preencheram os critérios para as outras categorias 
- MINIMAMENTE ATIVOS

- Três ou mais dias de atividade vigorosa por tempo mínimo de 20 minutos/dia OU

- Cinco ou mais dias de atividade moderada ou caminhada por tempo mínimo de 30 minutos/dia OU

- Cinco ou mais dias de qualquer combinação de caminhada, atividade moderada ou vigorosa atingindo pelo menos $600 \mathrm{MET}-\mathrm{min} / \mathrm{semana}$

- HEPA ' - Atividade física para promoção da saúde

- Três ou mais dias de atividade vigorosa atingindo pelo menos $1.500 \mathrm{MET}-\mathrm{min} / \mathrm{semana}$ $\mathrm{OU}$

- Sete dias de qualquer combinação de caminhada, atividade moderada ou vigorosa atingindo pelo menos 3.000 MET-min/semana.

A categoria HEPA se refere a um grupo de indivíduos muito ativos que realizam mais que o mínimo recomendado de atividade física. Equivale a aproximadamente 1,5-2 horas de atividade total por dia, em nível moderado. É muito recomendável para todos os indivíduos ter nível HEPA de atividade física, principalmente por que estão sendo acessados todos os domínios da atividade física.

Segundo os critérios do QIAF, foram consideradas atividades vigorosas aquelas que fazem suar bastante, ou que aumentam muito a respiração ou os batimentos do coração. Foram consideradas atividades moderadas aquelas que fazem suar leve, ou aumentam moderadamente a respiração ou batimentos do

\footnotetext{
${ }^{1}$ HEPA - Health Enhancing Physical Activity ou Atividade Física para Promoção da Saúde. Neste trabalho optamos por utilizar a sigla HEPA em razão do seu fácil reconhecimento e uso comum, mesmo em publicações de língua portuguesa.
} 
coração. Avaliou-se, assim, a prática de atividades vigorosas, moderadas e caminhadas, segundo estes critérios, nas questões L10a a L12b.

Como o Questionário Internacional de Atividade Física, em sua forma curta, não fornece o contexto em que foi realizada a atividade física, na questão L17 os indivíduos foram interrogados sobre a prática regular, pelo menos uma vez por semana, de algum esporte ou exercício físico, com intuito de avaliar pelo menos uma parte das atividades de lazer. Os dados foram relatados segundo algumas categorias mais freqüentes, como caminhada, futebol, andar de bicicleta e ginástica/musculação, e também num outro momento, analisados como variável dicotômica, separando-se os indivíduos que relataram praticar algum esporte ou exercício físico daqueles que não praticaram.

Devido à praticidade e importância da caminhada como exercício, foi realizada análise em separado da prática de caminhada como exercício físico, também a partir da questão L17, analisada como variável dicotômica (sim / não).

\subsubsection{Tabagismo}

A partir das questões L18 e L20 foi estruturada a variável tabagismo, avaliada em três categorias: nunca fumou, ex-tabagista e fuma atualmente.

O tempo após acordar em que fuma o primeiro cigarro (questão L25), variável indicadora de dependência (PILLITTERI et al. 1997), foi avaliado em três categorias: na primeira meia hora, na segunda meia hora, e após.

A quantificação do tabagismo foi realizada a partir da questão L26, e avaliada também em três categorias: $<10$ cigarros/dia, 10-20 cigarros/dia e $>20$ cigarros/dia. 


\subsubsection{Etilismo}

A partir da questão L37 obtivemos dados da freqüência de ingestão de bebida alcoólica, avaliada em três categorias: até 1 a 2 vezes/mês, 1 vez/semana e 2 a 3 vezes/semana ou mais.

As questões L33 a L36 compõem o CAGE, questionário utilizado para detectar possível abuso ou dependência de álcool em estudos clínicos e populacionais. Desenvolvido em 1968, é composto de quatro perguntas (Cut down / Annoyed by criticism / Guilty / Eye-opener) e considera como caso suspeito de etilismo, ou "bebedor-problema", alguém que responda afirmativamente a duas ou mais perguntas. No Brasil sua validação foi feita por MASUR \& MONTEIRO (1983), observando-se sensibilidade de $88 \%$ e especificidade de $83 \%$. No ISA-SP, foi considerado indicativo de abuso ou dependência de álcool quando apresentou duas ou mais respostas SIM.

\subsubsection{Hábito alimentar}

Os dados para avaliação da dieta foram obtidos a partir de inquérito recordatório de 24 horas (questão L08). O cálculo do valor nutritivo dos alimentos consumidos foi realizado utilizando-se o programa Virtual Nutri (PHILIPPI et al.1996) com banco de dados de alimentos modificado. O banco foi adaptado com a introdução de informações das tabelas de composição química dos alimentos do United States Department of Agriculture-USDA (2003), PHILIPPI (2001) e SOUCI et al (1994). As informações dos alimentos industrializados foi obtida a partir dos rótulos e/ou nos serviços de atendimento ao consumidor. Para as preparações caseiras, seus ingredientes foram desdobrados e foram utilizadas as padronizações de receitas propostas por PINHEIRO et al (2000) e FISBERG \& VILLAR (2002). Foram excluídos da análise indivíduos com ingestão de energia abaixo de $500 \mathrm{kcal}$ ou acima de $4.000 \mathrm{kcal}$, por possível sub ou superestimação do consumo alimentar nesses casos (WILLETT 1998). A descrição detalhada do treinamento para coleta do 
recordatório, crítica dos registros, análises de consistência e digitação já foram discutidas em outros trabalhos (MORIMOTO 2004; FISBERG et al. 2005).

Para avaliação da qualidade da dieta foi utilizado o Índice de Qualidade da Dieta-IQD, adaptado do Healthy Eating Index de KENNEDY et al (1995) por FISBERG e colaboradores (2004), conforme ilustrado a seguir.

\section{“Componentes do Índice de Qualidade da Dieta}

O Índice de Qualidade da Dieta (IQD) foi obtido por uma pontuação distribuida em dez componentes que caracterizam uma dieta saudável:

- Componentes de 1-6: medem o grau de adequação do consumo das porções de cada um dos seis principais grupos de alimentos, estipulados pelo guia alimentar: cereais, pães, tubérculos e raizes; verduras e legumes; frutas; leites e produtos lácteos; carnes e ovos; leguminosas.

- Componente 7: mede a ingestão de gordura total como percentual do total de energia consumido.

- Componente 8: mede ingestão de colesterol.

- Componente 9: mede a ingestão de sódio.

- Componente 10: mede a variedade da dieta, ou seja, número total de diferentes alimentos ingeridos no dia.

Cada componente é avaliado e pontuado de zero a dez, sendo que os valores intermediários são calculados proporcionalmente. A pontuação máxima dos dez componentes é 100 e a qualidade da dieta foi determinada pela distribuição dos escores encontrados na população alvo. O escore total dos individuos foi dividido em três categorias: abaixo de 51 pontos - dieta "inadequada", entre 51 a 80 pontos dieta que "necessita de modificação", e superior a 80 pontos - dieta "saudável" (BOWMAN et al. 1998). 
QUADRO 4 - Critérios para pontuação máxima e mínima de cada componente do IQD.

\begin{tabular}{|c|c|c|}
\hline Componente & $\begin{array}{c}\text { Critério para a } \\
\text { Pontuação Mínima } \\
(0 \text { ponto })\end{array}$ & $\begin{array}{c}\text { Critério para a } \\
\text { Pontuação Máxima } \\
\text { (10 pontos) }\end{array}$ \\
\hline $\begin{array}{l}\text { 1. Grupo dos cereais, pães, } \\
\text { tubérculos e raízes }\end{array}$ & 0 porção & 5 ou mais porções \\
\hline 2. Grupo das verduras e legumes & 0 porção & 4 ou mais porções \\
\hline 3. Grupo das frutas & 0 porção & 3 ou mais porções \\
\hline 4. Grupo do leite e produtos lácteos & 0 porção & 3 ou mais porções \\
\hline 5. Grupo das carnes e ovos & 0 porção & I ou mais porções \\
\hline 6. Grupos das leguminosas & 0 porção & I ou mais porções \\
\hline 7. Gordura total & $\begin{array}{l}45 \% \text { ou mais do total } \\
\text { de energia }\end{array}$ & $\begin{array}{l}30 \% \text { ou menos do } \\
\text { total de energia }\end{array}$ \\
\hline 8. Colesterol & +50 mg ou mais & $300 \mathrm{mg}$ ou menos \\
\hline 9. Sódio & 4800 mg ou mais & $2400 \mathrm{mg}$ ou menos \\
\hline 10. Variedade da dieta & $\begin{array}{c}3 \text { ou menos tipos } \\
\text { diferentes de } \\
\text { alimentos }\end{array}$ & $\begin{array}{l}8 \text { ou mais tipos } \\
\text { diferentes de } \\
\text { alimentos" }\end{array}$ \\
\hline
\end{tabular}

O Índice de Qualidade da Dieta proposto por FISBERG et al (2004) modificou o original, com substituição do componente 'gordura saturada' pelo 'grupo das leguminosas', e considerando o tamanho da porção de cada alimento para o cálculo da variedade da dieta.

O processamento de dados para o cálculo do Índice de Qualidade da Dieta foi realizado no software Statistical Package for the Social Sciences, versão 
10 , por meio de um programa desenvolvido especificamente para este estudo, o qual calcula e atribui a pontuação para cada componente do IQD e para cada indivíduo.

Neste trabalho, o IQD foi avaliado em três categorias: dieta inadequada, dieta que necessita modificação e dieta saudável. Na análise de cluster, o IQD é avaliado como variável contínua.

A partir dos componentes do IQD são avaliados também o consumo de verduras e legumes, o consumo de frutas e a composição de gorduras na dieta. Estas variáveis são avaliadas em tercis, e apenas na análise de cluster como variáveis quantitativas contínuas. Todas estas variáveis são analisadas como componentes do IQD, apresentando pontuação mínima de 0 e máxima de 10 , conforme indicado no Quadro 1.

\subsection{ANÁLISE DOS DADOS}

Para a análise geral dos dados foi necessário que os programas de processamento e análise incorporassem os fatores de ponderação da amostra, baseados no sexo e idade dos entrevistados e na fração amostral do setor censitário, a partir do percentual de chefes de família com nível universitário. Os cálculos para definições dos pesos utilizaram as informações do Censo IBGE de 2000. O Banco de dados foi estruturado utilizando-se o Statistical Package for the Social Sciences SPSS, versão 10.0. Para análise, foram utilizados os softwares SPSS 13.0 e Stata 7.0.

Apresentamos, no decorrer do trabalho, em todas as tabelas e gráficos, os números absolutos na amostra não-ponderada acompanhados das respectivas porcentagens na amostra ponderada.

Para avaliar o efeito das variáveis demográficas e sócio-econômicas sobre as variáveis do estilo de vida optamos por realizar Regressão de Poisson. Neste estudo, como avaliamos variáveis relacionadas ao estilo de vida, sendo a maioria delas de prevalência elevada, o uso de regressão logística (odds ratio) poderia 
superestimar as razões de prevalência. Assim, optamos por utilizar um modelo estatístico que proporcionasse melhor ajuste e estimasse diretamente as razões de prevalências e seus intervalos de confiança (SKOV et al. 1998; BARROS \& HIRAKATA 2003).

O Anexo 2 apresenta a aderência à distribuição de Poisson das variáveis em estudo. Para a análise de Regressão de Poisson simples, todas as variáveis foram avaliadas em categorias e transformadas em variáveis indicadoras, permitindo a comparação das razões de prevalência entre as categorias de cada variável analisada. As variáveis que obtiveram p menor que 0,20 na análise de Regressão de Poisson simples foram incluídas nos modelos múltiplos. Optamos pela modelagem stepwise forward, ou seja, do modelo mais simples para o mais complexo. As variáveis que permaneceram significativas foram mantidas nos modelos múltiplos finais. Foram realizados modelos de Regressão de Poisson separados para os sexos masculino e feminino. Apresentamos em tabelas as razões de prevalência apenas das variáveis que obtiveram $p$ menor que 0,20 . Tendências lineares foram exploradas para variáveis categóricas ordinais.

A análise dos resíduos (Anexo 3) foi realizada para verificar a presença de viés nos modelos ou valores aberrantes. Optou-se pela utilização dos resíduos deviance padronizados contrastando com valores preditos (HAIR et al. 1995; FAHRMEIR \& TUTZ 1997; VIOLA 2001). Como os resíduos deviance apresentam distribuição próxima à Normal se o modelo estiver bem ajustado (HOJSGAARD \& HALEKOH 2006), QQPlots destes resíduos também são apresentados no Anexo 3. Após realização dos modelos múltiplos, foram avaliadas possíveis interações entre as variáveis.

Após a realização dos modelos de Regressão de Poisson múltiplos para cada uma das doze variáveis escolhidas para compor o estilo de vida neste estudo, foi realizada Análise de Cluster (TwoStep Cluster) com objetivo de explorar os dados e revelar possíveis agrupamentos inicialmente não aparentes entre as diversas variáveis. A Análise de Cluster também foi estratificada por sexo. 
Para a realização da Análise de Cluster, as variáveis renda familiar mensal em salários-mínimos per capita, consumo de frutas e verduras na dieta, composição de gorduras na dieta e IQD (Índice de Qualidade da Dieta), foram incluídas como variáveis quantitativas contínuas. Utilizou-se, então, o teste de Kolmogorov-Smirnov para verificar o grau de concordância da distribuição destas variáveis com a distribuição Normal. São apresentados, também, histogramas e QQPlots destas variáveis.

Os métodos tradicionais de análise de cluster recaem em duas grandes categorias: realocação e hierarquização. Métodos de realocação - como o k-means movem os registros de um cluster para outro, a partir de uma divisão inicial. Os métodos hierárquicos procedem por estágios produzindo uma seqüência de divisões em que cada uma se aloca na divisão seguinte da hierarquia. A análise de cluster hierárquica também pode ser realizada por aglomeração ou divisão.

Todos estes métodos de análise de cluster necessitam de uma medida de distância. Algumas medidas aceitam apenas variáveis contínuas, como a distância Euclidiana, e outras apenas variáveis categóricas, como a medida de dissimilaridade utilizada no método k-modes de HUANG (1998). Em 1993, BANFIELD \& RAFTERY propuseram uma medida de distância para dados qualitativos com atributos contínuos. Em 1998, MEILA \& HECKERMAN aplicaram este mesmo conceito probabilístico e produziram uma outra medida de distância para dados com atributos categóricos apenas. A análise de cluster TwoStep do SPSS engloba estas medidas de distância possibilitando a inclusão tanto de variáveis contínuas quanto categóricas (SPSS 2003).

Além disso, os métodos tradicionais de análise de cluster funcionam bem em pequenas amostras. Grandes conjuntos costumam limitar a análise por estes métodos, necessitando que estes bancos de dados fossem subdivididos em conjuntos menores. Este é o conceito básico que envolve o método TwoStep. ZHANG et al, em 1996, desenvolveram então um método em dois estágios em que no primeiro é aplicado um método seqüencial rápido para um grande conjunto de dados a fím de comprimir as regiões mais densas e formar sub-clusters (THEODORIDIS \& 
KOTROUMBAS 1999). Num segundo momento, os sub-agrupamentos resultantes do primeiro passo são agrupados no número desejado de clusters, ou determinado a partir da função auto-cluster. Como o número de sub-agrupamentos é inferior ao número de registros originais, então os métodos tradicionais podem ser utilizados efetivamente. O auto-cluster utilizou o Bayesian Information Criterion (BIC) e as mudanças de distância, conforme relatado por FRALEY \& RAFTERY (1998).

A medida de distância utilizada nesta análise foi a logverossimilhança, em que distribuições normais para as variáveis contínuas e multinomiais para as variáveis categóricas foram assumidas. Da mesma forma, considerou-se que as variáveis eram independentes umas das outras, assim como os casos.

Para análise geral dos dados deste estudo, inicialmente apresentamos uma descrição das variáveis de estudo. Em seguida, apresentamos as razões de prevalência brutas e ajustadas dos modelos de Regressão de Poisson múltiplos para cada uma das variáveis do estilo de vida. Após, procedemos à Análise de Cluster incluindo variáveis dos quatro componentes do estilo de vida abordados neste estudo - atividade física, tabagismo, etilismo e dieta - e variáveis sócio-econômicas. Todas as análises são estratificadas por sexo e em todas utilizou-se o nível de significância de $5 \%$. 


\subsection{CARACTERISTICAS DA POPULAÇÃO ADULTA}

A amostra total obtida do banco de dados do ISA-SP para as quatro áreas foi de 6.819 indivíduos entrevistados. Destes, 1.646 indivíduos apresentavam idade entre 20 e 59 anos, sendo 826 do sexo masculino e 820 do sexo feminino. Após ponderação, estes valores correspondem a 48,0 \% (IC 95\% 45-51) de entrevistados do sexo masculino e $52 \%$ (IC $95 \% 49-55$ ) do sexo feminino.

Quanto à faixa etária observamos, em nossa amostra, predomínio de indivíduos na faixa 20-29 anos (33,8\%). As faixas etárias 30-39 anos, 40-49 anos e 50-59 anos apresentaram, respectivamente, percentuais de $25,1 \%, 24,1 \%$ e $17,0 \%$. Esta diferença na estrutura etária é estatisticamente significativa $(p=0,000)$.

A Tabela 1 apresenta as características demográficas e sócioeconômicas segundo sexo da população adulta nas quatro áreas. No sexo masculino, observamos que 66,2 \% dos entrevistados são casados (com companheira), 40,3\% com escolaridade entre 8-11 anos e 80,9 \% exercendo atividade remunerada de trabalho. Dentre as mulheres, $60,3 \%$ vivem com companheiro, $40,5 \%$ têm entre $8 \mathrm{e}$ 11 anos de escolaridade e $62,6 \%$ exercem atividade remunerada de trabalho. Declararam-se católicos $69,6 \%$ dos homens e $62,8 \%$ das mulheres. Em relação à cor ou raça, 70,3\% dos homens e 67,4\% das mulheres se declararam brancos. Quanto ao IMC, $50,3 \%$ dos homens e $62,6 \%$ das mulheres se apresentaram na faixa da normalidade (Índice de Massa Corpórea < 25). A variável IMC apresentou 6,8\% de não-resposta nesta amostra.

Para a maioria das variáveis não houve diferenças significativas entre os sexos feminino e masculino. Houve diferença apenas para as seguintes variáveis: situação conjugal $(p=0,043)$, religião $(p=0,004)$, IMC $(p=0,000)$ e exerce atividade de trabalho $(\mathrm{p}=0,000)$ (dados não apresentados em tabela). 
Tabela 1. Características demográficas e sócio-econômicas segundo sexo em população adulta no Estado de São Paulo, 2002

\begin{tabular}{|c|c|c|c|c|}
\hline \multirow[b]{2}{*}{ Variável } & \multicolumn{2}{|c|}{ Masculino } & \multicolumn{2}{|c|}{ Feminino } \\
\hline & $n^{\prime}$ & $\%^{2}$ & $n^{1}$ & $\%^{2}$ \\
\hline \multicolumn{5}{|l|}{ Faixa etária } \\
\hline 20-29 anos & 279 & 34,0 & 274 & 33,5 \\
\hline 30-39 anos & 205 & 22,6 & 219 & 27,5 \\
\hline $40-49$ anos & 198 & 24,7 & 187 & 23,5 \\
\hline $50-59$ anos & 144 & 18,7 & 139 & 15,5 \\
\hline \multicolumn{5}{|l|}{ Situação conjugal } \\
\hline Com companheiro & 550 & 66,2 & 491 & 60,3 \\
\hline Sem companheiro & 273 & 33,8 & 329 & 39,7 \\
\hline \multicolumn{5}{|l|}{ Cor ou raça } \\
\hline Branca & 592 & 70,6 & 564 & 68,0 \\
\hline Preta & 45 & 7,0 & 65 & 9,2 \\
\hline Parda & 171 & 21,1 & 166 & 21,1 \\
\hline Outras & 12 & 1,3 & 18 & 1,7 \\
\hline \multicolumn{5}{|l|}{ Religião } \\
\hline Sem religião & 71 & 9,3 & 43 & 5,7 \\
\hline Católica & 565 & 69,6 & 528 & 62,8 \\
\hline Evangélica & 116 & 12,0 & 162 & 19,3 \\
\hline Espirita & 34 & 4,3 & 37 & 6,3 \\
\hline Outras & 38 & 4,9 & 46 & 5,9 \\
\hline \multicolumn{5}{|l|}{ Escolaridade } \\
\hline$<3$ anos & 91 & 12,7 & 117 & 13,8 \\
\hline 4-7 anos & 240 & 29,8 & 221 & 25,0 \\
\hline $8-11$ anos & 344 & 40,3 & 320 & 40,5 \\
\hline$\geq 12$ anos & 150 & 17,2 & 162 & 20,7 \\
\hline \multicolumn{5}{|l|}{ IMC* } \\
\hline Menor que 25 & 411 & 50,3 & 458 & 62,6 \\
\hline Sobrepeso & 279 & 36,8 & 187 & 23,6 \\
\hline Obesidade & 106 & 12,8 & 100 & 13,8 \\
\hline \multicolumn{5}{|c|}{ Exerce atividade de trabalho } \\
\hline Sim & 676 & 80,9 & 507 & 62,6 \\
\hline Não & 150 & 19,1 & 313 & 37,4 \\
\hline \multicolumn{5}{|c|}{$\begin{array}{l}\text { Renda familiar mensal } \\
\text { (salários-mínimos per capita) }\end{array}$} \\
\hline$<0,5$ & 65 & 8,3 & 87 & 9,0 \\
\hline $0,5-1,49$ & 237 & 29,3 & 243 & 31,2 \\
\hline $1,5-2,9$ & 225 & 28,7 & 209 & 28,2 \\
\hline$\geq 3$ & 255 & 33,6 & 235 & 31,6 \\
\hline
\end{tabular}

'Números absolutos na amostra não-ponderada.

${ }^{2}$ Porcentagens na amostra ponderada.

*Indice de massa corpórea calculado a partir de peso e altura referidos 
A Tabela 2 apresenta as prevalências das variáveis relacionadas ao estilo de vida na população de 20 a 59 anos de idade nas quatro áreas de estudo segundo sexo.

Quanto ao exercício físico na população adulta, observamos que $42,2 \%$ dos homens e $26,0 \%$ das mulheres relataram praticar esporte ou exercício físico pelo menos uma vez/semana $(\mathrm{p}=0,000)$. Ao avaliarmos o nível geral de atividade física (QIAF), observa-se o inverso, com 57,1\% das mulheres na categoria mais elevada de atividade fisica (HEPA) e 43,1 \% dos homens nesta mesma categoria $(p=0,000)$. Em relação à prática de caminhada, não houve diferença entre os sexos.

Em relação ao tabagismo, $60,0 \%$ das mulheres relataram nunca ter fumado e, dentre as tabagistas, $29,4 \%$ fumam menos que 10 cigarros/dia. No sexo masculino estas freqüências são de $51,4 \%$ e $23,4 \%$, respectivamente. Esta diferença entre os sexos é estatisticamente significativa $(\mathrm{p}=0,004)$.

Houve grande diferença entre os sexos quanto à freqüência de ingestão de bebida alcoólica $(\mathrm{p}=0,000)$. Apenas $14,2 \%$ das mulheres referiram ingerir álcool em freqüência de duas a três vezes por semana ou mais, enquanto que $46,2 \%$ dos homens adultos relataram beber nesta freqüência. Dentre os que referiram ingerir álcool, houve maior percentual de homens com CAGE positivo $(\geq$ 2), porém sem significância estatística.

Devido às importantes diferenças nas variáveis de estudo segundo sexo, serão apresentados modelos de análises de regressão de Poisson separados para os sexos masculino e feminino. 
Tabela 2. Estilo de vida segundo sexo em população adulta no Estado de São Paulo,

\begin{tabular}{|c|c|c|c|c|}
\hline \multirow[b]{2}{*}{ Variável } & \multicolumn{2}{|c|}{ Masculino } & \multicolumn{2}{|c|}{ Feminino } \\
\hline & $n^{\prime}$ & $\%^{2}$ & $n^{\prime}$ & $\%^{2}$ \\
\hline \multicolumn{5}{|l|}{ Exercicio fisico $^{3}$} \\
\hline Não & 461 & 57,8 & 596 & 74,0 \\
\hline Sim & 363 & 42,2 & 219 & 26,0 \\
\hline \multicolumn{5}{|l|}{ Atividade física (QIAF) } \\
\hline Inativo & 228 & 29,3 & 127 & 14,9 \\
\hline Minimamente ativo & 206 & 27,6 & 206 & 28,0 \\
\hline HEPA $^{4}$ & 392 & 43,1 & 487 & 57,1 \\
\hline \multicolumn{5}{|l|}{ Caminhada ${ }^{5}$} \\
\hline Não & 682 & 83,5 & 670 & 83,2 \\
\hline Sim & 144 & 16,5 & 150 & 16,8 \\
\hline \multicolumn{5}{|l|}{ Tabagismo } \\
\hline Nunca fumou & 403 & 51,4 & 489 & 60,0 \\
\hline Ex-tabagista & 229 & 26,8 & 200 & 25,0 \\
\hline Fuma atualmente & 184 & 21,8 & 129 & 15,0 \\
\hline \multicolumn{5}{|l|}{$\begin{array}{l}\text { Quanto tempo após acordar fuma o } \\
\text { primeiro cigarro }\end{array}$} \\
\hline Primeira meia hora & 156 & 64,3 & 123 & 63,9 \\
\hline Segunda meia hora & 35 & 13,2 & 31 . & 15,1 \\
\hline Após & 43 & 22,5 & 45 & 21,0 \\
\hline \multicolumn{5}{|l|}{ Quantos cigarros fuma/dia } \\
\hline$<10$ & 55 & 23,4 & 63 & 29,4 \\
\hline $10-20$ & 144 & 58,8 & 120 & 59,5 \\
\hline$>20$ & 35 & 17,8 & 19 & 11,0 \\
\hline \multicolumn{5}{|c|}{$\begin{array}{l}\text { Frequêência com que toma bebida } \\
\text { alcoólica }\end{array}$} \\
\hline Até 1 a 2 vezes/mês & 153 & 25.6 & 213 & 57,0 \\
\hline $1 \mathrm{vez} / \mathrm{semana}$ & 153 & 28,2 & 101 & 28,9 \\
\hline 2 a 3 vezes/semana ou mais & 258 & 46,2 & 52 & 14,2 \\
\hline \multicolumn{5}{|l|}{$\mathrm{CAGE}^{\circ}$} \\
\hline$<2$ & 104 & 53,6 & 36 & 64,3 \\
\hline$\geq 2$ & 82 & 46,4 & 21 & 35,7 \\
\hline \multicolumn{5}{|l|}{$1 \mathrm{QD}^{7}$} \\
\hline Inadequada & 171 & 19,8 & 207 & 24,0 \\
\hline Necessita modificação & 569 & 75,5 & 558 & 1,2 \\
\hline Saudável & 30 & 4,7 & 35 & 4,8 \\
\hline \multicolumn{5}{|l|}{ Porções de fruta na dieta } \\
\hline $1^{\circ}$ tercil (mais baixo) & $4 ! 9$ & 57,6 & 360 & 47,5 \\
\hline $2^{\circ}$ tercil & 104 & 12,0 & 164 & 17,0 \\
\hline $3^{\circ}$ tercil (mais elevado) & 248 & 30,4 & 276 & 35,5 \\
\hline \multicolumn{5}{|c|}{$\begin{array}{l}\text { Porçōes de verduras/legumes na } \\
\text { dieta }\end{array}$} \\
\hline $1^{\circ}$ tercil (mais baixo) & 217 & 25,5 & 306 & 36,8 \\
\hline $2^{\circ}$ tercil & 284 & 39,0 & 240 & 31,5 \\
\hline $3^{\circ}$ tercil (mais elevado) & 270 & 35,5 & 254 & 31,7 \\
\hline \multicolumn{5}{|l|}{ Gerdura total na dieta (\%) } \\
\hline $1^{\circ}$ tercil (mais baixo) & 240 & 30,0 & 283 & 33,4 \\
\hline $2^{\circ}$ tercil & 255 & 31,1 & 269 & 33,7 \\
\hline $3^{\circ}$ tercil (mais elevado) & 276 & 38,9 & 248 & 32,9 \\
\hline
\end{tabular}

Números absolutos na amostra não-ponderada

${ }^{2}$ Porcentagens na amostra ponderada.

${ }^{3}$ Prática de esporte ou exercicio fisico pelo menos uma vez/semana.

HEPA-health enhancing physical activity (atividade fisica para promoção da saúde).

${ }^{5}$ Prática de caminhada como exercício fisico pelo menos uma vez/semana.

${ }^{\circ} \mathrm{CAGE}$-questionário para detectar adição etilica (duas ou mais respostas SIM).

$\left.{ }^{7} \mathrm{IQD}\right)$-Índice de qualidade da dieta. 


\subsection{EXERCÍCIO FÍSICO, ATIVIDADE FÍSICA E CAMINHADA}

Para os entrevistados do sexo masculino, a prática regular de esporte ou exercício físico pelo menos uma vez por semana associou-se inversamente à faixa etária e ao IMC, e diretamente à escolaridade. Observamos as maiores freqüências de prática de exercício físico nos indivíduos com escolaridade de nível universitário $(53,2 \%)$. No modelo multivariado, mantiveram-se estatisticamente significativas escolaridade $(\mathrm{p}=0,001)$ e IMC $(\mathrm{p}=0,019)$ (Tabela 3$)$.

Tabela 3. Prática de exercício físico (\%) segundo variáveis demográficas e sócioeconômicas em população adulta do sexo masculino, Estado de São Paulo, 2002

\begin{tabular}{|c|c|c|c|c|c|}
\hline \multirow[b]{2}{*}{ Variável } & \multirow[b]{2}{*}{$\%^{1}$} & \multicolumn{2}{|c|}{ Razão de Prevalências } & \multicolumn{2}{|c|}{ Razão de Prevalências } \\
\hline & & Bruta & IC $95 \%$ & Ajustada $^{2}$ & IC $95 \%$ \\
\hline \multicolumn{6}{|l|}{ Faixa etária } \\
\hline 20-29 anos & 52,2 & 1,00 & & 1,00 & \\
\hline 30-39 anos & 41,0 & 0,92 & $0,85-0,99$ & 0,95 & $0,88-1,03$ \\
\hline 40-49 anos & 35,1 & 0,88 & $0,82-0,95$ & 0,92 & $0,84-1,00$ \\
\hline 50-59 anos & 34,7 & 0,88 & $\mathrm{p}=0,002$ & 0,93 & $\begin{aligned} & 0,84-1,02 \\
= & 0(667\end{aligned}$ \\
\hline \multicolumn{6}{|l|}{ Situação conjugal } \\
\hline Com companheiro & 36,9 & 1,00 & & 1,00 & \\
\hline Sem companheiro & 52,8 & 1,11 & $1,05-1,18$ & 1,03 & $0,96-1,10$ \\
\hline \multicolumn{6}{|l|}{ Cor ou raça } \\
\hline Branca & 44,5 & 1,00 & & 1,00 & \\
\hline Não-branca & 36,7 & 0,94 & $0,89-1,00$ & 0,96 & $0,91-1,02$ \\
\hline \multicolumn{6}{|l|}{ Escolaridade } \\
\hline$<3$ anos & 22,9 & 1,00 & & 1,00 & \\
\hline 4-7 anos & 31,0 & 1,06 & $0,96-1,17$ & 1,04 & $0,92-1,17$ \\
\hline $8-11$ anos & 51,4 & 1,23 & $1,10-1,37$ & 1,17 & $1,04-1,31$ \\
\hline$\geq 12$ anos & 53,2 & 1,24 & $p=\begin{aligned} & 1,10-1,40 \\
& 0,000\end{aligned}$ & 1,19 & $1,05-1,36$ \\
\hline \multicolumn{6}{|l|}{ IMC } \\
\hline Menor que 25 & 48,5 & 1,00 & & 1,00 & \\
\hline Sobrepeso & 40,8 & 0,94 & $0,88-1,01$ & 0,95 & $0,89-1,01$ \\
\hline Obesidade & 29,8 & 0,87 & $\begin{aligned} & 0,79-0,96 \\
& \mathrm{p}= 0,004 \\
&\end{aligned}$ & $\mathbf{0 , 8 9}$ & $\begin{aligned} & \mathbf{0 , 8 0}-\mathbf{0 , 9 8} \\
& \mathrm{p}= \mathbf{0 , 0 1 9} \\
&\end{aligned}$ \\
\hline
\end{tabular}


No sexo feminino, houve associação direta da prática de exercício fisico com a faixa etária, escolaridade e renda. Mulheres negras referiram realizar menos exercício físico quando comparadas às de outras cores/raças, porém esta variável perde significância estatística com o ajuste no modelo múltiplo. Mantêm-se estatisticamente significativas neste modelo as variáveis faixa etária $(\mathrm{p}=0,000)$ e escolaridade $(\mathrm{p}=0,000)$. Foi observada interação entre cor e escolaridade (Tabela 4).

Tabela 4. Prática de exercício físico (\%) segundo variáveis demográficas e sócioeconômicas em população adulta do sexo feminino, Estado de São Paulo, 2002

\begin{tabular}{|c|c|c|c|c|c|}
\hline \multirow[b]{2}{*}{ Variável } & \multirow[b]{2}{*}{$\%^{1}$} & \multicolumn{2}{|c|}{ Razão de Prevalências } & \multicolumn{2}{|c|}{ Razão de Prevalências } \\
\hline & & Bruta & IC $95 \%$ & Ajustada $^{2}$ & IC $95 \%$ \\
\hline \multicolumn{6}{|l|}{ Faixa etária } \\
\hline 20-29 anos & 21,6 & 1,00 & & 1,00 & \\
\hline 30-39 anos & 22,4 & 1,00 & $0,92-1,09$ & 1,01 & $0,93-1,10$ \\
\hline $40-49$ anos & 25,4 & 1,03 & $0,94-1,12$ & 1,06 & $0,96-1,16$ \\
\hline $50-59$ anos & 43,4 & 1,17 & $\begin{aligned} & 1,07-1,29 \\
p= & 0,002\end{aligned}$ & 1,21 & $p_{=} \begin{array}{l}1,10-1,33 \\
0,000\end{array}$ \\
\hline \multicolumn{6}{|l|}{ Cor ou raça } \\
\hline Demais & 27,4 & 1,00 & & 1,00 & \\
\hline Negra & 12,4 & 0,88 & $0,81-0,95$ & 0,94 & $0,87-1,02$ \\
\hline \multicolumn{6}{|l|}{ Escolaridade } \\
\hline$<3$ anos & 15,6 & 1,00 & & 1,00 & \\
\hline 4-7 anos & 16,7 & 1,00 & $0,91-1,11$ & 1,03 & $0,94-1,13$ \\
\hline 8-11 anos & 27,3 & 1,10 & $1,01-1,19$ & 1,15 & $1,07-1,25$ \\
\hline$\geq 12$ anos & 41,7 & 1,22 & $1,11-1,35$ & 1,20 & $1,08-1,34$ \\
\hline \multicolumn{6}{|l|}{$\begin{array}{l}\text { Renda familiar } \\
\text { mensal (salários- } \\
\text { mínimos per capita) }\end{array}$} \\
\hline$<0,5$ & 17,3 & 1,00 & & 1,00 & $\therefore$ \\
\hline $0,5-1,49$ & 18,7 & 1,01 & $0,87-1,16$ & 0,97 & $0,85-1,11$ \\
\hline $1,5-2,9$ & 19,7 & 1,02 & $0,90-1,15$ & 0,94 & $0,83-1,07$ \\
\hline$\geq 3$ & 41,5 & 1,20 & $1,05-1,37$ & 1,06 & $0,92-1,22$ \\
\hline \multicolumn{6}{|l|}{ Cor*Escolaridade } \\
\hline Demais*Escolaridade & - & - & - & 1,00 & \\
\hline Negra*Escolaridade & - & - & - & 1,08 & $1,00-1,16$ \\
\hline
\end{tabular}


Na Tabela 5 estão apresentados os dados quanto à prática de atividade física segundo o QIAF para o sexo masculino. Homens mais jovens, sem companheira e de menor escolaridade apresentaram maior nível geral de atividade fisica segundo o QIAF nas análises bivariadas. No modelo múltiplo para o sexo masculino, faixa etária $(p=0,022)$ e escolaridade $(p=0,005)$ mantiveram-se estatisticamente significativas.

Quanto ao nível geral de atividade física segundo o QIAF para o sexo feminino, observamos que as mulheres com companheiro, que não exercem atividade remunerada de trabalho, e de menor renda e escolaridade foram mais ativas segundo o QIAF nas análises bivariadas. Após os ajustes no modelo múltiplo, a escolaridade se manteve estatisticamente significativa $(\mathrm{p}=0,000)$ e a faixa etária 30-39 anos, com razão de prevalências ajustada de 1,20 (IC 95\% 1,01-1,43), quando comparada à faixa etária 20-29 anos. Foram observadas interações entre renda e escolaridade, e situação conjugal e escolaridade (Tabela 6).

Tabela 5. Prática de atividade física - QIAF (\%) segundo variáveis demográficas e sócio-econômicas em população adulta do sexo masculino, Estado de São Paulo, 2002

\begin{tabular}{|c|c|c|c|c|c|}
\hline \multirow{2}{*}{ Variável } & \multirow[b]{2}{*}{$\% 1$} & \multicolumn{2}{|c|}{ Razão de Prevalências } & \multicolumn{2}{|c|}{ Razão de Prevalências } \\
\hline & & Bruta & IC $95 \%$ & Ajustada $^{2}$ & IC $95 \%$ \\
\hline \multicolumn{6}{|l|}{ Faixa etária } \\
\hline 20-29 anos & 50,5 & 1,00 & & 1,00 & \\
\hline 30-39 anos & 47,1 & 0,93 & $0,73-1,18$ & 0,97 & $0,77-1,23$ \\
\hline 40-49 anos & 34,7 & 0,68 & $0,49-0,95$ & 0,72 & $0,51-1,00$ \\
\hline $50-59$ anos & 35,6 & 0,70 & $\begin{aligned} & 0,50-0,98 \\
& p=0,010\end{aligned}$ & 0,72 & $\mathrm{P}=\mathbf{0 , 0 2 2}$ \\
\hline \multicolumn{6}{|l|}{ Situação conjugal } \\
\hline Com companheiro & 39,2 & 1,00 & & 1,00 & \\
\hline Sem companheiro & 50,1 & 1,27 & $1,05-1,54$ & 1,18 & $0,97-1,45$ \\
\hline \multicolumn{6}{|l|}{ Escolaridade } \\
\hline$<3$ anos & 52,8 & 1,00 & & 1,00 & \\
\hline 4-7 anos & 44,2 & 0,83 & $0,57-1,22$ & 0,77 & $0,52-1,15$ \\
\hline $8-11$ anos & 43,9 & 0,83 & $0,59-1,15$ & 0,72 & $0,51-1,02$ \\
\hline$\geq 12$ anos & 32,0 & 0,60 & $\begin{aligned} & 0,38-0,94 \\
p= & 0,025\end{aligned}$ & 0,55 & $p_{=} \begin{array}{l}\mathbf{0 , 3 5}-\mathbf{0 , 0 0 5}\end{array}$ \\
\hline
\end{tabular}

TCategoria HEPA (atividade fisica para promoção da saúde). Porcentagens na amostra ponderada

${ }^{2}$ Regressão de Poisson ajustada para variáveis apresentadas na tabela. 
Tabela 6. Prática de atividade física-QIAF (\%) segundo variáveis demográficas e sócio-econômicas em população adulta do sexo feminino, Estado de São Paulo, 2002

\begin{tabular}{|c|c|c|c|c|c|}
\hline \multirow[b]{2}{*}{ Variável } & \multirow[b]{2}{*}{$\%{ }^{1}$} & \multicolumn{2}{|c|}{ Razão de Prevalências } & \multicolumn{2}{|c|}{ Razão de Prevalências } \\
\hline & & Bruta & IC $95 \%$ & Ajustada $^{2}$ & IC $95 \%$ \\
\hline \multicolumn{6}{|l|}{ Faixa etária } \\
\hline 20-29 anos & 48,6 & 1,00 & & 1,00 & \\
\hline 30-39 anos & 62,5 & 1,28 & $1,06-1,54$ & 1,20 & $1,01-1,43$ \\
\hline $40-49$ anos & 58,0 & 1,19 & $0,97-1,46$ & 1,19 & $0,96-1,46$ \\
\hline $50-59$ anos & 63,8 & 1,31 & $p=0,043.01-1,70$ & 1,21 & $\begin{aligned} & 0,89-1,66 \\
\mathrm{p}= & 0,309\end{aligned}$ \\
\hline \multicolumn{6}{|l|}{ Situação conjugal } \\
\hline Com companheiro & 61,7 & 1,00 & & 1,00 & \\
\hline Sem companheiro & 50,1 & 0,81 & $0,68-0,96$ & 0,90 & $0,76-1,08$ \\
\hline \multicolumn{6}{|l|}{ Escolaridade } \\
\hline$<3$ anos & 71,7 & 1,00 & & 1,00 & \\
\hline 4-7 anos & 67,1 & 0,93 & $0,81-1,07$ & 0,98 & $0,82-1,16$ \\
\hline $8-11$ anos & 58,6 & 0,81 & $0,65-0,95$ & 0,90 & $0,74-1,10$ \\
\hline$\geq 12$ anos & 32,4 & 0,45 & $0,33-0,61$ & 0,51 & $0,36-0,73$ \\
\hline \multicolumn{6}{|l|}{$\begin{array}{l}\text { Exerce atividade de } \\
\text { trabalho }\end{array}$} \\
\hline Sim & 52,7 & 1,00 & & 1,00 & \\
\hline Não & 64,4 & 1,22 & $1,03-1,43$ & 1,07 & $0,89-1,29$ \\
\hline \multicolumn{6}{|l|}{$\begin{array}{l}\text { Renda familiar } \\
\text { mensal (salários- } \\
\text { mínimos per capita) }\end{array}$} \\
\hline$<0,5$ & 75,3 & 1,00 & & 1,00 & \\
\hline $0,5-1,49$ & 61,3 & 0,81 & $0,64-1,03$ & 0,87 & $0,68-1,12$ \\
\hline $1,5-2,9$ & 59,1 & 0,78 & $0,61-1,00$ & 0,87 & $0,67-1,13$ \\
\hline$\geq 3$ & 46,1 & 0,61 & $\begin{aligned} & 0,46-0,80 \\
= & 0,00 \mathrm{I}\end{aligned}$ & 0,82 & $\begin{array}{l}\quad 0,61-1,10 \\
p=0,156\end{array}$ \\
\hline \multicolumn{6}{|l|}{ Renda*Escolaridade } \\
\hline$<0,5^{*}$ Escolaridade & - & - & - & 1,00 & \\
\hline 0,5-1,49*Escolaridade & - & - & - & 1,09 & $0,86-1,39$ \\
\hline 1,5-2,9*Escolaridade & - & - & - & 1,07 & $0,83-1,38$ \\
\hline$\geq 3 *$ Escolaridade & - & - & - & 0,78 & $0,62-0,98$ \\
\hline \multicolumn{6}{|l|}{ Situação conjugal* } \\
\hline $\begin{array}{l}\text { Escolaridade } \\
\text { Com companheiro* }\end{array}$ & \multicolumn{5}{|c|}{ Escolaridade } \\
\hline Escolaridade & - & - & - & 1,00 & \\
\hline $\begin{array}{l}\text { Sem companheiro* } \\
\text { Escolaridade }\end{array}$ & - & - & - & 0,79 & $0,65-0,95$ \\
\hline
\end{tabular}

TCategoria HEPA (atividade fisica para promoção da saúde). Porcentagens na amostra ponderada.

${ }^{2}$ Regressão de Poisson ajustada para variáveis apresentadas na tabela. 
Em relação à prática de caminhada como esporte ou exercício físico pelo menos uma vez por semana, observamos que os homens brancos e que não exercem atividade remunerada de trabalho apresentaram maior freqüência de caminhada. Houve ainda relação direta no sexo masculino com a faixa etária e com a escolaridade. No modelo múltiplo, permaneceram estatisticamente significativas a faixa etária $(\mathrm{p}=0,003)$, a escolaridade $(\mathrm{p}=0,004)$ e não exercer atividade remunerada de trabalho, com razão de prevalências de 2,38 (IC 95\% 1,42-3,98) após ajuste (Tabela 7)

Tabela 7. Prática de caminhada (\%) segundo variáveis demográficas e sócioeconômicas em população adulta do sexo masculino, Estado de São Paulo, 2002

\begin{tabular}{|c|c|c|c|c|c|}
\hline \multirow[b]{2}{*}{ Variável } & \multirow[b]{2}{*}{$\%{ }^{1}$} & \multicolumn{2}{|c|}{ Razão de Prevalências } & \multicolumn{2}{|c|}{ Razão de Prevalências } \\
\hline & & Bruta & IC $95 \%$ & Ajustada $^{2}$ & IC $95 \%$ \\
\hline \multicolumn{6}{|l|}{ Faixa etária } \\
\hline 20-29 anos & 12,3 & 1,00 & & 1,00 & \\
\hline 30-39 anos & 14,2 & 1,15 & $0,64-2,07$ & 1,36 & $0,73-2,51$ \\
\hline 40-49 anos & 21,7 & 1,76 & $1,07-2,89$ & 1,89 & $1,19-3,00$ \\
\hline $50-59$ anos & 20,3 & \multicolumn{2}{|r|}{$p=0,006$} & 1,70 & $p=0,003$ \\
\hline \multicolumn{6}{|l|}{ Cor ou raça } \\
\hline Branca & 18,7 & 1,00 & & 1,00 & \\
\hline Não-branca & 11,3 & 0,60 & $0,37-0,96$ & 0,75 & $0,46-1,23$ \\
\hline \multicolumn{6}{|l|}{ Escolaridade } \\
\hline$<3$ anos & 13,1 & 1,00 & & 1,00 & \\
\hline 4-7 anos & 10,5 & 0,80 & $0,33-1,93$ & 0,96 & $0,37-2,46$ \\
\hline 8-11 anos & 17,4 & 1,32 & $0,61-2,84$ & 1,73 & $0,72-4,15$ \\
\hline$\geq 12$ anos & 27,4 & \multicolumn{2}{|r|}{$p=0,008$} & \multicolumn{2}{|r|}{$\mathrm{p}=\mathbf{0 , 0 0 4}$} \\
\hline \multicolumn{6}{|c|}{$\begin{array}{l}\text { Exerce atividade de } \\
\text { trabalho }\end{array}$} \\
\hline $\operatorname{Sim}$ & 13,6 & 1,00 & & 1,00 & \\
\hline Não & 28,8 & 2,10 & $1,31-3,39$ & 2,38 & $1,42-3,98$ \\
\hline
\end{tabular}


No sexo feminino, a caminhada apresentou relação direta com faixa etária, escolaridade e renda nas análises bivariadas. Mulheres brancas também referiram maior freqüência de prática de caminhadas. Após ajuste no modelo multivariado, a faixa etária $(\mathrm{p}=0,000)$ e a escolaridade $(\mathrm{p}=0,007)$ permaneceram estatisticamente significativas (Tabela 8).

Tabela 8. Prática de caminhada (\%) segundo variáveis demográficas e sócioeconômicas em população adulta do sexo feminino, Estado de São Paulo, 2002

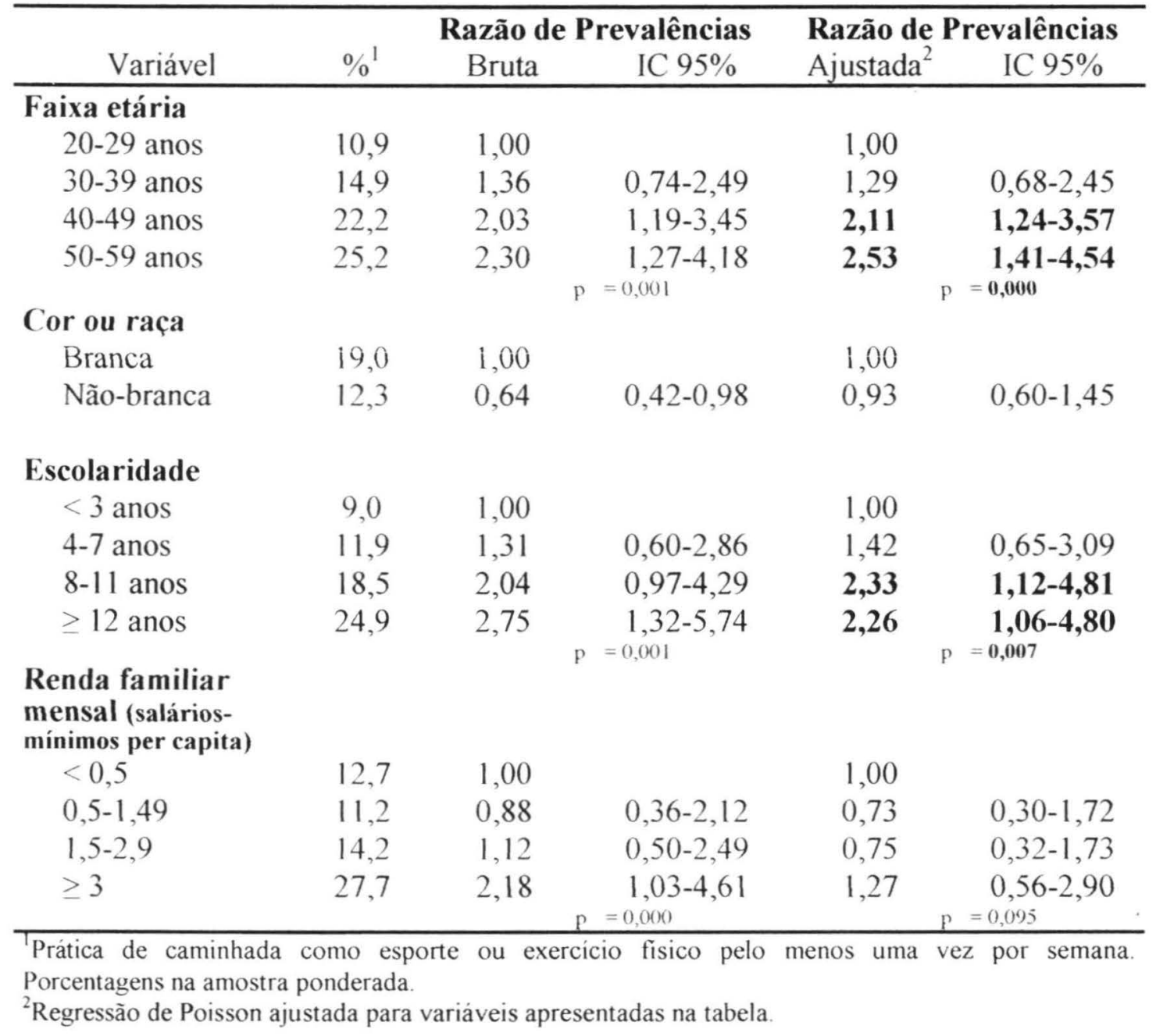




\subsection{TABAGISMO}

A Tabela 9 apresenta os dados para tabagismo no sexo masculino. $\mathrm{O}$ hábito de fumar no momento da entrevista foi mais freqüente nos indivíduos de menor escolaridade, nos que não exercem atividade remunerada de trabalho e nos de religião espírita. Os homens evangélicos tiveram menor prevalência de tabagismo quando comparados aos de outras religiões. Todas estas variáveis se mantiveram estatisticamente significativas no modelo multivariado ajustado por faixa etária

Quanto ao sexo feminino, observamos maior prevalência de tabagismo nas faixas etárias acima dos 30 anos e nas mulheres de menor escolaridade e renda. As entrevistadas que se declararam de religião evangélica apresentaram menor prevalência de tabagismo. No modelo multivariado, permaneceram estatisticamente significativas: faixa etária, renda e religião evangélica. Observou-se interações entre escolaridade e faixa etária, e renda e faixa etária (Tabela 10).

Tabela 9. Tabagismo (\%) segundo variáveis demográficas e sócio-econômicas em população adulta do sexo masculino, Estado de São Paulo, 2002

\begin{tabular}{|c|c|c|c|c|c|}
\hline \multirow[b]{2}{*}{ Variável } & \multirow[b]{2}{*}{$\%^{1}$} & \multicolumn{2}{|c|}{ Razão de Prevalências } & \multicolumn{2}{|c|}{ Razão de Prevalências } \\
\hline & & Bruta & IC $95 \%$ & Ajustada $^{2}$ & IC $95 \%$ \\
\hline \multicolumn{6}{|l|}{ Escolaridade } \\
\hline$<3$ anos & 34,7 & 1,00 & & 1,00 & \\
\hline 4-7 anos & 34,3 & 0,98 & $0,72-1,35$ & 1,01 & $0,75-1,37$ \\
\hline 8-11 anos & 20,5 & 0,59 & $0,40-0,86$ & 0,57 & $0,39-0,82$ \\
\hline$\geq 12$ anos & 22,9 & 0,66 & $\begin{aligned} & 0,42-1,03 \\
= & 0,004\end{aligned}$ & 0,62 & $\begin{aligned} & 0,40-0,95 \\
= & 0,001\end{aligned}$ \\
\hline \multicolumn{6}{|c|}{$\begin{array}{l}\text { Exerce atividade de } \\
\text { trabalho }\end{array}$} \\
\hline Sim & 24,3 & 1,00 & & 1,00 & \\
\hline Não & 37,0 & 1,52 & $1,07-2,15$ & 1,41 & $1,00-1,99$ \\
\hline \multicolumn{6}{|c|}{ Religião-Evangélica } \\
\hline Não & 28,8 & 1,00 & & 1,00 & \\
\hline Sim & 11,7 & 0,40 & $0,19-0,83$ & 0,40 & $0,19-0,83$ \\
\hline \multicolumn{6}{|c|}{ Religião-Espírita } \\
\hline Não & 25,9 & 1,00 & & 1,00 & \\
\hline Sim & 45,4 & 1,75 & $1,01-3,04$ & 1,98 & $1,15-3,40$ \\
\hline
\end{tabular}

TEntrevistados que relataram fumar no momento da entrevista. Porcentagens na amostra ponderada.

${ }^{2}$ Regressão de Poisson ajustada para faixa etária e demais variáveis apresentadas na tabela. 
Tabela 10. Tabagismo (\%) segundo variáveis demográficas e sócio-econômicas em população adulta do sexo feminino, Estado de São Paulo, 2002

\begin{tabular}{|c|c|c|c|c|c|}
\hline \multirow[b]{2}{*}{ Variável } & \multirow[b]{2}{*}{$\%^{1}$} & \multicolumn{2}{|c|}{ Razão de Prevalências } & \multicolumn{2}{|c|}{ Razão de Prevalências } \\
\hline & & Bruta & IC 95\% & Ajustada $^{2}$ & IC $95 \%$ \\
\hline \multicolumn{6}{|l|}{ Faixa etária } \\
\hline 20-29 anos & 15,3 & 1,00 & & 1,00 & \\
\hline 30-39 anos & 28,8 & 1,88 & $1,07-3,28$ & 1,80 & $1,11-2,91$ \\
\hline 40-49 anos & 32,0 & 2,09 & $1,22-3,55$ & 2,10 & $1,33-3,33$ \\
\hline 50-59 anos & 29,1 & 1,90 & $\begin{aligned} & 1,07-3,36 \\
p= & 0,009\end{aligned}$ & 1,97 & $\begin{aligned} & \mathbf{1}, 11-3,48 \\
= & \mathbf{0 , 0 0 9}\end{aligned}$ \\
\hline \multicolumn{6}{|l|}{ Escolaridade } \\
\hline$<3$ anos & 30,4 & 1,00 & & 1,00 & \\
\hline 4-7 anos & 30,7 & 1,00 & $0,62-1,61$ & 1,08 & $0,71-1,64$ \\
\hline $8-11$ anos & 24,1 & 0,79 & $0,49-1,27$ & 1,00 & $0,62-1,59$ \\
\hline$\geq 12$ anos & 16,1 & 0,53 & $0,31-0,90$ & 0,57 & $0,31-1,04$ \\
\hline \multicolumn{6}{|l|}{ Religião } \\
\hline Sem religião & 30,6 & 1,00 & & 1,00 & \\
\hline Católica & 29,2 & 0,95 & $0,53-1,70$ & 0,93 & $0,51-1,69$ \\
\hline Evangélica & 5,5 & 0,18 & $0,06-0,46$ & 0,12 & $0,04-0,34$ \\
\hline Espirita & 22,2 & 0,72 & $0,29-1,79$ & 0,84 & $0,33-2,12$ \\
\hline Outras & 41,8 & 1,36 & $0,69-2,70$ & 1,54 & $0,74-3,19$ \\
\hline \multicolumn{6}{|l|}{$\begin{array}{l}\text { Renda familiar } \\
\text { mensal (salários- } \\
\text { mínimos per capita) }\end{array}$} \\
\hline$<0,5$ & 36,0 & 1,00 & & 1,00 & \\
\hline $0,5-1,49$ & 28,9 & 0,80 & $0,51-1,25$ & 0,87 & $0,57-1,33$ \\
\hline $1,5-2,9$ & 24,4 & 0,67 & $0,38-1,19$ & 0,69 & $0,38-1,23$ \\
\hline$\geq 3$ & 18,9 & 0,52 & $\begin{aligned} & 0,31-0,88\end{aligned}$ & 0,60 & $\begin{aligned} & 0,34-1,05 \\
= & 0,039\end{aligned}$ \\
\hline \multicolumn{6}{|c|}{ Escolaridade* Faixa } \\
\hline \multicolumn{6}{|c|}{ Etária $(\mathrm{FE})$} \\
\hline$<3$ anos*FE & - & - & - & 1,00 & \\
\hline 4-7 anos*FE & - & - & - & 1,10 & $0,68-1,79$ \\
\hline 8-11 anos*FE & - & - & - & 1,76 & $1,17-2,63$ \\
\hline$\geq 12 \operatorname{anos}^{*} \mathrm{FE}$ & - & - & - & 2,59 & $1,52-4,41$ \\
\hline \multicolumn{6}{|c|}{$\begin{array}{l}\text { Renda*Faixa Etária } \\
(\text { FE) }\end{array}$} \\
\hline$<0,5^{*} \mathrm{FE}$ & - & - & - & 1,00 & \\
\hline $0,5-1,49 * \mathrm{FE}$ & - & - & - & 1,18 & $0,77-1,79$ \\
\hline $1,5-2,9 * \mathrm{FE}$ & - & - & - & 1,65 & $1,12-2,44$ \\
\hline$\geq 3 * \mathrm{FE}$ & - & - & - & 1,70 & $1,11-2,59$ \\
\hline
\end{tabular}

Entrevistados que relataram fumar no momento da entrevista. Porcentagens na amostra ponderada.

${ }^{2}$ Regressão de Poisson ajustada para variáveis apresentadas na tabela. 
Em relação à quantidade de cigarros consumidos num dia, fumar mais de 20 cigarros/dia, no sexo masculino, foi mais freqüente na faixa etária 50-59 anos (Tabela 11). No sexo feminino, associou-se diretamente à escolaridade e à religião espírita. Após ajuste no modelo multivariado, apenas a escolaridade permaneceu estatisticamente significativa. Foi observada interação entre escolaridade e religião espírita (Tabela 12).

Tabela 11. Hábito de fumar mais de 20 cigarros/dia (\%) segundo faixa etária em população adulta do sexo masculino, Estado de São Paulo, 2002

\begin{tabular}{cccc}
\hline & \multicolumn{3}{c}{ Razão de Prevalências } \\
Variável & $\mathbf{\%}^{1}$ & Bruta & IC 95\% \\
\hline Faixa etária & & & \\
$20-29$ anos & 10,8 & 1,00 & \\
$30-39$ anos & 11,7 & 1,07 & $0,26-4,33$ \\
$40-49$ anos & 20,2 & 1,86 & $0,62-5,59$ \\
$50-59$ anos & 30,4 & $\mathbf{2 , 8 1}$ & $\mathbf{1 , 0 8 - 7 , 2 5}$ \\
& & $\mathrm{p}=\mathbf{0 , 0 2 3}$ \\
\hline 'Entrevistados que relataram fumar mais de 20 cigarros/dia no \\
momento da entrevista. Porcentagens na amostra ponderada.
\end{tabular}

Tabela 12. Hábito de fumar mais de 20 cigarros/dia (\%) segundo variáveis demográficas e sócio-econômicas em população adulta do sexo feminino, Estado de São Paulo, 2002

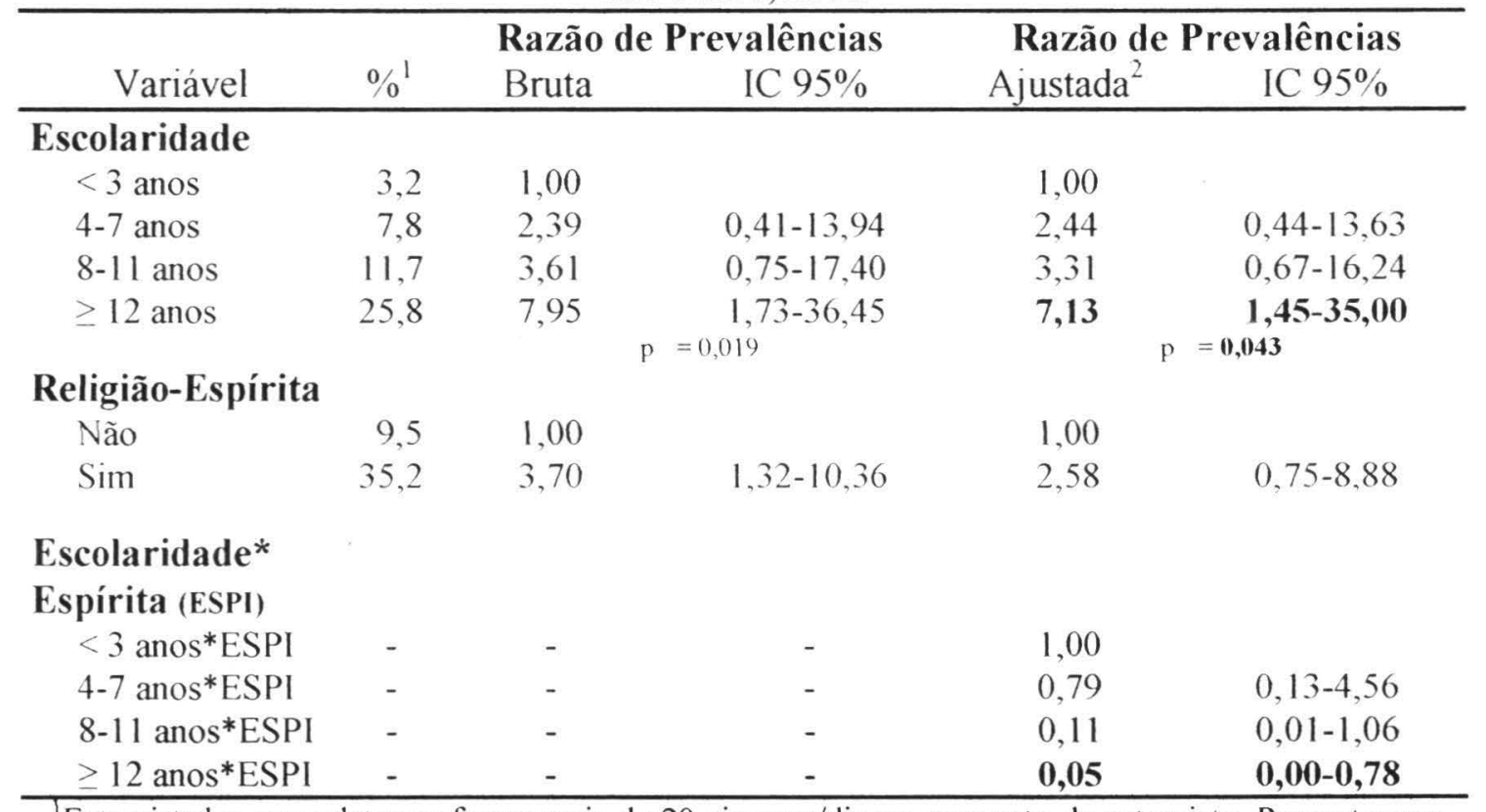

${ }^{1}$ Entrevistados que relataram fumar mais de 20 cigarros/dia no momento da entrevista. Porcentagens na amostra ponderada.

${ }^{2}$ Regressão de Poisson ajustada para faixa etária e demais variáveis apresentadas na tabela. 


\subsection{ETILISMO}

A Tabela 13 apresenta os dados de freqüência de consumo de bebida alcoólica no sexo masculino, onde observamos associação direta com a faixa etária. No sexo feminino, a única variável que se associou a ingerir bebida alcoólica uma vez/semana ou mais foi não ter religião, com razão de prevalências ajustada para faixa etária de 1,55 (1,03-2,32) (Tabela 14).

Tabela 13. Frequêencia de consumo de bebida alcoólica - uma vez por semana ou mais (\%) segundo faixa etária em população adulta do sexo masculino, Estado de São Paulo, 2002

\begin{tabular}{cccc}
\hline Variável & $\%^{1}$ & Razão de Prevalências \\
Bruta & IC 95\% \\
\hline Faixa etária & & & \\
20-29 anos & 66,1 & 1,00 & \\
$30-39$ anos & 74,9 & 1,13 & $0,96-1,32$ \\
$40-49$ anos & 81,5 & $\mathbf{1 , 2 3}$ & $\mathbf{1 , 0 4 - 1 , \mathbf { 4 4 }}$ \\
$50-59$ anos & 78,5 & 1,18 & $\begin{array}{l}0,98-1,43 \\
\text { (,0,023 }\end{array}$ \\
\hline
\end{tabular}

Entrevistados que relataram consumir bebida alcoólica na freqüência de uma vez por semana ou mais. Porcentagens na amostra ponderada

Tabela 14. Freqüência de consumo de bebida alcoólica - uma vez por semana ou mais (\%) segundo religião em população adulta do sexo feminino, Estado de São Paulo, 2002

\begin{tabular}{lccc}
\hline & & \multicolumn{2}{c}{ Razão de Prevalências } \\
Variável & $\%^{1}$ & Ajustada $^{2}$ & IC $95 \%$ \\
\hline Sem religião & & & \\
Não & 19,9 & 1,00 & \\
Sim & 38,7 & $\mathbf{1 , 5 5}$ & $\mathbf{1 , 0 3 - 2 , 3 2}$ \\
\hline
\end{tabular}

Entrevistados que relataram consumir bebida alcoólica na freqüência de uma vez por semana ou mais. Porcentagens na amostra ponderada

${ }^{2}$ Regressão de Poisson ajustada para faixa etária. 
Ao avaliar o questionário CAGE, indicativo de abuso ou dependência de álcool, observamos maior prevalência de CAGE positivo nos homens de menor escolaridade e nos que não exercem atividade remunerada de trabalho (Tabela 15). No sexo feminino não houve associação do CAGE com nenhuma das variáveis estudadas.

Tabela 15. Índice CAGE positivo (\%) segundo variáveis demográficas e sócioeconômicas em população adulta do sexo masculino, Estado de São Paulo, 2002

\begin{tabular}{|c|c|c|c|c|c|}
\hline \multirow[b]{2}{*}{ Variável } & \multirow[b]{2}{*}{$\% 1$} & \multicolumn{2}{|c|}{ Razão de Prevalências } & \multicolumn{2}{|c|}{ Razão de Prevalências } \\
\hline & & Bruta & IC $95 \%$ & Ajustada $^{2}$ & IC $95 \%$ \\
\hline \multicolumn{6}{|l|}{ Escolaridade } \\
\hline$<3$ anos & 61,1 & 1,00 & & 1,00 & \\
\hline 4-7 anos & 57,1 & 0,93 & $0,59-1,47$ & 1,08 & $0,64-1,84$ \\
\hline 8-11 anos & 41,5 & 0,67 & $0,36-1,24$ & 0,74 & $0,39-1,39$ \\
\hline$\geq 12$ anos & 16,6 & 0,27 & $0,09-0,79$ & 0,32 & $0,10-1,01$ \\
\hline \multicolumn{6}{|c|}{$\begin{array}{l}\text { Exerce atividade } \\
\text { de trabalho }\end{array}$} \\
\hline Sim & 40,3 & 1,00 & & 1,00 & \\
\hline Não & 68,4 & 1,69 & $1,21-2,37$ & 1,65 & $1,18-2,29$ \\
\hline
\end{tabular}




\subsection{DIETA}

A Tabela 16 apresenta os dados de avaliação do Índice de Qualidade da Dieta-IQD para o sexo masculino. Observamos maior percentual de indivíduos com dieta saudável ou que necessita modificação nos homens de maior escolaridade e nos que exercem atividade remunerada de trabalho. No sexo feminino houve associação direta do IQD com a escolaridade (Tabela 17).

Tabela 16. Índice de Qualidade da Dieta-IQD ${ }^{1}(\%)$ segundo variáveis sócioeconômicas em população adulta do sexo masculino, Estado de São Paulo, 2002

\begin{tabular}{|c|c|c|c|c|c|}
\hline \multirow[b]{2}{*}{ Variável } & \multirow[b]{2}{*}{$\%^{1}$} & \multicolumn{2}{|c|}{ Razão de Prevalências } & \multicolumn{2}{|c|}{ Razão de Prevalências } \\
\hline & & Bruta & IC $95 \%$ & Ajustada $^{2}$ & IC $95 \%$ \\
\hline \multicolumn{6}{|l|}{ Escolaridade } \\
\hline$<3$ anos & 69,4 & 1,00 & & 1,00 & \\
\hline 4-7 anos & 77,1 & 1,05 & $0,95-1,15$ & 1,05 & $0,96-1,16$ \\
\hline $8-11$ anos & 83,5 & 1,12 & $1,02-1,23$ & 1,14 & $1,03-1,26$ \\
\hline$\geq 12$ anos & 85,8 & 1,14 & $1,01-1,28$ & 1,14 & $1,02-1,28$ \\
\hline \multicolumn{6}{|l|}{$\begin{array}{l}\text { Exerce } \\
\text { atividade de } \\
\text { trabalho }\end{array}$} \\
\hline Sim & 81,7 & 1,00 & & 1,00 & \\
\hline Não & 73,8 & 0,92 & $0,87-0,97$ & 0,93 & $0,88-0,98$ \\
\hline
\end{tabular}

Tabela 17. Índice de Qualidade da Dieta-IQD' (\%) segundo escolaridade em população adulta do sexo feminino, Estado de São Paulo, 2002

\begin{tabular}{cccc}
\hline & \multicolumn{2}{c}{ Razão de Prevalências } \\
Variável & $\%$ & Ajustada $^{2}$ & IC 95\% \\
\hline Escolaridade & & & \\
$<3$ anos & 66,1 & 1,00 & $0,94-1,11$ \\
$4-7$ anos & 73,5 & 1,02 & $0,96-1,14$ \\
$8-11$ anos & 76,6 & 1,05 & $0,99-1,20$ \\
$\geq 12$ anos & 84,1 & 1,09 & $\begin{array}{r}0.047 \\
\hline\end{array}$
\end{tabular}

'Percentual de individuos com dieta saudável ou que necessita modificação. Porcentagens na amostra ponderada.

${ }^{2}$ Regressão de Poisson ajustada para faixa etária. 
Em relação ao consumo de verduras, observamos associação, após ajuste no modelo multivariado, com renda, tanto no sexo masculino (Tabela 18) quanto no sexo feminino (Tabela 19). No sexo masculino, observou-se interação entre renda e escolaridade.

Tabela 18. Consumo de verduras ${ }^{1}(\%)$ segundo variáveis demográficas e sócioeconômicas em população adulta do sexo masculino, Estado de São Paulo, 2002

\begin{tabular}{|c|c|c|c|c|c|}
\hline \multirow[b]{2}{*}{ Variável } & \multirow[b]{2}{*}{$\%^{1}$} & \multicolumn{2}{|c|}{ Razão de Prevalências } & \multicolumn{2}{|c|}{ Razão de Prevalências } \\
\hline & & Bruta & IC $95 \%$ & Ajustada $^{2}$ & IC $95 \%$ \\
\hline \multicolumn{6}{|l|}{ Escolaridade } \\
\hline$<3$ anos & 26,9 & 1,00 & & 1,00 & \\
\hline 4-7 anos & 30,4 & 1,06 & $0,96-1,17$ & 1,04 & $0,93-1,15$ \\
\hline 8-11 anos & 36,3 & 1,11 & $1,01-1,23$ & 1,05 & $0,94-1,19$ \\
\hline$\geq 12$ anos & 49,0 & 1,21 & $1,08-1,35$ & 1,10 & $0,96-1,25$ \\
\hline \multicolumn{6}{|l|}{$\begin{array}{l}\text { Renda familiar } \\
\text { mensal (salários- } \\
\text { mínimos per capita) }\end{array}$} \\
\hline$<0,5$ & 24,5 & 1,00 & & 1,00 & \\
\hline $0,5-1,49$ & 26,7 & 1,00 & $0,87-1,14$ & 0,99 & $0,86-1,15$ \\
\hline $1,5-2,9$ & 33,6 & 1,03 & $0,88-1,19$ & 1,01 & $0,86-1,19$ \\
\hline$\geq 3$ & 48,7 & 1,16 & $1,02-1,33$ & 1,12 & $0,96-1,32$ \\
\hline Renda*Escolaridade & & & & & $\mathrm{p}=\mathbf{0 , 0 1 8}$ \\
\hline$<0,5^{*}$ Escolaridade & - & - & - & 1,00 & \\
\hline 0,5-1,49*Escolaridade & - & - & - & 1,21 & $1,03-1,42$ \\
\hline $1,5-2,9 *$ Escolaridade & - & - & - & 1,27 & $1,08-1,49$ \\
\hline$\geq 3 *$ Escolaridade & - & - & - & 1,21 & $1,03-1,42$ \\
\hline
\end{tabular}

${ }^{\top}$ Consumo de verduras no $3^{\circ}$ tercil (mais elevado). Porcentagens na amostra ponderada.

${ }^{2}$ Regressão de Poisson ajustada para faixa etária e variáveis apresentadas na tabela. 
Tabela 19. Consumo de verduras ${ }^{1}(\%)$ segundo variáveis demográficas e sócioeconômicas em população adulta do sexo feminino, Estado de São Paulo, 2002

\begin{tabular}{|c|c|c|c|c|c|}
\hline \multirow[b]{2}{*}{ Variável } & \multirow[b]{2}{*}{$\%^{1}$} & \multicolumn{2}{|c|}{ Razão de Prevalências } & \multicolumn{2}{|c|}{ Razão de Prevalências } \\
\hline & & Bruta & IC $95 \%$ & Ajustada $^{2}$ & IC $95 \%$ \\
\hline \multicolumn{6}{|l|}{ Faixa etária } \\
\hline 20-29 anos & 25,7 & 1,00 & & 1,00 & \\
\hline 30-39 anos & 37,6 & 1,12 & $1,01-1,25$ & 1,11 & $0,99-1,24$ \\
\hline 40-49 anos & 31,2 & 1,07 & $0,95-1,21$ & 1,05 & $0,93-1,18$ \\
\hline $50-59$ anos & 33,7 & 1,12 & $1,01-1,25$ & 1,07 & $0,95-1,21$ \\
\hline \multicolumn{6}{|c|}{$\begin{array}{l}\text { Renda familiar } \\
\text { mensal (salários- } \\
\text { mínimos per capita) }\end{array}$} \\
\hline$<0,5$ & 20,1 & 1,00 & & 1,00 & \\
\hline $0,5-1,49$ & 28,9 & 1,09 & $0,92-1,30$ & 1,10 & $0,92-1,31$ \\
\hline $1,5-2,9$ & 27,5 & 1,10 & $0,93-1,30$ & 1,11 & $0,94-1,31$ \\
\hline$\geq 3$ & 43,9 & 1,27 & $\begin{aligned} & 1,07-1,51 \\
= & 0,001\end{aligned}$ & 1,27 & $\begin{aligned} & 1,07-1,51 \\
= & 0,002\end{aligned}$ \\
\hline
\end{tabular}

${ }^{T}$ Consumo de verduras no $3^{\circ}$ tercil (mais elevado). Porcentagens na amostra ponderada.

${ }^{2}$ Regressão de Poisson ajustada para variáveis apresentadas na tabela. 
Quanto ao consumo de frutas, houve associação direta, no sexo masculino, com a faixa etária, a escolaridade e a renda. Após ajuste no modelo multivariado, mantiveram-se estatisticamente significativas faixa etária e escolaridade. Foi observada interação entre renda e faixa etária (Tabela 20).

Tabela 20. Consumo de frutas ${ }^{1}(\%)$ segundo variáveis demográficas e sócioeconômicas em população adulta do sexo masculino, Estado de São Paulo, 2002

\begin{tabular}{|c|c|c|c|c|c|}
\hline \multirow[b]{2}{*}{ Variável } & \multirow[b]{2}{*}{$\%^{1}$} & \multicolumn{2}{|c|}{ Razão de Prevalências } & \multicolumn{2}{|c|}{ Razão de Prevalências } \\
\hline & & Bruta & IC $95 \%$ & Ajustada $^{2}$ & IC $95 \%$ \\
\hline \multicolumn{6}{|l|}{ Faixa etária } \\
\hline 20-29 anos & 25,3 & 1,00 & & 1,00 & \\
\hline 30-39 anos & 27,5 & 1,04 & $0,92-1,18$ & 1,06 & $0,93-1,21$ \\
\hline $40-49$ anos & 36,6 & 1,17 & $1,02-1,34$ & 1,20 & $1,06-1,36$ \\
\hline $50-59$ anos & 34,7 & 1,11 & $0,96-1,27$ & 1,15 & $1,00-1,31$ \\
\hline \multicolumn{5}{|l|}{ Escolaridade } & \\
\hline$<3$ anos & 13,2 & 1,00 & & 1,00 & \\
\hline 4-7 anos & 20,7 & 1,11 & $0,97-1,27$ & 1,12 & $0,96-1,30$ \\
\hline 8-11 anos & 34,8 & 1,30 & $1,10-1,52$ & 1,30 & $1,10-1,54$ \\
\hline$\geq 12$ anos & 49,9 & 1,51 & $1,29-1,76$ & 1,47 & $1,24-1,74$ \\
\hline \multicolumn{6}{|c|}{$\begin{array}{l}\text { Renda familiar } \\
\text { mensal (salários- } \\
\text { mínimos per capita) }\end{array}$} \\
\hline$<0,5$ & 18,1 & 1,00 & & 1,00 & \\
\hline $0,5-1,49$ & 19,1 & 1,07 & $0,88-1,30$ & 1,00 & $0,83-1,21$ \\
\hline $1,5-2,9$ & 31,6 & 1,22 & $1,03-1,45$ & 1,07 & $0,90-1,28$ \\
\hline$\geq 3$ & 41,3 & 1,35 & $\begin{aligned} & 1,13-1,60 \\
= & 0000\end{aligned}$ & 1,07 & $\begin{aligned} & 0,88-1,30 \\
= & 0,312\end{aligned}$ \\
\hline \multicolumn{6}{|c|}{$\begin{array}{l}\text { Renda*Faixa Etária } \\
\text { (FE) }\end{array}$} \\
\hline$<0,5^{*} \mathrm{FE}$ & - & - & - & 1,00 & \\
\hline $0,5-1,49 * \mathrm{FE}$ & - & - & - & 1,10 & $0,93-1,30$ \\
\hline $1,5-2,9 * \mathrm{FE}$ & - & - & - & 1,21 & $1,01-1,45$ \\
\hline$\geq 3 * \mathrm{FE}$ & - & - & - & 1,17 & $0,98-1,39$ \\
\hline
\end{tabular}

${ }^{1}$ Consumo de frutas no $3^{\circ}$ tercil (mais elevado). Porcentagens na amostra ponderada.

${ }^{2}$ Regressão de Poisson ajustada para variáveis apresentadas na tabela 
No sexo feminino, o consumo de frutas associou-se diretamente à renda e escolaridade, mesmo após ajuste no modelo multivariado. Observou-se interação entre escolaridade e renda (Tabela 21).

Tabela 21. Consumo de $\operatorname{frutas}^{1}(\%)$ segundo variáveis demográficas e sócioeconômicas em população adulta do sexo feminino, Estado de São Paulo, 2002

\begin{tabular}{|c|c|c|c|c|c|}
\hline \multirow[b]{2}{*}{ Variável } & \multirow[b]{2}{*}{$\%^{1}$} & \multicolumn{2}{|c|}{ Razão de Prevalências } & \multicolumn{2}{|c|}{ Razão de Prevalências } \\
\hline & & Bruta & IC $95 \%$ & Ajustada $^{2}$ & $2 \quad$ IC $95 \%$ \\
\hline \multicolumn{6}{|l|}{ Escolaridade } \\
\hline$<3$ anos & 19,6 & 1,00 & & 1,00 & \\
\hline 4-7 anos & 31,4 & 1,10 & $0,96-1,27$ & 1,08 & $0,93-1,25$ \\
\hline 8-11 anos & 35,7 & 1,17 & $1,03-1,32$ & 1,11 & $0,97-1,28$ \\
\hline$\geq 12$ anos & 50,1 & 1,35 & $1,21-1,52$ & 1,26 & $1,08-1,47$ \\
\hline \multicolumn{6}{|l|}{$\begin{array}{l}\text { Renda familiar } \\
\text { mensal (salários- } \\
\text { minimos per capita) }\end{array}$} \\
\hline$<0,5$ & 21,3 & 1,00 & & 1,00 & \\
\hline $0,5-1,49$ & 28,9 & 1,13 & $0,94-1,36$ & 1,10 & $0,91-1,33$ \\
\hline $1,5-2,9$ & 38,0 & 1,27 & $1,09-1,48$ & 1,20 & $1,02-1,41$ \\
\hline$\geq 3$ & 45,3 & 1,33 & $p=0,000$ & 1,19 & $\begin{array}{l}1,00-1,43 \\
p=0,033\end{array}$ \\
\hline \multicolumn{6}{|l|}{ Escolaridade ${ }^{*}$ Renda } \\
\hline$<3$ anos*Renda & - & - & - & 1,00 & \\
\hline 4-7 anos*Renda & - & - & - & 1,28 & $1,11-1,47$ \\
\hline 8-11 anos*Renda & - & - & - & 1,11 & $0,96-1,28$ \\
\hline$\geq 12$ anos $*$ Renda & - & - & - & 1,16 & $0,97-1,40$ \\
\hline
\end{tabular}

${ }^{1}$ Consumo de frutas no $3^{\circ}$ tercil (mais elevado). Porcentagens na amostra ponderada.

${ }^{2}$ Regressão de Poisson ajustada para faixa etária e variáveis apresentadas na tabela. 


\subsection{ANÁLISE DE AGRUPAMENTOS (CLUSTER)}

\subsubsection{Sexo Masculino}

Com objetivo de identificar grupos de características semelhantes em cada sexo, foi realizada análise de agrupamentos (cluster) em dois passos (TwoStep Cluster Analysis), a qual permite a inserção de variáveis tanto contínuas quanto categóricas

$\mathrm{Na}$ análise de cluster para o sexo masculino foram incluídas as seguintes variáveis categóricas:

- Escolaridade do indivíduo

- Tabagismo

- Exercício físico

- Faixa etária

- Freqüência de ingestão de álcool

As variáveis 'quanto tempo após acordar fuma o primeiro cigarro', 'quantos cigarros fuma/dia' e 'CAGE' foram excluídas por restringirem a análise aos subgrupos de fumantes e/ou etilistas. As variáveis 'caminhada' e 'atividade física (QIAF)' foram excluídas por estarem saturando o modelo.

Foram incluídas as seguintes variáveis contínuas:

- Renda familiar mensal em salários-mínimos per capita

- Consumo de frutas na dieta

- Consumo de verduras na dieta

- Composição de gorduras na dieta

- IQD-Índice de Qualidade da Dieta

Destas variáveis, apenas o IQD obteve aderência à distribuição Normal, com $\mathrm{p}=0,790$ no teste de Kolmogorov-Smirnov. As demais variáveis não obtiveram aderência à distribuição Normal $(\mathrm{p}<0,05)$. Optamos, então, por tentar transformar estas variáveis em seu logaritmo natural, sendo que a renda familiar 
mensal em salários-mínimos per capita apresentou aderência à distribuição Normal após a transformação, com $\mathrm{p}=0,290$. As variáveis consumo de frutas, consumo de verduras e composição de gorduras na dieta apresentaram melhora de sua distribuição quando transformadas em seu logaritmo natural (Anexo 4). Analisandose os QQPLOTs (Anexo 5) optou-se então por trabalhar com estas variáveis transformadas em seu logaritmo natural.

No sexo masculino houve a formação de quatro agrupamentos, conforme apresentado na Figura 1.

No Anexo 6 são apresentados os dados da importância das variáveis categóricas e contínuas para a formação de cada cluster, e as distribuições das variáveis segundo os agrupamentos ( 1 a 4 ).

Figura 1. Agrupamentos obtidos a partir de análise de cluster $\left(\%^{1}\right)$ em população adulta do sexo masculino, Estado de São Paulo, 2002
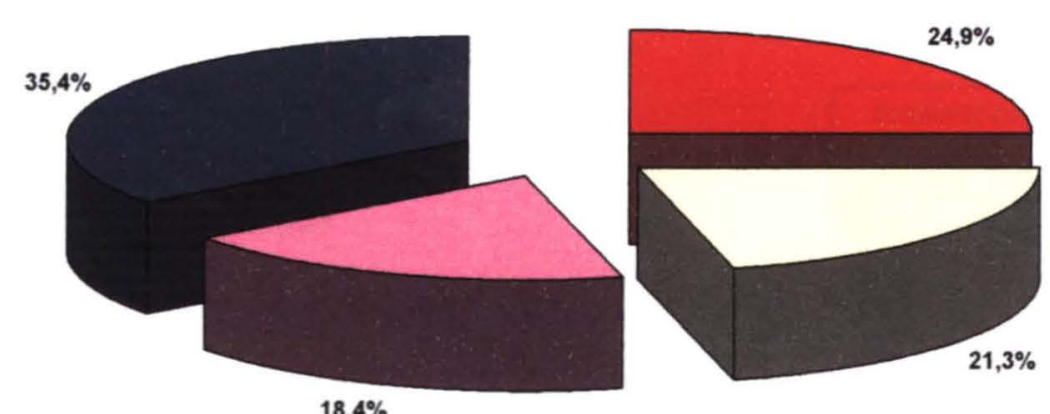

$18,4 \%$

$\begin{array}{llll}\text { aCluster } 1 & \text { 口Cluster } 2 & \text { aCluster } 3 & \text { ECluster } 4\end{array}$

${ }^{1}$ Porcentagens na amostra ponderada 
A Figura 2 apresenta um mapa conceitual da análise de agrupamentos na população adulta do sexo masculino, com as variáveis significativas para a formação de cada cluster, e suas respectivas distribuições. Observa-se que a escolaridade do indivíduo foi a variável determinante para a formação dos agrupamentos, sendo a única variável que apresentou significância estatística em todos eles.

Assim, observa-se que o CLUSTER 1 agrupa homens de baixa renda e escolaridade, na faixa etária 40-59 anos, tabagistas, etilistas e sedentários, com baixa ingestão de frutas e gorduras e também baixo IQD.

O CLUSTER 2 propõe um segundo grupo de indivíduos de baixa renda, escolaridade de 4-7 anos, porém que predominantemente nunca fumaram e têm alta ingestão de gorduras na dieta.

O CLUSTER 3 agrupa os indivíduos de alta renda e escolaridade, e elevada ingestão de frutas e verduras. E o CLUSTER 4 agrupa os indivíduos mais jovens, praticantes de exercício físico e com 8 a 11 anos de escolaridade.

Figura 2. Mapa conceitual da análise de agrupamentos em população adulta do sexo masculino, Estado de São Paulo, 2002

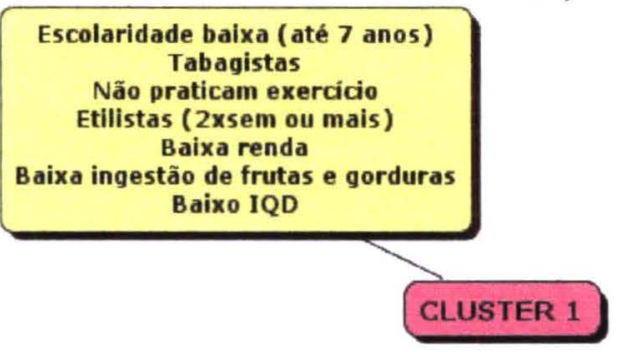

Escolaridade 4-7 anos Nunca fumaram Baixa renda

Elevada ingestão gorduras

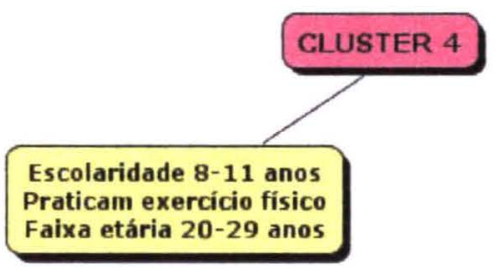

\section{CLUSTER 3}




\subsubsection{Sexo feminino}

$\mathrm{Na}$ análise de cluster para o sexo feminino foram incluídas as seguintes variáveis categóricas:

- Escolaridade do indivíduo

- Tabagismo

- Exercício físico

- Faixa etária

- Freqüência de ingestão de álcool

- Atividade física (QIAF)

Foram incluídas as seguintes variáveis contínuas:

- Renda familiar mensal em salários-mínimos per capita

- Consumo de frutas na dieta

- Consumo de verduras na dieta

- Composição de gorduras na dieta

- IQD-Índice de Qualidade da Dieta

Destas variáveis, apenas o IQD obteve aderência à distribuição Normal, com $\mathrm{p}=0,636$ no teste de Kolmogorov-Smirnov. As demais variáveis não obtiveram aderência à distribuição Normal $(\mathrm{p}<0,05)$. Optamos, então, por tentar transformar estas variáveis em seu logaritmo natural, sendo que a renda familiar mensal em salários-mínimos per capita, assim como no sexo masculino, também apresentou aderência à distribuição Normal após a transformação, com $\mathrm{p}=0,649$. As variáveis consumo de frutas, consumo de verduras e composição de gorduras na dieta apresentaram melhora de sua distribuição quando transformadas em seu logaritmo natural (Anexo 4). Analisando-se os QQPLOTs (Anexo 5), optou-se então por trabalhar com estas variáveis transformadas em seu logaritmo natural.

No sexo feminino houve a formação de dois agrupamentos, conforme apresentado na Figura 3. 
No Anexo 7 são apresentados os dados da importância das variáveis categóricas e contínuas para a formação dos agrupamentos 1 e 2 e as distribuições das variáveis segundo os agrupamentos.

Figura 3. Agrupamentos obtidos a partir de análise de cluster $\left(\%^{1}\right)$ em população adulta do sexo feminino, Estado de São Paulo, 2002

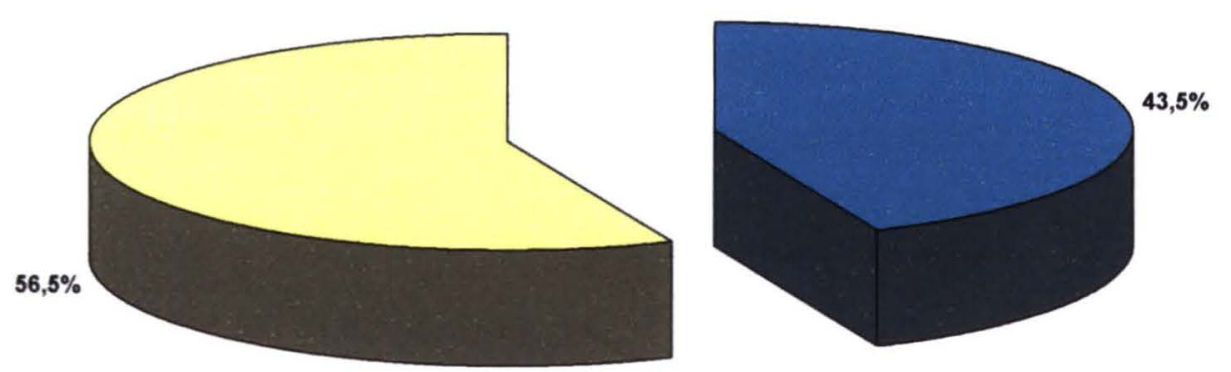

aCluster $1 \quad$ aCluster 2

${ }^{1}$ Porcentagens na amostra ponderada. 
A Figura 4 apresenta um mapa com resumo das variáveis da análise de agrupamentos no sexo feminino e suas distribuições.

Observa-se que o CLUSTER 1 agrupa as mulheres de alta renda, elevada ingestão de frutas, praticantes de exercício físico, que nunca fumaram e que ingerem bebida alcoólica em freqüência de até uma vez/semana.

O CLUSTER 2 propõe um grupo oposto, com mulheres de baixa renda, baixa ingestão de frutas, tabagistas, não praticantes de exercício físico e na categoria mais elevada (HEPA) de atividade física (QIAF).

Assim, no sexo feminino, a variável renda determinou a organização dos agrupamentos, enquanto que no sexo masculino, a escolaridade foi mais importante, apresentando-se significativa nos quatro agrupamentos.

Figura 4. Mapa conceitual da análise de agrupamentos em população adulta do sexo feminino, Estado de São Paulo, 2002

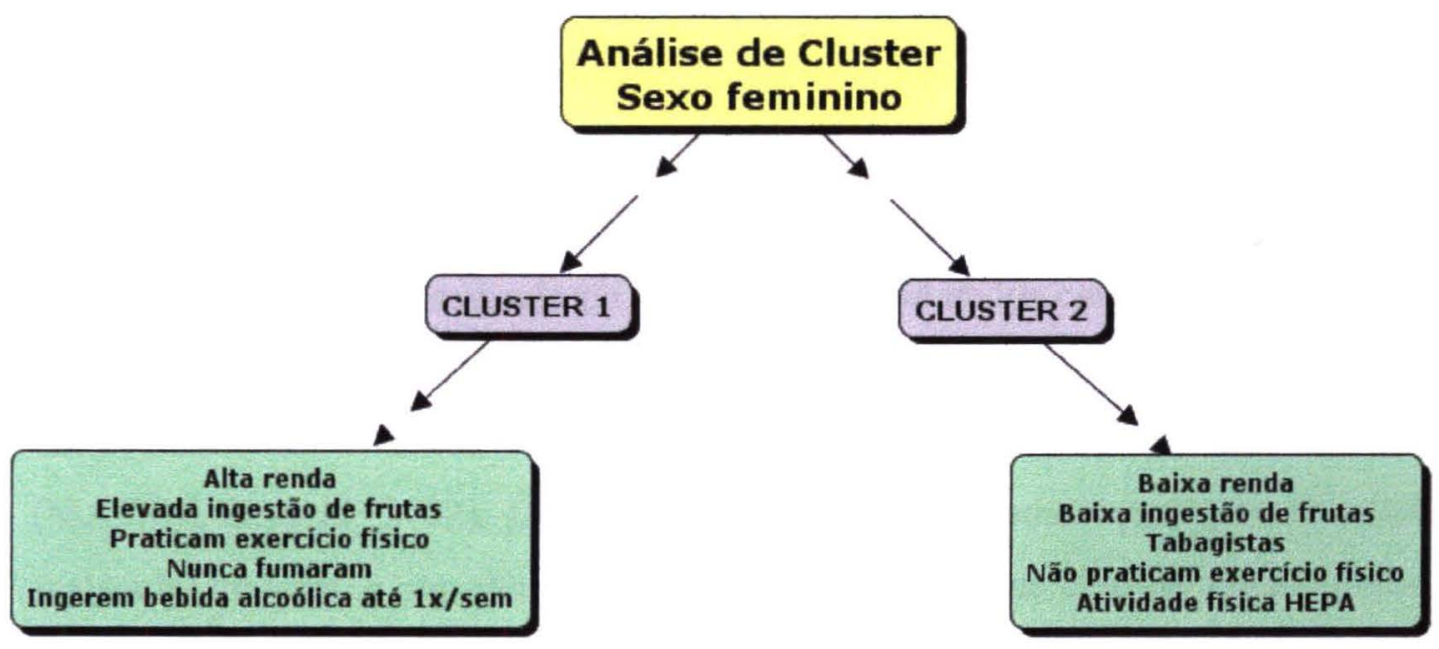




\subsection{ATIVIDADE FÍSICA, EXERCÍCIO FÍSICO E CAMINHADA}

Estilo de vida sedentário já está consistentemente relacionado a aumento de mortalidade, doenças cardíacas, acidente vascular cerebral, obesidade, diabetes, hipertensão, osteoporose e diversos cânceres (VUORI 2001). A prevalência de sedentarismo ainda é muito elevada em todo o mundo, e poucos progressos tem sido alcançados para redução consistente da proporção de adultos sedentários na população. Estudo de tendência temporal em Baltimore, EUA, de 1958 a 1998, observou discreta redução no percentual de homens sedentários e nenhuma mudança na proporção de mulkeres sedentárias ao longo de 40 anos (TALBOT et al. 2003). Deste modo, a mensuração dos níveis de atividade física e fatores associados é relevante para definir estratégias que possam aumentar os níveis de atividade física da população.

Nos dados do ISA-SP, observou-se prevalências muito próximas entre a categoria mais elevada de prática de atividade física $(43,1 \%)$ e o exercício físico $(42,2 \%)$ no sexo masculino. Para as mulheres, observou-se que $26,0 \%$ relataram praticar exercício físico regularmente e quanto ao QIAF, 57,1\% foram classificadas na categoria mais elevada de prática de atividade física.

Em nossos resultados houve elevada freqüência de indivíduos ativos e muito ativos (HEPA) segundo o QIAF. Estudo com dados coletados em $2002 \mathrm{com}$ o QIAF, em todo o estado de São Paulo, classificou 53,5\% dos indivíduos entrevistados como ativos ou muito ativos, sem grande diferença entre os sexos (MATSUDO et al. 2002). Em geral, quando são avaliadas apenas as atividades realizadas no lazer, a prevalência de sedentarismo é bastante elevada. Quando outros contextos de realização de atividade física são incluídos, o sedentarismo tem sua prevalência reduzida. Em estudo realizado na população urbana de Pelotas, observase que apenas $24,6 \%$ dos entrevistados referiram realizar atividade física de lazer. 
Quando se incluiu mais um contexto de realização de atividade física, neste caso o deslocamento, a prevalência de sedentarismo caiu de $75,4 \%$ para $55,8 \%$ (PICCINI \& VICTORA 1994). Outro estudo conduzido no município de Porto Alegre, ao avaliar apenas atividades de lazer, apresentou prevalências de sedentarismo de $69,0 \%$ para os homens e $82,0 \%$ para as mulheres. Ao incluir atividades ocupacionais e para locomoção, o sedentarismo caiu para $38,0 \%$ nos homens e $58,0 \%$ nas mulheres (DUNCAN et al. 1993).

Nossos dados para atividades físicas de lazer são semelhantes aos encontrados em outros estudos nacionais. Inquérito domiciliar conduzido em 1987 no município de São Paulo, para investigação de fatores de risco para doenças crônicas, relatou que $69,3 \%$ da população entre 15 e 59 anos não realizavam esporte ou exercício físico (REGO et al. 1990). Estudo conduzido em 1992, na população urbana de Pelotas, RS, apresentou dados em que atividades de lazer eram realizadas por apenas $24,6 \%$ da população (PICCINI \& VICTORA 1994). Inquérito de 1998, realizado em Catanduva, SP, relatou que $71,4 \%$ da população não realizavam atividade física de lazer (FREITAS et al. 2001). Estudo conduzido no município do Rio de Janeiro, em 1996, evidenciou que 59,8\% dos homens e 77,8\% das mulheres nunca realizavam esporte ou exercício físico (GOMES et al. 2001).

Vários estudos internacionais também apresentam resultados semelhantes para atividades físicas de lazer. Estudo em países da União Européia evidenciou que $57,0 \%$ da população não atingiam os níveis mínimos recomendados em atividades físicas de lazer, com uma grande variação entre os paísés (PAN-EU SURVEY citado por VUORI 2001).

Nos dados do ISA-SP, a prática de exercício físico se associou diretamente à escolaridade em ambos os sexos. No sexo masculino, associou-se inversamente ao IMC, e no sexo feminino diretamente à faixa etária, com razão de prevalências de 1,21 (IC 95\% 1,10-1,33) para a faixa etária 50-59 anos. Os dados revelaram menor prática de exercício físico nas mulheres de cor ou raça negra na análise bivariada. Entretanto, após ajuste no modelo múltiplo, a variável perde 
significância estatística. Foi observada, ainda, interação entre a cor ou raça negra e a escolaridade. Assim, nas mulheres negras, o aumento da escolaridade elevava a probabilidade de realizar exercício físico.

A associação inversa entre exercício físico e IMC no sexo masculino é de dificil interpretação por se tratar de um estudo transversal. Em nosso estudo, o IMC foi calculado a partir de dados referidos. Embora apresente menor precisão, a avaliação do IMC a partir de peso e altura referidos já foi validada (SILVEIRA et al. 2005). Estudo dinamarquês observou, em análises transversais, relações inversas entre exercício físico e obesidade. Entretanto, no acompanhamento longitudinal, não houve influência do exercício físico de lazer no desenvolvimento ou manutenção da obesidade em homens obesos e não-obesos (BAK et al. 2004). Este estudo concluiu que maior peso aumentava a probabilidade de sedentarismo a longo prazo.

Quanto à prática de atividade física segundo o QIAF, englobando todos os domínios de atividade física, observou-se que os homens de escolaridade universitária realizavam menos atividade física. Nas mulheres foi observada a mesma relação inversa com a escolaridade e maior prática de atividade física geral na faixa etária 30-39 anos. No sexo feminino ainda foram observadas duas importantes interações: entre renda e escolaridade, e entre situação conjugal e escolaridade. Deste modo, dentre as mulheres com renda familiar mensal per capita $\geq 3$ saláriosmínimos, o aumento da escolaridade diminuiu a probabilidade de realizar atividade física segundo o QIAF. Nas mulheres sem companheiro, o mesmo efeito da escolaridade foi observado.

Em geral, a prática de exercício físico é mais freqüente nos homens e tende a diminuir com a idade (REGO et al. 1990; CDC 2000; GOMES et al. 2001; LIVINGSTONE et al. 2001; DIAS-DA-COSTA et al. 2005). Diversos autores já associaram prática de esporte ou exercício físico a maior nível sócio-econômico (KUH \& COOPER 1992; CDC 2003a; SECLÉN-PALACÍN \& JACOBY 2003; MASSON et al. 2005). Em nossos dados, os homens realizam muito mais exercício físico que as mulheres nas faixas etárias mais jovens, em proporção maior que o 
dobro na faixa etária 20-29 anos. Entretanto, os homens tenderam a diminuir a prática de exercício físico com a elevação da idade. As mulheres, ao contrário, apresentaram tendência a aumentar esta prática com o decorrer da idade. Assim, na faixa etária 50-59 anos, a prevalência de homens que realizam exercício físico é de $34,7 \%$, e a das mulheres é de $43,4 \%$. Alguns estudos tentam explicar a menor freqüência de exercício físico nas mulheres mais jovens. Fatores que representam experiências-chave na vida das mulheres, como casar, ter filhos e iniciar atividade de trabalho relacionam-se à inatividade fisica (BROWN \& TROST 2003). Em contrapartida, o maior uso de serviço de saúde pela população feminina, associado a recomendações de profissionais da saúde e melhor auto-cuidado podem explicar pelo menos parte do incremento da prática de exercício físico nas mulheres de maior faixa etária.

Observamos importantes diferenças nos perfis das pessoas que realizam atividade física e exercício físico. Praticar esporte ou exercício no lazer foi mais freqüente na população de maior escolaridade, enquanto que realizar atividade física, o que engloba também atividades domésticas, de transporte e ocupacionais, foi mais freqüente nos indivíduos de menor nível sócio-econômico.

Devido à aceitabilidade da caminhada em todos os subgrupos sóciodemográficos, e por ser a atividade física mais reportada pelos indivíduos ativos (SIMPSON et al. 2003), realizamos análises de regressão de Poisson para a prática de caminhada, em particular. Observamos, então, que a caminhada como esporte ou exercício físico é uma prática concentrada nas faixas etárias mais elevadas, a partir dos 40 anos, e mais freqüente nos indivíduos de maior escolaridade, para ambos os sexos. Verificou-se ainda que os homens que não estavam exercendo atividade remunerada de trabalho caminharam mais, com razão de prevalência de 2,38 (IC $95 \%$ 1,42-3,98). Em todas as faixas etárias, à exceção da faixa 20-29 anos, as mulheres realizaram mais caminhada que os homens. Outros estudos já relataram a preferência das mulheres pela caminhada (KUH \& COOPER 1992). 
Questionários de atividade física, como o QIAF utilizado neste estudo, são usualmente escolhidos para estudos de base populacional, pois são práticos e de fácil aplicabilidade. A mensuração da atividade física é uma tarefa complexa e dispõe de instrumentos pouco precisos. Assim, a mensuração da atividade física global, incluindo atividades realizadas no trabalho, transporte e serviços domésticos, para ser obtida com alguma precisão, necessita de questionários longos e detalhados, o que é pouco viável para grandes levantamentos em populações.

Ao avaliarmos o conceito de nível de atividade física pelo QIAF, há a inclusão de atividades físicas praticadas no lazer, mas também aquelas realizadas no trabalho, no transporte e no ambiente doméstico. A ampliação dos contextos em que as atividades físicas são realizadas naturalmente reduz a prevalência de sedentarismo. Recentemente, alguns estudos vêm investigando os efeitos psicológicos da prática de atividade física doméstica ou no trabalho, comparados aos do exercício físico (SPENCE \& LEE 2003). Entretanto, ainda não há evidências conclusivas quanto ao papel do ambiente ou contexto em que é realizada a atividade física, e quanto este representa no montante total de seus beneficios.

O QIAF, apesar de ser um instrumento internacional - o que permitirá comparações - é um questionário novo, ainda sendo experimentado em diversas populações. Alguns estudos têm apontado superestimações do nível de atividade física com o uso do QIAF, principalmente com a utilização da forma curta (RZEWNICK et al. 2003; RÜTTEN et al. 2003; HALLAL et al. 2004). Entretanto, outros autores ainda consideram o QIAF curto aceitável para monitoramentos populacionais (CRAIG et al. 2003; BASSETT 2003). Nesta amostra do ISA-SP, possivelmente há também superestimação do nível de atividade física, principalmente na avaliação do componente doméstico (GUIMARÃES 2003).

Finalmente, ressaltamos que a maior parte dos estudos que associou atividade física e prevenção de doenças trabalhou com dados de atividades de lazer, predominantemente exercício físico dinâmico, contínuo, em intensidade pelo menos 
moderada. Como as novas recomendações de atividade física acumulada são recentes (PATE et al.1995), os primeiros resultados sobre os efeitos da atividade física intermitente, realizada nas atividades habituais, estão sendo conhecidos agora (McKECHNIE et al. 2001). Alguns estudos têm associado a redução na incidência de hipertensão, por exemplo, apenas para as atividades realizadas no lazer (PEREIRA et al. 1999). Outros estudos têm evidenciado maior redução de risco de mortalidade para as atividades de lazer, comparadas às ocupacionais (LISSNER et al. 1996; ANDERSEN et al. 2000). Estudo conduzido em Londres em mulheres idosas não observou benefícios sobre a obesidade em relação à prática de atividades domésticas (LAWLOR et al. 2002). Ou seja, não sabemos ainda qual o impacto que as atividades habituais, acumuladas, apresentam sobre a qualidade de vida em saúde, fatores de risco, morbidade e mortalidade dos indivíduos. Em nossos dados, os homens de idade mais avançada e as mulheres mais jovens são grupos mais vulneráveis e que merecem atenção dos programas voltados ao estímulo da prática de atividades físicas.

\subsection{TABAGISMO}

O uso de tabaco é a principal causa prevenível de morte em diversos países, e a segunda maior causa de morte em todo o mundo (CDC 2003b; GALEA et al. 2004). Apesar da importante queda no consumo de cigarros observada no Brasil nos anos 80 e 90, as prevalências do tabagismo continuam elevadas, mesmo com todas as evidências já consolidadas a respeito de seus prejuízos sobre a saúde (MINISTÉRIO DA SAÚDE 1996; WHO 2005d).

Na população adulta do ISA-SP, de 20 a 59 anos de idade, observouse prevalência de tabagismo atual de $21,8 \%$ para o sexo masculino e $15,0 \%$ para o sexo feminino. Dentre os tabagistas, $17,8 \%$ dos homens e $11,0 \%$ das mulheres relataram fumar mais de 20 cigarros/dia. Não houve diferença entre os sexos quanto ao percentual dos tabagistas que consomem o primeiro cigarro na primeira meia hora após acordar (cerca de 64,0\%), um importante indicador de dependência. 
A prevalência encontrada no ISA-SP é muito semelhante à observada em outros inquéritos realizados na população brasileira. Levantamento nacional envolvendo as 107 maiores cidades do Brasil em 2001, revelou uso de tabaco na vida de $41,1 \%$; uso no ano de $20,1 \%$; e uso no mês de $19,8 \%$. Ao compararmos o uso na vida segundo sexo, este estudo observou prevalência de $46,2 \%$ para o sexo masculino e $36,3 \%$ para o sexo feminino (CARLINI et al. 2002).

Nos Estados Unidos da América, em 2001, 25,7\% dos homens e $21,0 \%$ das mulheres eram tabagistas (CDC 2003b). Neste país, o tabagismo caiu de 37,4\% em 1970 para 25,5\% em 1990 (ARNETT et al. 1998; TOMAR 2003; MENDEZ \& WARNER 2004). Desde então, o tabagismo continua caindo, mas num ritmo mais lento. Para a maior parte dos países, o tabagismo apresenta prevalência maior no sexo masculino (WHO 2005d). No Canadá, a prevalência de tabagismo em adultos jovens é de 28,0\% (HAMMOND 2005). Na China, maior mercado produtor e consumidor de tabaco no mundo, o tabagismo ainda está em ascensão, com prevalência de 34,1\% na população em geral, ou seja, um aumento de 3,4\% em relação ao ano de 1984 (YANG et al. 1999).

Os dados do ISA-SP revelam, para o sexo masculino, maior prevalência de tabagismo atual nos indivíduos de menor escolaridade e que não estão exercendo atividade remunerada de trabalho. Observou-se, ainda, maior prevalência de tabagismo atual entre os homens que se declararam de religião espírita. Para o sexo feminino, observou-se associação inversa com a renda e direta com a faixa etária. As interações demonstram a relevância da faixa etária sobre o tabagismo atual no sexo feminino. Nas mulheres de escolaridade 8-11 anos e $\geq 12$ anos, $\mathrm{o}$ aumento na faixa etária aumentou a probabilidade de ser tabagista. O mesmo ocorreu com as mulheres nas duas categorias mais elevadas de renda familiar mensal per capita.

Maior prevalência de tabagismo e mais elevado consumo de cigarros já foram associados a baixa renda, menor escolaridade e ocupações de nível mais elementar em ambos os sexos, em diferentes lugares e contextos (HORTA et al. 1997; CHAIEB \& CASTELLARIN 1998; HELMERT et al. 2001; JEFFERIS et al. 
2003; BARBEAU et al. 2004; GALEA et al. 2004; DELL et al. 2005). Em mulheres climatéricas de baixa renda em Cuiabá, OLIVEIRA et al (2001) observaram prevalência de tabagismo de $54,0 \%$, muito mais elevada que a média nacional. Em relação à faixa etária, em 24 municípios do Estado de São Paulo, GALDURÓZ et al (2003) observaram associação direta do uso na vida de tabaco com a faixa etária, em ambos os sexos. Nas mulheres, a prevalência de uso na vida foi de $30,8 \%$ na faixa etária 18-24 anos e 39,7\% na faixa etária $\geq 35$ anos. Esta mesma tendência foi observada nas 107 maiores cidades do Brasil (CARLINI et al. 2002).

Para o sexo masculino, não se observou, no ISA-SP, diferença no hábito de fumar nas diferentes faixas etárias. Entretanto, dentre os tabagistas, aqueles na faixa etária 50-59 anos apresentaram razão de prevalências de 2,81 - comparados à faixa etária 20-29 anos - para o hábito de fumar mais de 20 cigarros/dia. Alguns estudos associam o tabagismo ao desemprego (MONTGOMERY et al. 1998). Nos dados do ISA-SP, não estar exercendo atividade remunerada de trabalho se associou a maior prevalência de tabagismo entre os homens.

Observou-se menor prevalência de tabagismo atual nos indivíduos que se declararam evangélicos, em ambos os sexos. Apenas 5,5\% das mulheres evangélicas relataram hábito de fumar atual. Os hábitos religiosos têm sido associados a menor uso de álcool, tabaco e drogas ilícitas em geral (KOENIG et al. 1998; PARK et al. 1998; POULSON et al. 1998; PIKO \& FITZPATRICK 2004), inclusive com trabalhos específicos na população adulta (WHOOLEY et al. 2002). As práticas religiosas são associadas não apenas a menor consumo de drogas ilícitas, mas também menor quantidade de marcadores inflamatórios na população em geral (KING et al. 2001), em diabéticos (KING et al. 2002), menor pressão arterial (HIXSON et al. 1998) e menor mortalidade (STRAWBRIDGE et al. 1997, 2000, 2001).

Em nossos dados, entretanto, o fato mais importante não é apenas o efeito da religiosidade sobre a prevalência de tabagismo, mas a relação entre ser evangélico e fumar menos. No sexo masculino, ser de religião espírita até se associou 
a aumento na prevalência de tabagismo atual, mesmo após ajuste para escolaridade e faixa etária.

A partir de estudo realizado na Região Metropolitana do Rio de Janeiro (FERNANDES et al. 1998), foi possível determinar diversos aspectos qualitativos sobre a configuração social dos evangélicos no Brasil. Observa-se, assim, que $70,0 \%$ dos evangélicos são "convertidos", ou seja, provenientes de outras instituições religiosas. Sobre estas mudanças, ALMEIDA (1999), comenta:

"Acrescente-se, contudo, que nesse trânsito
interdenominacional há fluxos preferenciais
direcionados para o protestantismo carismático e
$o$ pentecostalismo, em particular o
neopentecostalismo, o que resulta em uma
religiosidade mais mística e menos ascética."

O trânsito preferencial para o renovado protestantismo e o neopentecostalismo é essencial pelas conexões que promove. Os evangélicos apresentam eficiente inserção nos sistemas de reciprocidade, discutindo e vivenciando questões como solidariedade, compromisso mútuo, sociabilidade, confiança e redes de apoio social (FERNANDES et al. 1998). As fortes redes de solidariedade provavelmente estão entre os fatores que explicam o menor consumo de tabaco e álcool entre os evangélicos. STRAWBRIDGE et al (2001) observaram que a freqüência religiosa semanal se associou à manutenção da saúde mental, melhores relações sociais, estabilidade no casamento e melhores hábitos relacionados à saúde, principalmente em mulheres. Os mesmos autores (2000) observaram que, para as mulheres, a religiosidade tem efeito protetor comparável ao de outros grandes aspectos relacionados ao estilo de vida, como atividade física e dieta. Segundo FERNANDES et al (1998), os evangélicos compõem-se, em sua maioria, de mulheres, sendo a relação de $30,0 \%$ de homens e $70,0 \%$ de mulheres.

Observa-se ainda que a pregação evangélica apresenta um discurso muito mais eficaz para normatizar o comportamento dos fiéis quando comparada a outras religiões, como a católica e as afro-brasileiras. Assim, exige-se de um fiel 
"convertido" diversas mudanças de conduta quanto ao adultério, vícios de jogos, álcool e tabaco, dentre outros, bem como a freqüência aos cultos religiosos, o que não se observa em outras instituições religiosas menos normativas (FERNANDES et al. 1998; ALMEIDA 1999). GILLUM (2005), a partir de dados do III National Health and Nutrition Examination Survey detectou que a maior freqüência a cultos religiosos se associou a menor prevalência de tabagismo.

Outros estudos apontam a religiosidade como um dos mais importantes fatores sócio-ambientais para controle do uso, abuso e dependência de drogas lícitas e ilícitas, também pelo incremento da capacidade, que a religião proporciona, de lidar com o estresse (KENDLER et al. 1997; GALEA et al. 2004).

A relação entre ser evangélico e fumar menos, mais intensa no sexo feminino, requer outros estudos que possam elucidar seus mecanismos e interações. Além disto, existem poucos trabalhos nacionais sobre o efeito da religiosidade sobre a prevalência de tabagismo. A escassez de literatura nacional na área torna também muito limitada a discussão sobre possíveis fatores relacionados à maior prevalência de tabagismo entre os homens espíritas, uma vez que o espiritismo é uma expressão religiosa tipicamente brasileira, sem equivalentes estrangeiros. Utilizaremos, a seguir, principalmente os resultados das pesquisas realizadas pela $\mathrm{Dr}^{\mathrm{a}}$ Sandra Jacqueline Stoll, antropóloga, para discutir os resultados em relação ao espiritismo.

Em nossos dados, a categoria espiritismo não inclui, a princípio, as práticas afro-brasileiras clássicas, como umbanda e candomblé, mas apenas aqueles indivíduos que se denominaram espíritas. Há, entretanto, duas questões essenciais quanto a esta categorização: o fenômeno da "dupla pertença" e o sincretismo envolvendo as religiões que lidam com "espíritos". É fenômeno corrente no campo religioso brasileiro participar de várias práticas. Sobre a representação da vida pósmorte, em 1998 um levantamento detectou que 45,9\% dos católicos acreditavam em reencarnação. Assim, declarar-se católico é uma prática ainda vigente entre os espíritas, assim como se dizer espirita é uma prática dos adeptos de religiões afrobrasileiras, especialmente entre os segmentos sociais de baixa renda (STOLL 2002). 
Porém, a relação entre o espiritismo e as religiões afro-brasileiras vai além de classificações equivocadas. Embora tenham origens sabidamente diversas, há autores que pensam o espiritismo e as religiões de tradição afro em termos de uma continuidade - ou seja, variação empírica de um mesmo princípio de estruturação e produção da experiência religiosa (CAMARGO 1973; BIRMAN 1995). O espiritismo, ao se inserir na sociedade brasileira, adquiriu características peculiares, com ênfase no aspecto terapêutico, profundamente permeado por noções mágicas (GIUMBELLI 1997). Desta forma, o sincretismo envolvendo espíritas kardecistas e religiosos afro-brasileiros ocorre em diversos níveis dificultando, em muitas situações, a sua separação.

Recentemente o espiritismo vem alargando a sua inserção social, especialmente entre indivíduos da classe média, por meio do investimento no campo literário. Estudos de vendas apontam que hoje, um em cada dez clientes entra em livrarias para comprar livros que trazem conteúdos ditados por espíritos, e pessoas de todas as crenças consomem estas obras (AZEVEDO apud STOLL 2004). Além do grande número de "simpatizantes", o rótulo espiritismo engloba também uma parcela de indivíduos com características híbridas neo-esotéricas, grande parte deles portadores de uma disposição religiosa frente ao mundo, porém sem freqüência assídua aos serviços religiosos, nem envolvimentos pessoais com a comunidade moral (ALMEIDA 2004; STOLL 2004).

Denominar-se espírita, portanto, representa um conceito plural envolvendo grandes polissemias em termos religiosos no Brasil. Assim como no catolicismo, um percentual de "não-praticantes" associado, no caso do espiritismo, a um grande número de "simpatizantes", pode ter englobado na categoria espírita, razoável percentual de indivíduos que não freqüentam cultos ou trabalhos religiosos e, desta forma, não se beneficiam dos efeitos protetores das práticas de religião.

Quanto ao hábito de fumar mais de 20 cigarros/dia, no sexo feminino, observou-se que dentre as fumantes, aquelas de escolaridade universitária fumam maior quantidade de cigarros. Aqui, foi observada interação entre a escolaridade e a 
religião espírita sendo que, nas mulheres de escolaridade universitária, ser espírita diminui a probabilidade de fumar mais de 20 cigarros/dia.

Os dados do ISA-SP foram coletados a partir de informações referidas sobre o hábito de fumar. A validação da informação referida para tabagismo, tendo como padrão ouro o nível sérico de cotinina, encontra prevalências muito próximas estimadas pelos dois métodos (CARABALLO et al. 2004). No sexo masculino, a importante associação inversa do tabagismo com religião evangélica, escolaridade e atividade de trabalho, e no sexo feminino a associação direta com faixa etária e inversa com renda e religião evangélica, permitem a identificação dos grupos mais suscetíveis e assim, proporcionam auxílio para melhor alocação de recursos em programas anti-tabaco culturamente significativos para a população.

\subsection{ETILISMO}

O levantamento de dados para a análise de variáveis relacionadas ao consumo de álcool, freqüência, abuso e dependência, tem sido objeto de muitos estudos, com intuito de determinar seu impacto social e morbimortalidade geral. Existem duas estratégias freqüentemente utilizadas para determinar o consumo de álcool em uma população: as estimativas per capita e os dados derivados de inquéritos populacionais. Informações de base populacional apresentam o diferencial de permitir análises sócio-demográficas entre grupos específicos numa dada população (CASSWELL et al. 2002).

Dados sobre etilismo apresentam grande variação quanto às medidas de consumo, forma de coleta e instrumentos utilizados. Existem importantes variações quanto à quantidade de álcool contida em cada unidade de bebida alcoólica (KERR et al. 2005), o que diminui a precisão da avaliação da quantidade de álcool consumido. Outras limitações incluem a inexistência de um marcador biológico fidedigno e a multiplicidade de questionários utilizados. A avaliação do consumo de 
álcool a partir de informações auto-referidas já está validada como ótima estratégia para uso em estudos populacionais (DEL BOCA \& DARKES 2003).

Neste estudo, utilizamos dados auto-referidos sobre a freqüência de consumo de álcool. No sexo masculino, $46,2 \%$ dos entrevistados relataram consumir bebida alcoólica duas a três vezes por semana ou mais. Para o sexo feminino, esta freqüência foi de 14,2\%. Estes dados são consistentes com a literatura (ALMEIDA \& COUTINHO 1993; OLIVEIRA et al. 2001; GALDUROZ et al. 2003; COSTA et al. 2004) quanto à maior freqüência de consumo de bebida alcoólica nos homens. Em inquérito nacional envolvendo as 107 maiores cidades do Brasil, CARLINI et al (2002), relataram uso na vida de álcool de $77,3 \%$ para os homens e $60,6 \%$ para as mulheres.

Para o sexo masculino, consumir bebida alcoólica em freqüência de uma vez por semana ou mais se associou à faixa etária, sendo a razão de prevalências de 1,23 $(1,04-1,44)$ para a faixa etária 40-49 anos. Diversos estudos demonstram a associação direta entre idade e consumo de álcool na população adulta, porém não de forma unívoca. ALMEIDA \& COUTINHO (1993) observaram maior proporção de consumidores de álcool entre homens de 30 a 49 anos de idade, em moradores da Ilha do Governador, na cidade do Rio de Janeiro. Dados de 1999 coletados em 24 cidades do Estado de São Paulo apontam frequência de $70,5 \%$ de homens consumidores de álcool na faixa etária de 35 anos ou mais (GALDUROZ et al. 2003). Em revisão de estudos publicados no Brasil entre 1943 e 1985, também se observou concentração de consumo de álcool nos adultos jovens entre 20 e 49 anos de idade (CARDIM et al. 1986).

No sexo feminino, consımir bebida alcoólica uma vez por semana ou mais se associou a não professar nenhuma religião. Assim como para o tabagismo, a religiosidade tem sido inversamente associada a abuso/dependência etílica em diversas populações (PARK et al. 1998; POULSON et al. 1998; ASSANANGKORNCHAI et al. 2002; GALEA et al. 2004), incluindo ainda efeitos protetores com melhores resultados no tratamento (SIMÃO et al. 2002). O efeito das 
práticas religiosas sobre o consumo de álcool e cigarros já foi analisado na discussão sobre tabagismo.

Na população adulta do ISA-SP não houve associação da freqüência de consumo de álcool com escolaridade, renda, cor, atividade de trabalho ou situação conjugal. Alguns estudos evidenciam que o consumo de bebida alcoólica se distribui em todas as classes sociais (ALMEIDA \& COUTINHO 1993; COSTA et al. 2004), entretanto, a maioria aponta para maior freqüência de consumo em populações de menor renda e escolaridade (CHAIEB \& CASTELLARIN 1998; CASWELL et al. 2003; KARLAMANGA et al. 2006). Outros fatores associados incluem migração (ARAÚJO 1996), ser negro ou hispânico - nos Estados Unidos da América (CAETANO 2003), aculturação (ZEMORE 2005), ser solteiro e fumar (KARLAMANGA et al. 2006).

Quanto à dependência e abuso, avaliados pelo teste CAGE, observouse duas ou mais respostas positivas em $46,4 \%$ dos etilistas do sexo masculino e em $35,7 \%$ das mulheres que relataram consumir álcool. Isto corresponde a uma prevalência de dependência de 10,4\% (IC 95\% 7,7-13,9) nos homens e 2,6\% (IC 95\% 1,6-4,4) nas mulheres. Estes resultados são semelhantes aos encontrados em outros estudos de dependência alcoólica realizados na população brasileira. SAALFELD \& SILVA (1993) detectaram 6,3\% de dependência etílica em serviço de cuidado primário a saúde, numa proporção de 18 homens para 1 mulher. REGO et al (1991), a partir de dados de inquérito domiciliar no município de São Paulo, encontraram CAGE positivo em 12,6\% dos homens e 3,4\% das mulheres. Em 1999, GALDUROZ et al (2003) observaram 12,3\% de dependência alcoólica no sexo masculino para a faixa etária 25-34 anos, e 8,9\% para os homens com idade igual ou superior a 35 anos. Para o sexo feminino, estes autores observaram dependência de $3,3 \%$ e $1,3 \%$, respectivamente. Inquérito nacional nas 107 cidades do Brasil com mais de 200.000 habitantes evidenciou prevalência de dependência alcoólica mais elevada que em nosso estudo, de $17,1 \%$ para o sexo masculino e $5,7 \%$ no sexo feminino (CARLINI et al. 2002). 
No sexo masculino, observou-se associação inversa de CAGE positivo com escolaridade e com exercer atividade de trabalho. Os homens que relataram não exercer atividade remunerada de trabalho apresentaram razão de prevalências $65,0 \%$ maior em relação àqueles que estavam exercendo atividade de trabalho. Maior consumo de álcool e dependência em desempregados e indivíduos de menor escolaridade são observações relatadas por outros autores (CASWELL et al. 2003; JHINGAN et al.2003; MALYUTINA et al. 2004; KARLAMANGLA et al. 2006).

$\mathrm{Na}$ avaliação do sexo feminino no ISA-SP, CAGE positivo não se associou a nenhuma das variáveis sócio-demográficas estudadas. Isto talvez reflita a natureza multifatorial mais complexa relacionada ao consumo e dependência de álcool no sexo feminino (NAYAK \& KASKUTAS 2004). Nas mulheres, alguns autores relatam maior consumo abusivo de álcool e dependência nas faixas etárias mais jovens (GALDUROZ et al. 2003; COSTA et al. 2004). Em estudo de coorte de acompanhamento de gêmeas americanas, freqüentar universidade, mesmo após controle para variáveis demográficas, sócio-econômicas, de estilo de vida e de fatores familiares e ambientais, associou-se ao consumo ocasional de grandes quantidades de álcool (SLUTSKE et al. 2004). No estudo de GALDUROZ et al (2003), abrangendo 24 municípios do Estado de São Paulo, a prevalência de CAGE positivo foi de $4,3 \%$ nas mulheres de 18 a 24 anos. Caiu então para 3,3\% nas mulheres de 25 a 34 anos e para 1,3\% naquelas com idade maior ou igual a 35 anos.

O uso do teste CAGE apresenta algumas limitações. A validade do teste depende do contexto em que é utilizado. Em estudo de metanálise para avaliação do desempenho do questionário CAGE observou-se melhor desempenho em pacientes internados que nos pacientes de atendimento primário ou ambulatoriais (AERTGEERTS et al. 2004). O CAGE tem sido aplicado em diversos contextos, como local de trabalho (AMARAL \& MALBERGIERA 2004), salas de emergência (SODERSTROM et al. 1997; BORGES \& CHERPITEL 2001) e em pacientes infectados pelo HIV (SAMET et al. 2004), e é considerado válido por alguns autores (SAREMI et al. 2001) e não válido por outros (BISSON et al. 1999). Quanto ao uso 
populacional , CHERPITEL (1998) concluiu que o CAGE não apresenta o mesmo desempenho quando aplicado à população em geral, comparando-se com a sua aplicação em determinadas situações clínicas. Outro estudo, comparando três diferentes instrumentos de diagnóstico de abuso/dependência de álcool, concluiu pelo melhor desempenho dos outros dois instrumentos em relação ao CAGE (CHERPITEL 2002).

$\mathrm{O}$ resultado do teste CAGE ainda pode ser alterado pela ordem de apresentação das questões. ETTER (2004) encontrou menor percentual de respostas positivas às perguntas do CAGE quando estas eram antecedidas por perguntas sobre quantidade e freqüência de uso de álcool. No projeto ISA-SP essas questões foram formuladas posteriormente a aplicação do CAGE.

A mensuração do alcoolismo é controversa. Uma importante limitação de nossos dados foi não termos avaliado a quantidade e o tipo de bebida alcoólica consumida, nem o consumo ocasional de grandes quantidades de álcool (binge drinking). Apesar de diversos estudos avaliarem o consumo de álcool apenas a partir de relatos de freqüência, sabe-se que esta estratégia pode subestimar a prevalência do consumo abusivo (REHM 1998; REHM et al. 1999).

Apesar das evidências consistentes sobre o efeito benéfico do uso moderado de álcool sobre as doenças cardiovasculares (WILKINS 2002; STANDRIDGE et al. 2004; BURGER et al. 2004), e do seu possível efeito sobre a redução da mortalidade geral (DOLL et al. 2005), as conseqüências danosas são muitas e parecem estar mais relacionadas ao consumo abusivo ocasional (REHM et al. 2001). A dependência/abuso de álcool tem sido relacionada a eventos fatais, transtornos psiquiátricos (PALJARVI et al. 2005), traumas (SALOME et al. 2005), violência doméstica (CUNRADI et al. 2002), quedas (MUKAMAL et al. 2004), cânceres (POLEDNAK 2005), doenças sexualmente transmissíveis (COOK \& CLARK 2005) e cirrose (RAMSTEDT 2003), dentre outros. É preocupante a freqüência elevada de consumo observada em nosso estudo, principalmente entre os 
homens, sendo que $61,1 \%$ dos etilistas do sexo masculino com até três anos de escolaridade apresentaram CAGE positivo.

Estudos de tendência nos Estados Unidos da América apontam uma estagnação no declínio do consumo de behidas alcoólicas (GREENFIELD et al. 2000). Por ser socialmente aceito, e também pela alta prevalência de consumidores e dependentes, é essencial a identificação dos segmentos sócio-demográficos mais suscetiveis ao álcool. Novamente, a associação revelada em nosso estudo entre a dependência/abuso e não estar exercendo atividade de trabalho, no sexo masculino, sugere componentes para programas de intervenção e controle

\subsection{DIETA}

A avaliação do padrão de consumo de alimentos por uma população é informação relevante para o direcionamento de políticas nas áreas de agricultura, comércio e saúde, dentre outras. Os problemas decorrentes da inadequação de consumo de alimentos apresentam grande impacto sobre a vida dos indivíduos. São múltiplas as evidências que associam a expansão da "dieta ocidental" - rica em gorduras (particularmente as de origem animal), açúcar e alimentos refinados, e reduzida em carboidratos complexos e fibras - ao aumento da obesidade e elevada prevalência de doenças crônicas (POPKIN 1993; STAMLER 1993; WHO 2005a). No Brasil, o papel da transição nutricional como causa e conseqüência da transição epidemiológica não está perfeitamente compreendido. Comparando-se os dados de dois inquéritos nutricionais realizados pelo Instituto Brasileiro de Geografia e Estatística - IBGE, em 1974 e 1989, observou-se que a proporção de adultos desnutridos foi reduzida substancialmente, mas a de adultos obesos quase dobrou (5,7\% para 9,6\%). Para as mulheres, em 1989, a obesidade supera a desnutrição em todos os níveis de renda (MONTEIRO et al. 2000).

O Brasil vem, então, rapidamente substituindo o problema da escassez pelo problema do excesso alimentar, aliado à má qualidade da dieta. A 
coleta de dados de consumo alimentar em nível populacional é essencial para detectar as populações que podem estar em risco nutricional pelo baixo consumo (deficiência de micronutrientes) ou consumo excessivo (alta ingestão de gordura ou colesterol, p.ex) e para o aprimoramento da PNAN (Política Nacional de Alimentação e Nutrição).

Dada a complexidade da dieta humana, há uma tendência recente a considerar os alimentos juntamente com os nutrientes, e a utilizar ferramentas mais complexas para investigação da dieta, possibilitando medidas mais globais dos hábitos alimentares (KANT 1996). Os índices de qualidade da dieta se alinham a esta proposta.

$\mathrm{Na}$ população adulta do ISA-SP, observou-se valores baixos de adequação dietética pelo IQD, com 4,7\% dos homens e 4,8\% das mulheres apresentando dieta saudável. Utilizando dados populacionais norte-americanos, com índices muito semelhantes, BOWMAN et al (1998) encontraram 12,0\% de indivíduos com dieta saudável, e BASIOTIS et al (2002) e GUO et al (2004) encontraram 10,0\%. No sexo masculino foi observado, no presente estudo, a associação direta do Índice de Qualidade da Dieta com a escolaridade e associação inversa com exercer atividade de trabalho - ou seja, os homens que não trabalhavam apresentaram pior qualidade da dieta. No sexo feminino, houve associação direta do IQD apenas com escolaridade. Diversos autores já relataram a associação entre qualidade da dieta e escolaridade em ambos os sexos (HANN et al. 2001; RAFFERTY et al. 2002; GUO et al. 2004).

Quanto ao consumo de verduras, os dados do ISA-SP demonstraram, para o sexo masculino, maior importância da variável renda. Observou-se ainda interação da renda com escolaridade. Nos indivíduos com renda familiar mensal maior ou igual a 0,5 salário mínimo per capita observamos que o aumento da escolaridade proporcionou maior consumo de legumes e verduras. No sexo feminino, a mesma associação com a renda foi observada. 
Em relação ao consumo de frutas, observou-se, no sexo masculino, associação direta com faixa etária e escolaridade. Houve ainda interação da variável renda com a faixa etária. Nos homens com renda familiar mensal entre 1,5 e 2,9 salários-mínimos per capita observou-se que o aumento na faixa etária elevou a probabilidade de consumir mais frutas. Quanto ao sexo feminino, os dados do ISASP demonstraram associação direta do consumo de frutas com renda e escolaridade. Novamente observamos interação entre escolaridade e renda, significativa apenas para as mulheres com escolaridade de quatro a sete anos, onde o aumento da renda proporcionou elevação no consumo de frutas. É preocupante, quanto ao consumo de frutas, a observação de que $57,6 \%$ dos homens e $47,5 \%$ das mulheres estão no tercil mais baixo de consumo. Cerca de $50,0 \%$ dos indivíduos em nossa amostra obtiveram pontuação próxima de zero, o que significa o consumo de praticamente nenhuma porção de fruta em um dia.

Os dados observados para o consumo de legumes, verduras e frutas são semelhantes aos encontrados por outros pesquisadores (BOWMAN et al. 1998; BASIOTIS et al. 2002; MISHRA et al. 2002; RAFFERTY et al. 2002; THIELE et al. 2004), inclusive quanto à baixa ingestão de frutas. Esses autores também relatam consumos mais elevados em indivíduos de maior nível sócio-econômico. THIELE et al (2004) relatam melhor qualidade da dieta com o aumento da faixa etária. Em nosso estudo, apenas a ingestão de frutas no sexo masculino se manteve significativamente associada à faixa etária no modelo múltiplo.

Ao analisarmos os dados de composição de gorduras na dieta na população adulta do ISA-SP foram observados valores mais elevados nas mulheres de cor ou raça negra. No entanto, esta variável perde sua significância estatística com o ajuste para renda.

O achado de composição de gorduras na dieta alerta para o fato de que o consumo de gorduras está distribuído em todos os estratos sócio-econômicos. Observamos ainda uma distribuição proporcional entre os três tercis, em ambos os 
sexos. Estes resultados são semelhantes aos observados na população chinesa (WOO et al. 1998) e dinamarquesa (HULSHOF et al. 2003).

O recordatório de 24 horas, método utilizado para coleta dos dados, apresenta algumas limitações, tais como depender da memória do entrevistado, dificuldade para estimar o tamanho das porções e o fato de não necessariamente refletir a ingestão habitual (FISBERG et al. 2005b). Entretanto, é metodologia largamente validada para avaliação de padrões alimentares em populações. As análises neste estudo utilizaram um índice geral de qualidade da dieta, associado à avaliação do consumo de alimentos - frutas e verduras - e componentes - gorduras. Entretanto, as análises de frutas, verduras e composição de gorduras foram realizadas a partir da pontuação no IQD e não pela sua quantificação real na dieta do indivíduo.

Os dados de consumo alimentar na população brasileira são diversos, entretanto corroboram os achados deste estudo quanto ao baixo consumo de verduras e frutas na população (GALEAZZI et al. 1997; MONTEIRO et al. 2000; BONOMO et al. 2003; SICHIERI et al. 2003)

A qualidade da nutrição de um indivíduo durante sua vida é um dos grandes determinantes de sua saúde. O IQD é uma medida resumo da qualidade da dieta, mas seus componentes são diferentemente sensíveis aos fatores sócioeconômicos. Assim, embora o consumo de pães ou gorduras seja amplamente distribuído em todos os grupos de escolaridade e renda (FISBERG et al. 2005a), o consumo de frutas não é. A Organização Mundial de Saúde recomenda o consumo de pelo menos $400 \mathrm{~g}$ de frutas e hortaliças por dia para redução do risco de desenvolvimento de câncer (WHO 2005a). Programas para elaboração de hortas comunitárias e aumento do consumo de alimentos da estação, cujos custos são mais baixos, são propostas para otimizar a disponibilidade de frutas e verduras para a população. 


\subsection{ANÁLISE DE CLUSTER}

A análise de cluster é largamente utilizada nos mais diferentes campos de investigação e implica o agrupamento de objetos similares em subgrupos diferentes. Deste modo, os elementos dentro de um cluster compartilham um elevado grau de 'associação natural', enquanto que os agrupamentos são relativamente distintos entre si. Recentemente, a análise de cluster tem sido utilizada com maior freqüência para avaliação de grupos de pacientes, doenças, análises populacionais, de comportamento e de estilo de vida (BORGEN \& BARNETT 1987).

Trabalho norte-americano avaliando as principais causas de morte no ano 2000 nos Estados Unidos da América concluiu que 18,1\% do total de mortes naquele país era atribuível ao uso de tabaco, 16,6\% a dieta inadequada e inatividade física, e 3,5\% ao consumo de álcool. Outras causas incluíram: agentes microbianos e tóxicos, acidentes automobilísticos, incidentes relacionados a armas de fogo, comportamentos sexuais não-seguros e uso de drogas ilícitas; entretanto, todos estes, em menor proporção (MOKDAK et al. 2004). Fatores modificáveis relacionados ao estilo de vida respondem pelas quatro principais causas de morte naquele país. No entanto, apesar de passíveis de modificação, a abordagem das mudanças de hábitos de vida persistem como fator limitante essencial no contexto do atendimento multidisciplinar em saúde.

Nos dados do ISA-SP, a análise de cluster para o sexo masculino apontou para a formação de quatro agrupamentos, relacionados diretamente aos subgrupos de escolaridade.

O Cluster 1 - Masculino agrupou os indivíduos com maior concentração de comportamentos de risco: tabagistas, não-praticantes de exercício físico, etilistas em freqüência de duas vezes/semana ou mais, reduzida ingestão de frutas e baixo IQD (Índice de Qualidade da Dieta). Observou-se que 24,9\% dos homens adultos se encontram neste grupo de alto risco, que se caracteriza por reunir indivíduos de faixas etárias mais elevadas (acima dos 40 anos), baixa renda e baixa escolaridade (até 7 anos). Este percentual é bem mais elevado que o encontrado por 
PATTERSON et al (1994) em estudo semelhante também com análise de cluster, porém com enfoque na dieta. Neste estudo da população adulta norte-americana, o percentual de indivíduos nesta categoria de maior risco foi de $2,0 \%$. A baixa ingestão de gorduras talvez esteja relacionada ao elevado consumo de álcool.

No Cluster 2 - Masculino, no qual se incluíram 21,3\% dos homens adultos, observou-se a afluência de homens também de baixa renda, porém com escolaridade um pouco mais alta - principalmente 4-7 anos. Caracterizaram-se por elevada ingestão de gorduras e por nunca terem fumado.

A menor proporção observada, de 18,4\%, coube ao Cluster 3 Masculino, o qual englobou os homens de alta renda e escolaridade universitária. Os comportamentos associados a este cluster foram elevada ingestão de verduras e de frutas.

No Cluster 4 - Masculino se concentraram os homens mais jovens (20-29 anos), com escolaridade 8-11 anos e praticantes de exercício físico.

Observa-se, assim, que, apesar do exercício físico ser mais freqüente nas populações de mais alta escolaridade, a sua prática não se associou ao cluster dos homens de nível universitário (cluster 3). Ao mesmo tempo, elevada ingestão de frutas e verduras foi observada neste cluster, porém apenas neste, ou seja, todos os demais subgrupos apresentaram dieta deficiente em fibras (frutas e verduras). Desta forma, o incentivo ao exercício físico deve ser direcionado aos grupos de homens de mais baixo nível sócio-econômico e maior faixa etária, mas deve incluir também os homens de alta renda e escolaridade. O incentivo ao consumo de frutas e verduras deve enfocar os homens de escolaridade menor que 12 anos.

Quanto ao sexo feminino, observou-se a formação de dois agrupamentos, relacionados diretamente à variável renda.

O Cluster 1 - Feminino agrupou 43,5\% das entrevistadas, concentrando mulheres que praticam esporte ou exercício físico, nunca fumaram, 
com elevada ingestão de frutas e que ingerem bebida alcoólica em freqüência de até uma vez/semana. Estes comportamentos caracterizaram as mulheres de mais alta renda. Neste cluster, atenção especial deve ser dada à associação de ingerir álcool até uma vez/semana neste grupo específico de mulheres de mais alta renda. Alguns estudos já observaram que a dependência alcoólica em geral se inicia a partir de baixos níveis de ingestão, ou seja, este consumo social/ocasional pode ser um precursor de consumo crescente e excessivo, e até mesmo dependência (CAETANO \& CUNRADI 2002). Entretanto, como em nosso estudo não determinamos a quantidade de álcool consumida, apenas a freqüência, esta análise fica limitada.

O Cluster 2 - Feminino concentrou as mulheres com baixa ingestão de frutas, tabagistas, não-praticantes de esporte ou exercício físico, porém na categoria mais elevada de prática de atividade física. Observou-se predominância de entrevistadas de mais baixa renda neste cluster. Para as mulheres de mais baixo nível sócio-econômico, é fundamental o estabelecimento de programas para controle do tabagismo e incentivo ao consumo de frutas.

Em geral, em ambos os sexos, observou-se fato já relatado por diversos outros autores: a associação de vários comportamentos de risco e sua concentração em subgrupos específicos de maior vulnerabilidade (HULSHOF et al. 1992; CHAIEB \& CASTELLARIN 1998; VON et al. 2004; KING et al. 2005). As diversas interações que associam, por exemplo, o consumo de álcool às mulheres de mais alta renda, propõem reflexões sobre o papel social deste consumo e sua representação para este grupo específico. Assim, como observado neste estudo, as distribuições desiguais dos componentes do estilo de vida sugerem agregações mais complexas, bem além da dicotomia 'pobre-rico'.

Uma das limitações desta análise é a utilização do método TwoStep que, apesar de já validado como técnica para análise de cluster, é um método novo, com poucas publicações a seu respeito. 
Para reduzir as desigualdades em saúde é essencial conhecer os segmentos mais afetados e vulneráveis e a análise de cluster, neste estudo, mostrouse um instrumento útil para identificação dos grupos de maior risco. 


\section{CONSIDERAÇÕES FINAIS}

Os estudos transversais, apesar de não representarem o ideal metodológico da epidemiologia moderna, persistem como o desenho de pesquisa mais empregado na prática concreta de investigação no campo da Saúde Coletiva. Os inquéritos domiciliares de saúde apresentam dois grandes diferenciais: a possibilidade de construção de indicadores associados à saúde, e não apenas às doenças; e a obtenção de informações da parcela da população que não tem acesso aos serviços de saúde (CÉSAR \& TANAKA 1996; ALMEIDA FILHO 2000; VIACAVA 2002; BARROS 2005). Os inquéritos têm produzido no Brasil um volume formidável de informações que têm sido utilizadas por instâncias governamentais de diferentes níveis e setores para formulação e aprimoramento de políticas públicas gerais e específicas na área da saúde.

O Relatório LALONDE, em 1974, ao retratar o conceito de campo da saúde [health field], já incluía o estilo de vida como parte dos fatores que intervêm sobre a saúde, juntamente com a biologia humana, o meio ambiente e a organização da assistência à saúde (LALONDE 2002). Desde então, grande ênfase tem sido dada ao estudo do estilo de vida, compreendendo diversos desdobramentos, tais como o enfoque individual para fatores de risco específicos e esforços para prevenção de doenças. Recentemente, entretanto, a perspectiva individual tem sido ampliada com a investigação dos determinantes sociais do estilo de vida e dos modos singulares pelos quais as pessoas incorporam ações e valores do mundo, e respondem com diferentes reações e comportamentos (TESTA 1997; ALMEIDA FILHO 2000).

Nestes esforços para promoção da saúde e prevenção de doenças, alguns componentes específicos do estilo de vida estão consistentemente relacionados à deterioração da saúde e agravamento de morbidades. Dentre as várias possibilidades de investigações quantitativas e qualitativas do estilo de vida, a mensuração destes comportamentos de elevada prevalência, com detecção dos segmentos mais vulneráveis, é tarefa essencial para planejamento das ações assistenciais e preventivas de saúde. 
Os dados do ISA-SP evidenciam, assim, importantes gradientes em quatro componentes do estilo de vida sabidamente associados a doenças crônicas e outros agravos à saúde.

$\mathrm{Na}$ avaliação de cada um dos componentes em particular, a análise obtida a partir de modelos de Regressão de Poisson facilitou a interpretação dos resultados, uma vez que se trabalhou com as razões de prevalência, ao invés das razões de chance [odds ratio]. Da mesma forma, a análise de cluster possibilitou observar agrupamentos inicialmente não aparentes entre as diversas variáveis, revelando subgrupos específicos de alto risco e elevada vulnerabilidade.

Esta análise demonstrou, para o sexo masculino, um grupo de elevada prevalência, de alto risco, com concomitância de tabagismo, etilismo, sedentarismo e má qualidade da dieta. Demonstrou a baixa ingestão de frutas e verduras para os indivíduos com escolaridade menor que 12 anos. E ainda a necessidade do incentivo à prática de exercício físico para os grupos de baixa escolaridade e renda, mas também para os homens de escolaridade universitária.

Para o sexo feminino, a análise de cluster revelou um grupo de risco de mulheres de baixa renda, tabagistas e com reduzida ingestão de frutas. A associação de ingestão de álcool em freqüência de até uma vez/semana com as mulheres de mais alta renda aponta para a cuidadosa observação da ingestão etílica neste grupo.

Outras informações relevantes obtidas a partir dos resultados deste estudo incluem a queda na prática de atividade fisica e exercício físico nos homens com o aumento da idade, o papel da religião evangélica associado a menor prevalência de tabagismo, e a inserção no mercado de trabalho como fator protetor para tabagismo e etilismo no sexo masculino.

As políticas públicas de saúde, tanto para promoção da saúde e prevenção de doenças quanto para assistência, não se fazem em pessoas que têm 
apenas risco de uma doença ou apenas uma doença. Os beneficiários das ações de saúde, vistos como indivíduos e como grupos sociais, têm sempre um amplo conjunto de necessidades (MATTOS 2003). Pretende-se, portanto, a apreensão adequada destas necessidades das pessoas portadoras ou não de doenças e, numa perspectiva muito ampliada, preencher as necessidades das pessoas, e não as necessidades das doenças.

Deste modo, os desafios postos pela busca da saúde e tratamento ou prevenção de doenças envolvem tanto questões relativas à oferta dos serviços assistenciais para responder às necessidade de assistência dos portadores das doenças existentes hoje, como questões referentes às possibilidades futuras de redução no número de portadores destes agravos à saúde (MATTOS 2003). Ações voltadas para melhora do estilo de vida da população cumprem, então, um duplo papel - preventivo e assistencial.

Estilo de vida saudável, em seus vários desdobramentos e possibilidades, desenvolve promoção da saúde, prevenção e tratamento de diversas doenças crônicas, bem como reabilitação, desempenhando função essencial em todos os estágios do processo saúde-doença-cuidado.

Os quatro componentes do estilo de vida avaliados neste trabalho atividade/exercício físico, tabagismo, etilismo e dieta - apresentam distribuições desiguais na população estudada, com predominância de fatores de risco nos estratos de menor nível sócio-econômico. As análises aqui realizadas pretendem contribuir para melhor caracterização destes segmentos, com fins de desenvolver programas e políticas de combate às desigualdades em saúde. 
Aertgeerts B, Buntinx F, Kester A. The value of the CAGE in screening for alcohol abuse and alcohol dependence in general clinical populations: a diagnostic metaanalysis. J Clin Epidemiol 2004; 57: 30-9.

Almeida LM, Coutinho ESF. Prevalência de consumo de bebidas alcoólicas e de alcoolismo em uma região metropolitana do Brasil. Rev Saúde Pública 1993; 27: 23-9.

Almeida R. Religião e comportamento. Rev Bras Ci Soc 1999; 14: 175-178.

Almeida R. Dinâmica religiosa na metrópole paulistana. São Paulo: Centro de Estudos da Metrópole. Disponível em: www.cebrap.org.br [22 ago 2004].

Almeida-Filho N. A Ciência da Saúde. São Paulo: HUCITEC, 2000. 255 p.

Almeida-Filho N. Modelos de determinação social das doenças crônicas nãotransmissíveis. Ciênc Saúde Coletiva 2004; 9: 865-884.

Almeida-Filho N, Lessa I, Magalhães L, Araújo MJ, Aquino E, James AS, Kawachi I. Social inequality and depressive disorders in Bahia, Brazil: interactions of gender, ethnicity and social class. Soc Sci Med 2004; 59: 1339-53.

Alves MCGP. Técnicas de replicação em análise de dados de inquéritos domiciliares. São Paulo; 2002 [Tese de Doutorado - Faculdade de Saúde Pública da USP].

Alves MCGP. Plano de amostragem. In: César CLG et al, org. Saúde e condição de vida em São Paulo. São Paulo: FSP/USP; 2005. p.47-62.

Amaral RA, Malbergiera A. Avaliação de instrumento de detecção de problemas relacionados ao uso do álcool (CAGE) entre trabalhadores da prefeitura do campus da Universidade de São Paulo (USP)-Campus Capital. Rev Bras Psiquiatr 2004; 26 : 156-63. 
Andersen LB, Schnohr P, Schroll M, Hein HO. All-cause mortality associated with physical activity during leisure time, sports and cycling to work. Arch Intern Med 2000; 160: 1621-28.

Araújo, EAC. Processo migratório e doença: fatores de risco cardiovasculares em migrantes e naturais da região metropolitana de São Paulo. Dissertação de Mestrado - Faculdade de Saúde Pública, USP; 1996. 138 p.

Araújo T, Matsudo S, Matsudo V, Andrade D, Andrade E, Oliveira LC. Reprodutibilidade do Questionário Internacional de Atividade Física em adolescentes e adultos brasileiros (IPAQ versão 8). In: CELAFISCS. Anais do XXIII Simpósio Internacional de Ciências do Esporte 2000; Atividade Física, Fitness e Esporte. São Caetano do Sul, CELAFISCS, 2000. p.136. São Paulo, 5-8 out.

Arnett DK, Sprafka JM, McGovern PG, Jacobs DR, Shahar D, McCarty M et al. Trends in cigarette smoking: the Minnesota Heart Survey, 1980 through 1992. Am J Public Health 1998; 88: 1230-33.

Assanangkornchai S, Conigrave KM, Saunders JB. Religious beliefs and practice, and alcohol use in Thai men. Alcohol and Alcoholism 2002; 37: 193-7.

Azevedo S apud Stoll SJ. Narrativas biográficas: a construção da identidade espírita no Brasil e sua fragmentação. Estudos Avançados 2004; 18: 181-199.

Bak H, Petersen L, Sorensen TIA. Physical activity in relation to development and maintenance of obesity in men with and without juvenile onset obesity. Int $\mathbf{J}$ Obes 2004; 28: 99-104.

Banfield D, Raftery AE. Model -based Gaussian and non-Gaussian clustering. Biometrics 1993; 49: 803-821.

Barbeau EM, Krieger N, Soobader M. Working class matters: socioeconomic disadvantage, race/ethnicity, gender, and smoking in NHIS 2000. Am J Public Health 2004; $94: 269-78$.

Basiotis PP, Carlson A, Gerrior SA, Juan WY, Lino M. The Healthy Eating Index: 1999-2000. U.S. Department of Agriculture, Center for Nutrition Policy and Promotion; 2002. 
Bassett DR. Commentary to accompany: International Physical Acitivity Questionnaire: 12-country reliability and validity. Med Sci Sports Exerc 1003; 35: 1396.

Barros AJD, Hirakata VN. Alternatives for logistic regression in cross-sectional studies: an empirical comparison of models that directly estimate the prevalence ratio. BMC Med Res Methodol 2003; 3:21-27.

Barros MBA, César CLG, Goldbaum M, Carandina L. Eqüidade e saúde: prevalência do tabagismo e fatores associados (Projeto ISA-SP). In: Anais do VI Congresso Brasileiro de Epidemiologia 2004; Recife, Associação Brasileira de Saúde Coletiva, 2004a.

Barros MBA. Consumo de álcool. In: César CLG et al, org. Saúde e condição de vida em São Paulo. São Paulo: FSP/USP; 2005. p.115-128.

Bau CHD. Estado atual e perspectivas da genética e epidemiologia do alcoolismo. Ciênc Saúde Coletiva 2002; 7: 183-190.

Birman P. Cultos de possessão e pentecostalismo no Brasil: passagens. Religião e Sociedade 1995; 17: 90-109.

Bisson J, Nadeau M, Demers A. The validity of the CAGE scale to screen for heavy drinking and drinking problem in a general population survey. Addiction 1999; 94 : 715-22.

Bonomo E, Caiaffa WT, César CC, Lopes ACS, Lima-Costa MF. Consumo alimentar da população adulta segundo perfil sócio-econômico e demográfico: Projeto Bambuí. Cad Saúde Pública 2003; 19(5): 1461-71.

Borgen FH, Barnett DC. Applying cluster analysis in counseling psychology research. J Couns Psychol 1987; 34: 456-68.

Borges G, Cherpitel CJ. Selection of screening items for alcohol abuse and alcohol dependence among mexicans and mexican americans in the emergency department. J Stud Alcohol 2001; 62: 277-85. 
Bowman SA, Lino M. Gerrior SA, Basiotis PP. The Healthy Eating Index: 199496. U.S. Department of Agriculture, Center for Nutrition Policy and Promotion. 1998.

Brito FC, Litvoc J. Envelhecimento: prevenção e promoção da saúde. São Paulo: Atheneu; 2004. Conceitos básicos; p. 1-16.

Brown WJ, Trost SG. Life transitions and changing physical activity patterns in young women. Am J Prev Med 2002; 25: 140-143.

Burger M, Mendink G, Bronstrup A, Thierfelder W, Pietrzik K. Alcohol consumption and its relation to cardiovascular risk factors in Germany. Eur J Clin Nutr 2004; 59: 605-14.

Caetano R, Cunradi C. Alcohol dependence: a public health perspective. Addiction 2002; 97: 633-45.

Camargo CP. Católicos, espíritas e protestantes. Petrópolis: Vozes; 1973.

Caraballo RS, Giovino GA, Pechacek TF. Self-reported cigarette smoking vs. serum cotinine among US adolescents. Nicotine Tob Res 2004; 6: 19-25.

Cardim MS, Assis SG, Sberze M, Iguchi T, Morgado AF. Epidemiologia descritiva do alcoolismo em grupos populacionais do Brasil. Cad Saúde Pública 1986; 2: 191211.

Carey KB. Understanding binge drinking: introduction to the special issue. Psychology of addictive behaviors 2001; 15: 283-6.

Carlini EA, Galduróz JCF, Noto AR, Nappo SA. I Levantamento domiciliar sobre o uso de drogas psicotrópicas no Brasil: estudo envolvendo as 107 maiores cidades do país, 2001. São Paulo: CEBRID/UNIFESP; 2002. Disponível em: www. unifesp.br/dpsicobio/cebrid/levantamento_brasil/parte_2.pdf [03 fev 2006]

Casswell S, Pledger M, Hooper R. Socioeconomic status and drinking patterns in young adults. Addiction 2003; 98: 601-610. 
[CDC] Centers for Disease Control. Prevalence of leisure-time and occupational physical activity among employed adults-United states, 1990. MMWR 2000; 49: $421-5$.

[CDC] Centers for Disease Control. Increasing physical activity: a report on recommendations of the Task Force on Community Preventive Services. MMWR 2001; 50 (RR-18): 1-14.

CDC [Centers for Disease Control]. Informe sobre la actividad fisica en horas libres y en horas de trabajo en la población estadounidense. Rev Panam Salud Publica 2003a; 14: 265-273.

CDC [Centers for Disease Control]. Prevalence of current cigarette smoking among adults and changes in prevalence of current and some day smoking - United States, 1996-2001. MMWR 2003; 52: 303-307.

[CDC] Centers for Disease Control. State-specific prevalence of current cigarette smoking among adults, United States, 2003. MMWR 2004a; 53 (44): 1035-37.

[CDC] Centers for Disease Control. Alcohol attributable deaths and years of potential life lost, United States, 2001. MMWR 2004b; 53 (37): 866-70.

[CDC] Centers for Disease Control. Binge drinking among adults. Http://www.cdc.gov/mmwr/preview/mmwrhtml/figures/r311a3i9.gif 15 de novembro $2004 \mathrm{c}$.

[CDC] Centers for Disease Control. Heavy drinking among adults male aged $\geq 18$ years. Http://www.cdc.gov/mmwr/preview/ mmwrhtml/figures/r31la3i13.gif 15 de novembro $2004 \mathrm{~d}$.

[CDC] Centers for Disease Control. Heavy drinking among adults female aged $\geq$ 18 years. Http://www.cdc.gov/mmwr/ preview/mmwrhtml/figures/r311a3i9. gif $15 \mathrm{de}$ novembro $2004 \mathrm{e}$.

César CLG, Tanaka OY. Inquérito domiciliar como instrumento de avaliação de serviços de saúde: um estudo de caso na região sudoeste da área metropolitana de São Paulo, 1989-1990. Cad Saúde Pública 1996; 12 (supl. 2): 59-70. 
Chaieb JA, Castellarin C. Associação tabagismo-alcoolismo: introdução às grandes dependências humanas. Rev. Saúde Pública 1998; 32: 246-54.

Chaieb J, Ruschel SP, Costa JTF. Estudo epidemiológico sobre tabagismo - Parte I: informações epidemiológicas sobre área periférica de Porto Alegre, RS. Rev AMRIGS 1993; 37: 251-257.

Chalmers $J$ et al. Guidelines set new definition, update treatment for hypertension. Bulletin of the World Health Organization 1999; 77(3): 293.

Cherpitel CJ. Performance of screening instruments for identifying alcohol dependence in the general population, compared with clinical populations. Alcohol Clin Exp Res 1998; 22: 299.

Cherpitel CJ. Sreening for alcohol problems in the U.S. General population: comparison of the CAGE, RAPS4, and RAPS4-QF by gender, ethnicity, and service utilization. Alcohol Clin Exp Res 2002; 26: 1686-91.

Costa JSD, Silveira MF, Gazalle FK, Oliveira SS, Hallal PC, Menezes AMB, Gigante DP, Olinto MTA, Macedo S. Consumo abusivo de álcool e fatores associados: estudo de base populacional. Rev Saúde Pública 2004; 38: 284-91.

Cook RL, Clark DB. Is there na association between alcohol consumption and sexually transmitted diseases? A systematic review. Sexually Transmitted Diseases 2005; 32: 156-164.

Craig CL, Marshall AL, Alison L, Sjöstrom M, Bauman AE, Booth ML et al. International Physical Activity Questionnaire: 12-country reliability and validity. Med Sci Sports Exerc 2003; 35: 1381-1395.

Cunradi $\mathrm{Cb}$, Caetano R, Schafer J. Alcohol-related problems, drug use, and male intimate partner vio!ence severity among US couples. Alcoholism: Clinical \& Experimental Research 2002; 26: 493-500.

Del Boca FK, Darkes J. The validity of self-reports of alcohol consumption: state of the science and challenges for research. Addiction 2003; 98(suppl. 2): 1-12. 
Dell JL, Whitman S, Shah AM, Silva A, Ansell D. Smoking in 6-diverse Chicago communities-a population study. Am J Public Health 2005; 95: 1036-1042.

Dias-da-Costa JS, Hallal PC, Wells JCK, Daltoé T, Fuchs SC, Menezes AMB, Olinto MTA. Epidemiology of leisure-time physical activity: a population-based study in southern Brazil. Cad Saúde Pública 2005; 21: 275-82.

Doll R, Peto R, Boreham J, Sutherland I. Mortality in relation to alcohol consumption: a prospective studyamong male British doctors. Int J Epidemiol 2005; 34: 199-204.

Drumond Jr M \& Barros MBA. Desigualdades socioespaciais na mortalidade do adulto no município de São Paulo. Rev Bras Epidemiol 1999; 2: 34-49.

Duncan BB, Schmidt MI, Polanczik CA, Homrich CS, Rosa RS, Achutti AC. Fatores de risco para doenças não-transmissíveis em área metropolitana na região Sul do Brasil. Prevalência e simultaneidade. Rev Saúde Públ 1993; 27: 143-8.

Etter JF. Asking about quantity and frequency of alcohol consumption before asking the CAGE questions produces lower ratings on the CAGE test. Drug Alcohol Dependence 2004; 74: 211-4.

Fahrmeir L, Tutz G. Multivariate statistical modeling based on Generalized Linear Models. 3.ed. New York: Springer; 1997.

Fernandes RC, Sanchis P, Velho OG, Piquet L, Mariz C, Mafra C. Novo nascimento: os evangélicos em casa, na política e na igreja. Rio de Janeiro: Mauad; 1998. 264 p.

Fezeu L, Minkoulou E, Balkau B, Kengne AP, Awah P, Unwin N et al. Association between socioeconomic status and adiposity in urban Cameroon. Int $\mathbf{J}$ Epidemiol 2006; 35: 105-111.

Fisberg RM, Slater B, Barros RR, Lima FD, Carandina L, Barros MBA, Goldbaum M, César CLG. Índice de Qualidade da Dieta - IQD: avaliação e aplicabilidade. Rev Nutr 2004; 17(4). No prelo. 
Fisberg RM, Slater B, Morimoto JM, Bueno MB. Índice de Qualidade da Dieta. In: César CLG et al, organizadores. Saúde e condição de vida em São Paulo: inquérito multicêntrico de saúde no Estado de São Paulo (ISA-SP). São Paulo: FSP/USP; 2005. p. 81-90

Fisberg RM, Villar BS. Manual de receitas e medidas caseiras para cálculo de inquéritos alimentares: manual elaborado para auxiliar o processamento de inquéritos alimentares. São Paulo: Signus; 2002.

Fraley C, Raftery AE. How many clusters? Which clustering method? Answers via model-based cluster analysis. Computer Journal 1998; 4: 578-588.

Freitas OC, Carvalho FR, Neves JM, Veludo PK, Parreira RS, Gonçalves RM et al. Prevalência de hipertensão arterial sistêmica na população urbana de Catanduva, SP. Arq Bras Cardiol 2001; 77: 9-15.

Fries JF. Aging, natural death, and the compression of morbidity. NEJM 1980; 303: $130-135$.

Galduróz JCF, Noto AR, Nappo SA, Carlini ELA. First household survey on drug abuse in São Paulo, Brazil, 1999: principal findings. São Paulo Med J 2003; 121: 231-237.

Galea S, Nandi A, Vlahov D. The social epidemiology of substance use. Epidemiologic Reviews 2004; 26: 36-52.

Galeazzi MAM, Domene SMA, Sichieri R. Estudo multicêntrico sobre consumo alimentar. Brasília: Ministério da Saúde; 1997. Disponível em: http: //dtr2001.saude.gov.br/bvs/publicações/cadernoespecial.pdf

Gillum RF. Frequency of attendance at religious services and cigarette smoking in American women and men: the Third National Health and Nutrition Examination Survey. Prev Med 2005; 41: 607-13.

Giumbelli E. Heresia, doença, crime ou religião. Revista de Antropologia, São Paulo, USP 1997; 40: 54-63. 
Gomes VB, Siqueira KS, Sichieri R. Atividade física em uma amostra probabilística da população do Município do Rio de Janeiro. Cad Saúde Públ 2001; 17: 969-76.

Greenfield TK, Midanik LT, Rogers JD. A 10-year national trend study of alcohol consumption, 1984-1995: is the period of declining drinking over? Am J Public Health 2000; 90: 47-52.

Guimarães VMV. Atividade física e hipertensão arterial na Grande São Paulo, 2002: um estudo de base populacional. Dissertação de Mestrado - Faculdade de Saúde Pública, USP; 2003. 143 p.

Guimarães VMV, César CLG, Goldbaum M, Carandina L, Barros MBA. Atividade física e hipertensão arterial na Grande São Paulo (ISA-SP), 2002. In: Anais do VII Congresso Brasileiro de Saúde Coletiva 2003; Brasília, Associação Brasileira de Saúde Coletiva, 2003.

Guimarães VMV, César CLG, Goldbaum M, Carandina L, Barros MBA. Atividade física, exercício físico e sedentarismo em mulheres de 20 a 59 anos no Estado de São Paulo (ISA-SP). In: Anais do VI Congresso Brasileiro de Epidemiologia 2004; Recife, Associação Brasileira de Saúde Coletiva, 2004a.

Guimarães VMV, César CLG, Goldbaum M, Carandina L, Barros MBA. Atividade física, exercício físico e sedentarismo em diabéticos auto-referidos no Estado de São Paulo (ISA-SP). In: Anais do VI Congresso Brasileiro de Epidemiologia 2004; Recife, Associação Brasileira de Saúde Coletiva, 2004b.

Guo X, Warden BA, Paeratakul S, Bray GA. Healthy Eating Index and obesity. Eur J Clin Nutr advance online publication, 19 maio 2004; 1-7.

Hallal PC, Victora CG, Wells JC, Lima RC. Physical inactivity: prevalence and associated variables in Brazilian adults. Med Sci Sports Exerc 2003; 35: 1894-900.

Hallal PC, Victora CG, Wells JCK, Lima RC, Valle NJ. Comparison of short and full-length International Physical Activity Questionnaires. JPAH 2004; 1: $12-18$.

Hammond D. Smoking behaviour among young adults: beyond youth prevention. Tobacco Control 2005; 14: 181-185. 
Hann CS, Rock CL, King I, Drewnowski A. Validation of the Healthy Eating Index with use of plasma biomarkers in a clinical sample of women. Am J Clin Nutr 2001; 74: 479-86.

Hair Jr JF, Anderson RE, Tatham RL, Black WC. Multivariate data analysis. 4.ed. New Jersey: Prentice Hall; 1995.

He FJ, Markandu ND, MacGregor GA. Modest salt reduction lowers blood pressure in isolated systolic hypertension and combined hypertension. Hypertension 2005; 46: $66-70$

Helmert U, Borgers D, Bammann K. Social determinants of smoking behavior in Germany: results of a 1995 micro-census. Soz Praventivmed 2001; 46: 172-81.

Hixson KA, Gruchow HW, Morgan DW. The relation between religiosity, selected health behaviours and blood pressure among adult females. Prev Med 1998; 27 : $545-52$.

Hojsgaard S, Halekoh U. Count Data and Poisson Regression - Biometry Research Unit, Danish Institute of Agricultural Sciences. Disponivel em: http://gbi agrsci. dk/statistics/courses/phd06/material/Day6-poisson/handout-poisson.pdf. [2006 Aug 27]

Horta BL, Victora CG, Barros FC, Santos IS, Menezes AMB. Tabagismo em gestantes de área urbana da região Sul do Brasil, 1982 e 1993. Rev. Saúde Pública 1997; 31: 247-53.

Huang Z. Extensions of the k-means algorithm for clustering large data sets with categorical values. Data mining and Knowledge Discovery 1998; 2: 282-304.

Hulshof KF, Wedel M, Lowik MR, Kok FJ, Kistemaker C, Hermus RJ et al. Clustering of dietary variables and other lifestyle factors (Dutch Nutritional Surveillance System). J Epidemiol Community Health 1992-; 46: 417-24.

Hulshof KFAM, Brussaard JH, Kruizinga AG, Telman J, Lowik MRH. Socioeconomic status, dietary intake and $10 \mathrm{y}$ trends: the Dutch National Food Consumption Survey. Eur J Clin Nutr 2003; 57: 128-137. 
[IBGE] Instituto Brasileiro de Geografia e Estatística. Projeção da população do Brasil: 1980-2050. Disponível em: www.ibge.gov.br [2006 Jan 6]

[IPAQ] International Physical Activity Questionnaire. Disponível em: URL:http://ipaq.ki.se/ [2005 Dec 22]

Ishitani LH \& França E. Desigualdades socioespaciais e mortes precoces de adultos na região centro-sul do município de Belo Horizonte em 1996. Inf Epidemiol SUS 2000; 9: 229-39.

Jefferis B, Graham H, Manor O et al. Cigarette consumption and socioeconomic circumstances in adolescence as predictors of adult smoking. Addiction 2003; 98 : 1765-72.

Jefferis B, Power C, Graham $\mathrm{H}$ et al. Effects of childhood socioeconomic circumstances on persistent smoking. Am J Public Health 2004; 94: 279-85.

Jhingan HP, Shyangwa P, Sharma A, Prasad KM, Khandelwal SK. Prevalence of alcohol dependence in a town in Nepal as assessed by the CAGE questionnaire. Addiction 2003; 98: 339-43.

Jong-Wook L. Public health is a social issue [comment]. Lancet 2005; 365: 1005-6.

Kannel WB \& Belanger AJ. Epidemiology of heart failure. Am Heart J 1991; 121 : 951-7.

Kant AK. Indexes of overall diet quality: a review. J Am Diet Assoc 1996; 96: 785 91.

Karlamanga A, Zhou K, Reuben D, Greendale G, Moore A. Longitudinal trajectories of heavy drinking in adults in the United States of América. Addiction 2006; 101 : 91-99.

Kawachi I, Subramanian SV, Almeida-Filho N. A glossary for health inequalities. J Epidemiol Community Health 2002; 56: 647-652. 
Kendler KS, Gardner CO, Prescott CA. Religion, psychopathology, and substance use and abuse: a multimeasure, genetic-epidemiologic study. Am J Psychiatry 1997; 154: $322-9$.

Kerr WC, Greenfield TK, Tujague J, Brown SE. A drink is a drink? Variation in the amount of alcohol contained in beer, wine and spirits drinks in a US methodological sample. Alcoholism: Clinical and Experimental Research 2005; 29: 2015-21.

King AC, Epstein AM. Alcohol dose-dependent increase in smoking urge in cigarette-deprived light smokers. Alcohol Clin Exp Res 2005; 29: 137-143.

King DE, Mainous AG, Steyer TE, Pearson WS. The relationship between attendance at religious services and cardiovascular inflammatory markers. Int $\mathbf{J}$ Psychiatry Med 2001; 31: 415-25.

King DE, Mainous AG, Pearson WS. C-reactive protein, diabetes and attendance at religious services. Diabetes Care 2002; 25: 1172-6.

Koenig HG, George LK, Cohen HJ, Hays JC, Larson DB, Blazer DG. The relationship between religious activities and cigarette smoking in older adults. $\mathbf{J}$ Gerontol A Biol Sci Med Sci 1998; 53: M426-34.

Krieger N. Embodiment: a conceptual glossary for epidemiology. J Epidemiol Community Health $2005 ; 59: 350-355$.

Kuh DJL, Cooper C. Physical activity at 36 years: patterns and childhood predictors in a longitudinal study. J Epidemiol Comm Health 1992; 46: 114-119.

Lalonde M. New perspective on the health of Canadians: 28 years later. Pan Am J Public Health 2002; 12: 149-152.

Lawlor DA, Taylor M, Bedford C, Ebrahim S. Is housework good for health? Levels of physical activity and factors associated with activity in elderly women. Results from the British Women's Heart and Health Study. J Epidemiol Community Health 2002; 56: 473-478.

Leigh BC, Stacy AW. Alcohol expectancies and drinking in different age groups. Addiction 2004; 99: 215-227. 
Lessa I. Anos produtivos de vida perdidos no Brasil por mortalidade cardiovascular. Bol Oficina Sanit Panam 1991; 110: 118-25.

Lissner L, Bengtsson C, Björkelund C, Wedel H. Physical activity levels and changes in relation to longevity: a propective study of Swedish women. Am $\mathbf{J}$ Epidemiol 1996; 143: 54-62.

Livingstone MBE, Robson PJ, McCarthy S, Kiely M, Harrington K, Browne P et al. Physical activity patterns in a nationally representative sample of adults in Ireland. Publ Health Nutr 2001; 4(5A): 1107-16.

Mackenbach JP, Martijntje JB. Tackling socioeconomic inequalities in health: analysis of European experiences. Lancet 2003; 362: 1409-14.

Malyutina S, Bobak M, Kurilovitch D, Nikitin Y, Marmot M. Trends in alcohol intake by education and marital status in urban population in Russia between the mid 1980s and the mid 1990s. Alcohol Alcohol 2004; 39: 64-9.

Marmot M, Shipley M, Brunner E, Hemingway H. Relative contribuition of early life and adult socioeconomic factors to adult morbidity in the Whitehall II study. $\mathbf{J}$ Epidemiol Community Health 2001; 55: 301-307.

Marmot M. Tackling health inequalities since the Acheson Inquiry [editorial]. J Epidemiol Community Health 2004a; 58: 262-263.

Marmot M. Creating healthier societies [editorial]. Bull W Health Org 2004b; 82: $320-321$.

Marmot M. Social determinants of health inequalities. Lancet 2005; 365: 1099-1104.

Masson CR, Dias-da-Costa JS, Olinto MTA, Meneghel S, Costa CC, Bairros F, Hallal PC. Prevalência de sedentarismo nas mulheres adultas na cidade de São Leopoldo, Rio Grande do Sul, Brasil. Cad Saúde Pública 2005; 21: 1685-95. 
Masur J, Monteiro MG. Validation of the "CAGE"Alcoholism Screening Test in a brazilian psychiatric inpatient hospital setting. Brazilian Journal of Medical and Biological Research 1983; 16:215-18.

Matsudo S, Araújo T, Matsudo V, Andrade D, Andrade E, Oliveira LC et al. Questionário Internacional de Atividade Física (IPAQ): Estudo de validade e reprodutibilidade no Brasil. Rev Ativ Fís Saúde 2001; 6: 5-18.

Matsudo SM, Matsudo VR, Araújo T, Andrade D, Andrade E, Oliveira L et al. Nível de atividade física da população do estado de São Paulo: análise de acordo com gênero, idade, nível sócio-econômico, distribuição geográfica e de conhecimento. Rev Bras Ciên e Mov 2002; 10: 41-50.

Mattos RA. Integralidade e a formulação de políticas específicas de saúde. In: Pinheiro R \& Mattos RA, org. Construção da integralidade: cotidiano, saberes e práticas em saúde. Rio de Janeiro: UERJ/IMS/ABRASCO; 2003. p.45-60.

Matzger H, Kaskutas LA, Weisner C. Reasons for drinking less and their relationship to sustained remission from problem drinking. Addiction 2005; 100: 1637-46.

McGinnis MC, Williams-Russo P, Knickman J. The case for more active policy attention to health promotion. Health Affairs 2002; 21: 78-93.

McKechnie R, Rubenfire M, Mosca L. association between self-reported physical activity and vascular reactivity in postmenopausal women. Atherosclerosis 2001; 159: $483-90$

Melia M, Heckerman D. An experimental comparison of several clustering and initialization methods. Microsoft Research Technical Report MSR-TR-98-06.

Mendez D, Warner KE. Adult cigarette smoking prevalence: declining as expected (not as desired). Am J Public Health 2004; 94: 251-252.

Midanik LT, Greenfield TK. Trends in social consequences and dependence symptoms in the United States: The National Alcohol Surveys, 1984-1995. Am J Public Health 2000; 90: 53-56. 
Ministério da Saúde. Coordenação Nacional de Controle de Tabagismo e Prevenção Primária de Câncer. Bases para a implantação de um programa de controle do tabagismo. Rio de Janeiro: INCA; 1996.

Mishra G, Ball K, Arbuckle J, Crawford D. Dietary patterns od australian adults and their association with socioeconomic status: results from the 1995 National Nutrition Survey. Eur J Clin Nutr 2002; 56: 687-93.

Monteiro CA, Mondini L, Costa RBL. Mudanças na composição e adequação nutricional da dieta familiar nas áreas metropolitanas do Brasil (1988-1996). Rev Saúde Públ 2000; 34: 251-8.

Monteiro CA, Conde WL, Matsudo SM, Matsudo VR, Benseñor IM, Lotufo PA. A descriptive epidemiology of leisure-time physical activity in Brazil, 1996-1997. Rev Panam Salud Publica 2003; 14(4): 246-54.

Montgomery SM, Cook DG, Bartley MJ et al. Substance abuse: unemployment, cigarette smoking, alcohol consumption and body weight in young British men. Eur J Public Health 1998; 8: 21-7.

Mokdak AH, Marks JS, Stroup DF, Gerberding JL. Actual causes of death in the United States, 2000. JAMA 2004; 291: 1238-45.

Moreira MCN. A dádiva da sobriedade: a ajuda mútua nos grupos de alcoólicos anônimos [resenha]. Ciêne Saúde Coletiva 2004; 9: 1079-1080.

Morimoto JM. Fatores associados à qualidade da dieta de adultos residentes na Região Metropolitana de São Paulo. São Paulo; 2004 [Dissertação de Mestrado Faculdade de Saúde Pública da USP].

Mukamal KJ, Mittleman MA, Longstreth WT, Newman NB, Fried LP, Siscovick DS. Self-reported alcohol consumption and falls in older adults: cress-sectional and longitudinal analyses of the Cardiovascular Health Study. Journal of the American Geriatric Society 2004; 1174-79.

Nayak MB, Kaskutas LA. Risky drinking and alcohol using patterns in a national sample of women of childbearing age. Addiction 2004; 99:01393-1402. 
Oliveira VN, Valente JG, Medeiros SF. Hábitos e estilo de vida em mulheres climatéricas de baixa renda em Cuiabá. Reprod Clim 2001; 16: 253-258.

Paljarvi T, Makela P, Poikolainen K. Pattern of drinking and fatal injury: a population-based follow-up study of Finnish men. Addiction 2005; 100: 1851-9.

Park HS, Ashton L, Causie T, Moon SS. The impact of religious proscriptiveness on alcohol use among high-school students. Journal of Alcohol and Drug Education 1998; 44: 34-46.

Pate RR, Pratt M, Blair SN, Haskell WL, Macera CA, Bouchard C et al. Physical activity and Public Health: a recommendation from the Centers for Disease Control and the American College of Sports Medicine. JAMA 1995; 273: 402-407.

Patterson RE, Haines PS, Popkin BM. Health lifestyle patterns of U.S. adults. Prev Med 1994; 23: 453-60.

Pensola $\mathrm{TH}$, Martikainen P. Cumulative social class and mortality from various causes of adult men. J Epidemiol Community Health 2003; 57: 745-751.

Pereira MA, Folsom AR, McGovern PG, Carpenter M, Arnett DK, Liao D et al. Physical activity and incident hypertension in black and white adults: the Atherosclerosis Risk in Communities Study. Prev Med 1999; 28: 304-12.

Philippi ST, Szarfarc SC, Latterza AR. Virtual Nutri [software]. Versão 1.0 for Windows. São Paulo: Departamento de Nutrição, Faculdade de Saúde Pública, Universidade de São Paulo; 1996.

Philippi ST. Tabela de composição química de alimentos: suporte para decisão nutricional. Brasília: ANVISA, FINATEC/NUT - UnB; 2001.

Piccini RX \& Victora CG. Hipertensão arterial sistêmica em área urbana no sul do Brasil: prevalência e fatores de risco. Rev Saúde Públ 1994; 28: 261-7.

Piko BF, Fitzpatrick KM. Substance use, religiosity, and other protective factors among Hungarian adolescents. Addict Behav 2004; 29: 1095-1 107. 
Pillitteri JL, Kozlowski LT, Sweeney CT, Heatherton TF. Individual differences in the subjective effects of the first cigarette of the day: a self-report method for studying tolerance. Experimental \& Clinical Psychopharmacology 1997; 5: 83-90.

Pinheiro ABV, Lacerda EMA, Benzecry EH, Gomes MCS, Costa VM. Tabela para avaliação de consumo alimentar em medidas caseiras. $4^{\mathrm{a}}$ ed. São Paulo: Atheneu; 2000 .

Plsek PE, Greenhalgh T. The challenge of complexity in health care. BMJ 2001; 323: $625-628$.

Polednak AP. Recent trends in incidence rates for selected alcohol-related cancers in the United States. Alcohol \& Alcoholism 2005; 40: 234-8.

Popkin BM. Nutritional patterns and transitions. Population and Development Review 1993; 19: 138-57.

Poulson RL, Eppler MA, Satterwhite TN,Wuensch KL, Bass LA. Alcohol consumption, strength of religious beliefs, and risky sexual behavior in college students. J Am Coll Health 1998; 46: 227-32.

Puras A, Sanchis C, Artigao LM, Divison JA. Prevalence, awareness, treatment, and control of hypertension in a Spanish population. European Journal of Epidemiology 1998; 14:31-36.

Rafferty AP, Anderson JV, McGee HB, Miller CE. A Healthy Diet Indicator: quantifying compliance with the dietary guidelines using the BRFSS. Prev Med 2002; 35: 9-15.

Rego RA, Berardo FAN, Rodrigues SSR, Oliveira ZMA, Oliveira MB, Vasconcellos $\mathrm{C}$ et al. Fatores de risco para doenças crônicas não-transmissíveis: inquérito domiciliar no município de São Paulo, Brasil. Metodologia e resultados preliminares. Rev Saúde Públ 1990; 24(4): 277-85.

Ramstedt M. Alcohol consumption and liver cirrhosis mortality with and without mention of alcohol-the case of Canada. Addiction 2003; 98: 1267-1276. 
Rego RA, Oliveira ZMA, Berardo FAN, Oliveira MB, Ramos LR. Epidemiologia do alcoolismo: prevalência de positividade do teste CAGE em inquérito domiciliar no município de São Paulo. Rev ABP-APAL 1991; 13: 75-80.

Rehm J. Measuring quantity, frequency and volume of drinking. Alcohol Clin Exp Res 1998; 22: 4-8.

Rehm J, Greenfiel TK, Walsh G, Xie X, Robson L, Single E. Assessment methods for alcohol consumption, prevalence of high risk drinking and harm: a sensitivity analysis. Int J Epidemiol 1999; 28: 219-24.

Rehm J, Greenfield TK, Rogers JD. Average volume of alcohol consumption, patterns of drinking, and all-cause mortality: results from the US National Alcohol Survey. Am J Epidemiol 2001; 153: 64-71.

Riley JC, Lennon MA, Ellwood RP. The effect of water fluoridation and social inequalities on dental caries in 5-year-old children. Int $\mathbf{J}$ Epidemiol 1999; 28: 300 305.

[RIPSA] Rede Interagencial de informações para a saúde, Ministério da Saúde. IDBIndicadores e Dados Básicos para a Saúde 2004; 2005.

Rose G. Individuos enfermos y poblaciones enfermas. In: Buck C et al, org. EI desafio de la epidemiologia: problemas y lecturas seleccionadas. Washington, D.C: OPAS; 1988. p. 900-909.

Rose G. The strategy of preventive medicine. Oxford: Oxford University Press; 1992. $138 \mathrm{p}$.

Rütten A, Vuillemin A, Ooijendijk WTM, Schena F, Sjöstrom M, Stahl T et al. Physical activity monitoring in Europe. The European Physical Activity Surveillance System (EUPASS) appriach and indicator testing. Public Health Nutrition 2003; 6: 377-84.

Rzewnicki R, Auweele YV, Bourdeaudhuij ID. Adressing overreporting on the International Physical Activity Questionnaire (IPAQ) telephone survey with a population sample. Public Health Nutrition 2003; 6: 299-305. 
Saalfeld V, Silva MRA. Prevalência do alcoolismo em cuidado primário à saúde. Pesqui. méd. (Porto Alegre) 1993; 27: 5-9.

Salome HJ, French MT, Matzger H, Weisner C. Alcohol consumption, risk of injury, and high-cost medical care. Journal of Behavioral Health Services and Research $2005 ; 32: 368-380$.

Samet JH, Philips SJ, Horton NJ, Traphagen ET, Freedberg KA. Detecting alcohol problems in HI-infected patients: use of the CAGE questionnaire. AIDS Res Hum Retroviruses 2004; 20: 151-5.

Saremi A, Hanson RL, Williams DE, Rumain J, Robin RW, Long JC et al. Validity of the CAGE questionnaire in an American Indian population. J Study Alcohol 2001; 62: 294-300.

Scott LT. Trends and patterns of tobacco use in the United States. Am J Med Sci 2003; 326: 248-254.

Seclén-Palacín JA, Jacoby ER. Factores sociodemográficos y ambientales asociados con la actividad físia deportiva en la población urbana del Peru. Rev Panam Salud Publica 2003; 14: 255-264.

Sichieri R, Castro JFG, Moura AS. Fatores associados ao padrão de consumo alimentar da população brasileira urbana. Cad. Saúde Pública 2003; 19 (Sup. 1): S47-S53.

Silveira EA, Araújo CL, Gigante DP, Barros AJD, Lima MS. Validação do peso e altura referidos para o diagnóstico do estado nutricional em uma população de adultos no Sul do Brasil. Cad Saúde Pública 2005; 21: 235-45.

Simão MO, Kerr-Correa F, Dalben I, Smaira SI. Alcoholic women and men: a comparative study of social and familial aspects and outcome. Rev Bras Psiquiatr $2002 ; 24: 121-129$.

Simpson ME, Serdula M, Galuska DA, Gilespie C, Donehoo R, Macera C, Mack K. Walking trends among U.S. adults. Am J Prev Med 2003; 25: 95-100. 
Skov T, Deddens J, Petersen MR, Endahl L. Prevalence proportion ratios: estimation and hypothesis testing. Int J Epidemiol 1998; 27: 91-95.

Slutske W, Hunt-Carter EE, Nabors-Oberg RE, Sher KJ, Bucholz KK, Madden PAF et al. Do college students drink more than their non-college attending peers? Evidence from a population-based longitudinal female twin study. Journal of Abnormal Psychology 2004; 113: 530-40.

Soderstrom CA, Smith GS, Kufera JA, Dischinger PC, Hebel JR, McDuff DR et al. The accuracy of the CAGE, the Brief Michigan Alcoholism Screening Test, and the Alcohol Use Disorders Identification Test in screening trauma center patients for alcoholism. J Trauma 1997; 43: 962-9.

Souci SW, Farchman W, Kraut P. Food composition and nutrition tables. $5^{\mathrm{a}}$ ed. Stutgard: CRC Press; 1994.

Spence JC, Lee RE. Toward a comprehensive model of physical activity. Psychol Sport Exerc 2003; 4: 7-24.

[SPSS] Statistical Package for the Social Sciences. The SPSS TwoStep Cluster Component: a scalable component enabling more efficient customer segmentation. White paper-technical report 2003. Disponível em: www.spss.com.

Stamler J, Dyer AR, Shekelle RB, Neaton J, Stamler R. Relationship of baseline major risk factors to coronary and all-cause mortality, and to longevity: findings from long-term follow-up of Chicago cohorts. Cardiology 1993; 82: 191-222.

Standridge JB, Zylstra RG, Adams SM. Alcohol consumption: an overview of benefits ans risks. South Med J 2004; 97: 664-72.

Stephens C, Timaeus I, Ackerman M, Avle S, Maia PB, Campanario P et al. Environment and health in developing countries: an analysis of intra-urban differentials using existing data. São Paulo: London School Of Hygiene \& Tropical Medicine/Fundação SEADE; 1994.

Stoll SJ. Religião, ciência ou auto-ajuda? Trajetos do Espiritismo no Brasil. Revista de Antropologia, São Paulo, USP 2002; 45: 361-402. 
Stoll SJ. Narrativas biográficas: a construção da identidade espírita no Brasil e sua fragmentação. Estudos Avançados 2004; 18: 181-199.

Strawbridge WJ, Cohen RD, Shema SJ, Kaplan GA. Frequent attendance at religious services and mortality over 28 years. Am J Public Health 1997; 87: 957-61.

Strawbridge WJ, Cohen RD, Shema SJ. Comparative strength of association between religious attendance and survival. Int J Psychiatry Med 2000; 30: 299-308.

Strawbridge WJ, Shema SJ, Cohen RD, Kaplan GA. Religious attendance increases survival by improving and maintaining good health behavious, mental health and social relationships. Ann Beba Med 2001; 23: 68-74.

Swan G. Findings from the latest National Diet and Nutrition Examination Survey. Proceedings of the Nutrition Society 2004; 63: 505-512.

Talbot LA, Fleg JL, Metter EJ. Secular trends in leisure-time physical activity in men and women across four decades. Prev Med 2003; 37: 52-60.

Testa M. Saber en salud - la construcción del conocimiento. Buenos Aires: Lugar Editorial; 1997

Tilly B, Guilhot J, Salanave B, Fender P, Allemand H. Management of severe hypertension in France in 1999 and 2000: intermediate results of a health insurance intervention program. Arch Mal Couer Vaiss 2002; 95: 687-94.

Theodoridis S, Koutroumbas K. Pattern recognition. New York: Academic Press, 1999 .

Thiele S, Mensink GBM, Beitz R. Determinants of diet quality. Public Health Nutr 2004; 7: 29-37.

Tomar SL. Is use of smokeless tobacco a risk factor for cigarette smoking? The US experience. Nicotine and Tobacco research 2003; 5: 561-569. 
Tormo MJ, Navarro C, Chirlaque MD, Pérez-Flores D. Prevalence and control of arterial hypertension in the south-east of Spain: a radical but still insufficient improvement. European Journal of Epidemiology 1997; 13:301-8.

Townsend J, Roderick P, Cooper J. Cigarette smoking by socioeconomic group, sex and age: effects of price, income and publicity. BMJ 1994; 309: 923-927.

United States Department of Agriculture [USDA]. Agriculture Research Service. USDA National Nutrient Database for Standard Reference, Release 16. [tabela de composição de alimentos] 2003. Disponível em: URL:http://www.nal.usda.gov/fnic/foodcomp [2004jan 28]

Vega J \& Irwin A. Tackling health inequalities: new approaches in public policy [editorial]. Bull W Health Org 2004; 82: 482-483.

Viacava F. Informações em saúde: a importância dos inquéritos populacionais. Ciênc Saúde Coletiva 2002; 7: 607-621.

Victora CG, Wagstaff A, Schellenberg JA, Gwatkin D, Claeson M, Habicht JP. Applying an equity lens to child health and mortality: more of the same is not enough. Lancet 2003; 362: 233-41.

Viola DN. Redução no vício da distribuição da deviance para dados de contagem. Dissertação de Mestrado - ESALQ, USP; 2001. 72 p.

Virtanen M, Kivimäki M, Elovainio M, Virtanen P, Vahtera J. Local economy and sickness absence: prospective cohort study. J Epidemiol Community Health 2005; 59: 973-978.

Von Ah D, Ebert S, Ngamvitroj A, Park N, Kang DH. Predictors of health behaviours in college students. J Advanced Nursing 2004; 48: 463-74.

Vuori IM. Health benefits of physical activity with special reference to interaction with diet. Publ Health Nutr 2001; 4(2B): 517-28.

Wannamethee SG. Commentary: alcohol and mortality: diminishing returns for benefits of alcohol. Int J Epidemiol 2005; 34: 205-206. 
[WHO] World Health Organization. Department of Chronic Diseases and Health Promotion. Genebra. http://www. who.int/chp/en/ 22 de Outubro de 2005a.

[WHO] World Health Organization. Global cardiovascular infobase. Genebra. Http://www. who.int/noncommunicable_diseases/about/ chp/en/ 26 de outubro $2005 b$.

[WHO] World Health Organization. Global cardiovascular infobase. Genebra. Http://www. who.int/dietphysicalactivity/en/ 26 de outubro 2005c.

[WHO] World Health Organization. Global cardiovascular infobase. Genebra. Http: //www. who.int/dietphysicalactivity/publications /facts/ chronic/en/ 26 de outubro $2005 \mathrm{~d}$.

[WHO] World Health Organization. Global cardiovascular infobase. Genebra. Http: //www. who.int/tobacco/about/en/ 15 de novembro 2005e.

[WHO] World Health Organization. Comission on Social Determinants of Health. Genebra. http://www. who.int/social determinants/en/ 07 de Janeiro de 2006.

Whooley MA, Boyd AL, Gardin JM, Williams DR. Religious involvement and cigarette smoking in young adults: the CARDIA study. Arch Intern Med 2002; 162: $1604-10$

Willett WC. Nutritional epidemiology. $2^{\mathrm{a}}$ ed. New York: Oxford University Press; 1998.

Wilkins K. Moderate alcohol consumption and heart disease. Health Rep 2002; 14: 9-24.

Wilkinson R \& Marmot M. The solid facts. $2^{\mathrm{a}}$ ed. Denmark: WHO-Regional Office for Europe; 2003. 33 p.

Woo J, Leung SSF, Ho SC, Lam TH, Janus ED. Dietary intake and practices in the Hong Kong Chinese population. J Epidemiol Community Health 1998; 52: 631637. 
Woodward A, Kawachi I. Why reduce health inequalities? J Epidemiol Community Health 2000; 54: 923-929.

Yang G, Fan L, Tan J, Qi G, Zhang Y, Samet J et al. Smoking in China: findings of the 1996 National Prevalence Survey. JAMA 1999; 282: 1247-53.

Zemore SE. Re-examing whether and why acculturation relates to drinking outcomes in a rigorous, national survey of latinos. Alcohol Clin Exp Res 2005; 29: 2144-53.

Zhang T, Ramakrishnon R, Livny M. BIRCH: An efficient data clustering method for very large databases. Proceedings of the ACM SIGMOD Conference on Management of Data 1996. p.103-114.

Ziglio E, Barbosa R, Charpak Y, Turner S. Health systems confront poverty: public health case studies. Denmark: WHO-Regional Office for Europe; 2003. 182 p. 